Portland State University

PDXScholar

Summer 1-1-2012

\title{
Teacher Stress and Coping: Does the Process Differ According to Years of Teaching Experience?
}

Jeffry Childs Beers

Portland State University

Follow this and additional works at: https://pdxscholar.library.pdx.edu/open_access_etds

Part of the Educational Psychology Commons, Industrial and Organizational Psychology Commons, and the School Psychology Commons

Let us know how access to this document benefits you.

\section{Recommended Citation}

Beers, Jeffry Childs, "Teacher Stress and Coping: Does the Process Differ According to Years of Teaching Experience?" (2012). Dissertations and Theses. Paper 809.

https://doi.org/10.15760/etd.809

This Thesis is brought to you for free and open access. It has been accepted for inclusion in Dissertations and Theses by an authorized administrator of PDXScholar. Please contact us if we can make this document more accessible: pdxscholar@pdx.edu. 
Teacher Stress and Coping: Does the Process Differ

According to Years of Teaching Experience?

by

Jeffry Childs Beers

A thesis submitted in partial fulfillment of the requirements for the degree of

Master of Science

in

Psychology

Thesis Committee:

Ellen Skinner, Chair

Robert Roeser

Thomas Kindermann

Portland State University

(C)2012 


\begin{abstract}
Teaching is stressful. The demands placed on teachers can result in emotional exhaustion and burnout, causing many to leave the profession. Teachers early in their careers seem to be at special risk, with desistence rates estimated as high as $40 \%$ in the first five years. This study was based on the notion that constructive coping can be a resource for teachers, and that teachers later in their professional lives may provide a model for adaptive ways of dealing with professional demands. The goal of the study was to examine whether the coping process utilized by teachers (including reported demands, appraisals, ways of coping, resolutions, and post-coping assessment) differed at different stages of their career. Participants $(n=57)$ were teachers $(90 \%$ female) ranging in age from $28-63$, teaching in grades 4 to 12 . The current study utilized a portion of the baseline open-ended interview of a randomized waitlist control study conducted to explore the effects of a mindfulness-based program. After coding the interview data for each step of the coping process, frequency analyses revealed that: (1) as in previous studies, the most frequently reported demands were problems with students (40\%), followed by workload (18\%) and parents (15\%); (2) the most frequently reported appraisal was extreme negative emotion (44\%); (3) the most frequently reported ways of coping were adaptive, including problem-solving (65\%), support seeking (35\%), and selfregulation (22\%); (4) the most frequently reported resolution of the stressful episode was successful (51\%); and (5) with regards to post coping assessment, teachers most frequently reported that they would do something differently in future episodes if they could (54\%). A series of Chi-square analyses to explore whether there is an association between how the teachers responded to questions corresponding to each step revealed
\end{abstract}


that (1) teachers who reported parents as a demand in teaching were more likely to report extreme negative emotion and the use of self-regulation, which was associated with a successful resolution; (2) teachers who reported the administration as a demand were also more likely to use support seeking as a way of coping; and (3) teachers who reported using more maladaptive ways of coping were also more likely to report an unsuccessful resolution. Finally, pairwise comparisons to determine which groups of teachers differed from each other showed that, in keeping with expectations, early career teachers reported "no negative emotion" less and "extreme negative emotion" more than other groups, while late career teachers mentioned "no negative emotion" more. In terms of demands, early career teachers mentioned the environment less whereas late career teachers mentioned parents less and students more often. In terms of coping, late career teachers reported using self-regulation less and cognitive accommodation more than the other groups. Finally, early career teachers were more likely to say that they would try different effective strategies in future coping episodes while late career teachers were less likely to report that they would do so. Applications of these findings are discussed for processoriented theories of teacher stress and coping, for future studies examining how coping develops over the course of a professional career, and for preservice training and schoolbased interventions designed to promote adaptive coping for teachers at every phase of their profession. 


\section{Acknowledgments}

A special thanks goes out to the committee members for all of the tiresome work put forth in the completion of this thesis:

\section{Ellen Skinner, Chair}

Robert Roeser

Thomas Kindermann

I will forever be grateful for the tutelage provided by the committee members throughout the course of this project. 


\section{Table of Contents}

Abstract.....................................................................

Acknowledgements............................................. iii

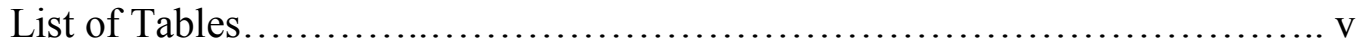

List of Figures................................................. vii

Chapter 1

Introduction........................................................... 1

Chapter 2

Review of the Literature on Teacher Stress and Coping..................... 8

Chapter 3

Purpose of the Study............................................. 58

Chapter 4

Methods............................................................ 71

Chapter 5

Results.......................................................... 81

Chapter 6

Discussion......................................................... 108

References................................................... 154

Appendices
A. Studies Reviewed Investigating Teacher Stress and Coping........ 161
B. Coding Menu.............................................. 162
C. Coping Utterances..................................... 173
D. Summary of Total Results............................... 185 


\section{List of Tables}

Table 2.1

Teacher Stressors Investigated in the Teacher Stress and Coping................. 13

Table 2.2

Ways of Coping Investigated in the Teacher Stress and Coping.................. 31

Table 3.1

Twelve Families of Coping and Their Adaptive Processes....................... 65

Table 4.1

Coping Episode Interview Questions.................................... 73

Table 4.2

Teacher Groups Based on Years Experience................................... 74

Table 4.3

Coping Kappas........................................................ 79

Table 5.1

Reported Demands by Teachers......................................... 85

Table 5.2

Reported Demands according to Levels of Teaching Experience.................. 86

Table 5.3

Teacher Reported Appraisals of the Stressful Event............................. 87

Table 5.4

Teacher Appraisal by Levels of Experience................................... 89

Table 5.5

Interaction Between Demands and Emotional Reaction.......................... 90

Table 5.6

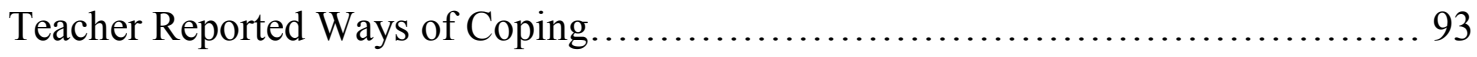

Table 5.7

Interaction between Ways of Coping and Levels of Experience..................... 94

Table 5.8

Interaction between Ways of Coping and Appraisals.......................... 95 
Table 5.9

Interaction Between Ways of Coping and Demands............................. 97

Table 5.10

Teacher Reported Resolutions of the Stressful Event........................... 98

Table 5.11

Resolutions According to Levels of Experience................................... 99

Table 5.12

Interaction Between Ways of Coping and Resolution............................ 101

Table 5.13

Interaction Between Total Coping and Resolution................................ 102

Table 5.14

Frequency Count of Teacher Assessment..................................... 103

Table 5.15

Interaction Between Teacher Assessment and Levels of......................... 105

Table 5.16

Interaction Between Teacher Assessment and Resolution......................... 105

Table 5.17

Interaction Between Ways of Coping and Teacher Learning...................... 107 


\section{List of Figures}

Figure 3.1

Teacher Stress and Coping Model........................................ 62 


\section{CHAPTER 1}

\section{Introduction}

Teachers are important to students. A great deal is known about what students need from teachers and how big a difference high quality teaching makes to student learning, achievement, development, and success in school (Wentzel, 2009). Much less is known about what teachers need in order to provide high quality teaching to students. Teaching is a stressful profession, and those stressors may eventually erode teachers' enthusiasm and engagement in teaching, undermining their capacity to meet students' needs and eventually leading to burnout. In order to help students reach their full potential, it is imperative to understand how teachers become more effective at dealing with the everyday demands and challenges associated with the teaching profession over time, not only to protect teachers from burnout, but also as a way to promote their engagement, learning, and mastery.

The teaching profession is considered one of the most stressful occupations. Teacher burnout, a common problem that is especially likely during the first 3 years of a teacher's career, is expensive to all those involved, including students, the teachers themselves, and the institutions that hire and train them. Small adjustments early in a teacher's career may have the potential to set them on a positive course toward greater everyday resilience and more constructive engagement with their students and colleagues. This, in turn, might lead students to become more engaged in the curriculum, thereby increasing their ability and motivation to learn. The purpose of this study is to elucidate how novice and experienced teachers differ in the processes they use to cope with everyday demands of teaching, including those potentially linked to the 
development of resilience. Such information would be useful in order to begin to identify the points in the coping process that can be targeted for interventions designed to promote teacher effectiveness and engagement, thereby increasing the likelihood that teachers would remain in the profession and realize their full potential to mentor, nurture, and teach students.

\section{Overview of the Problem}

Teaching ranks as one of the most stressful occupations. For example, teaching ranked $2^{\text {nd }}$ in terms of poor physical health associated with stress, behind only that of ambulance drivers and higher than social service providers, prison officers, police, nurses, and medical/dental providers (Johnson et al., 2005). Further, teaching ranked $2^{\text {nd }}$ to only social service providers with respect to low psychological well-being, and $6^{\text {th }}$ in terms of low job satisfaction. In addition, Cox and colleagues (1978) reported that, in a study comparing school teachers with occupations matched for gender, age, and marital status, $79 \%$ of the teachers mentioned their job as a major source of stress in their life, while only $38 \%$ of non-teachers did the same.

In a review article on teacher stress and coping, Kyriacou (2001) reported that a quarter of teachers believe their profession to be either very or extremely stressful, while Borg (1990) reported that percentage to be as high as one third. Kyriacou's investigation revealed that the main sources of stress facing teachers are teaching pupils who lack motivation, maintaining discipline, time pressures and workload, coping with change, being evaluated by others, dealing with colleagues, self-esteem and status, administration and management, role conflict and ambiguity, and poor working conditions. Further, according to teachers, the three most stressful aspects were dealing with disruptive 
students, interacting with colleagues, and responsibilities handed down by the administration. The multiple competing demands from students, colleagues, and administrators place pressure on teachers and may create a great deal of stress.

Effects of stress on teachers. The demands placed on teachers have a major impact on their health, both mentally and physically, as they have been shown to be associated with outcomes ranging from headaches to cardiovascular disease, as well as depression, poor interpersonal relationships, and deterioration in work performance. These health related outcomes have been shown to lead to emotional exhaustion and burnout (Greenglass et al., 1998; Maslach et al., 2001; Mearns \& Cain, 2003; Rubino et al., 2009). Burnout has been described as "a prolonged response to chronic emotional and interpersonal stressors on the job" (Maslach et al., 2001, p. 397). Because teachers face an onslaught of stressors on a daily basis, their susceptibility to burnout is high. Emotional exhaustion and burnout are a major cause of employee turnover in the education profession.

Early career teachers. Some of the greatest challenges with regards to teaching occur during the early stages of one's career. In fact, the teacher attrition rate in the US has been estimated to be as high as $46 \%$ within the first 5 years (Jalongo \& Heider, 2006), and the most common reasons given for leaving the profession are fatigue, nervous tension, frustration, wear and tear, difficulties in adapting to pupils, personal fragility, and routine (Huberman, 1993). Learning how to cope with these demands may be particularly important when it comes to those who are new to the profession and are in the middle of learning how to build lesson plans, deliver information in a meaningful way, interact with colleagues, parents, and students, and incorporate requirements handed 
down by administration, all while learning how to manage 30 students in a classroom setting. In order to become proficient at juggling all of these aspects of the profession, young teachers would benefit from having access to a range of effective coping strategies.

\section{Coping as a Resource for Teachers}

Coping may be an important resource to teachers in dealing with the multiple demands of their profession. Teachers with more access to coping resources reported less burnout than those with less access to coping resources (Betoret, 2006). There is even evidence to suggest that learning effective coping strategies may contribute to a mastery orientation toward teaching, which significantly predicts enjoyment of work, participation, and positive career aspirations (Parker \& Martin, 2009). Coping likely mitigates the effects of stressors by changing one's emotional state during the encounter or by eliminating the source of the stressor all together (Lazarus, 1993). In fact, coping is viewed as one of the most important aspects of interventions designed to buffer the negative effects associated with stress caused by the many demands teachers face daily (Cooper, Dewe, \& Driscoll, 2001).

Coping as a process. In general, coping can be defined as "constantly changing cognitive and behavioral efforts to manage specific external and/or internal demands that are appraised as taxing or exceeding the resources of the person” (Lazarus \& Folkman, 1984, p. 141). Coping is typically viewed as a process because it involves change over time or across situations (Lazarus \& Folkman, 1987). The authors posit that the process begins with an initial appraisal of the event, assessing it as a harm, threat, or challenge. During the next step in the process, secondary appraisal, the individual assesses his or her 
own ability to deal with the stressor and selects an initial coping strategy. Depending on whether the individual chooses an effective strategy, the stress experienced during the event may be reduced or eliminated all together. If not, another episode of appraisal and coping may be initiated.

The actual actions used in response to a stressor are referred to as "ways of coping" and typically include problem-focused coping, emotion-focused coping, social support seeking, and avoidance. Problem-focused coping involves attempting to change the stressful event through direct action or active problem solving. Emotion-focused coping involves attempting to alleviate or soothe the emotions associated with the event. Support-seeking usually involves turning to others for advice, help, or comfort. Avoidance typically involves withdrawal or escape from the stressful situation, or failure to take any action at all. Research has demonstrated that teachers use these strategies and a variety of other methods to cope with stress, including keeping things in perspective, avoiding confrontations, trying to relax after work, take action to deal with problems, keeping feelings under control, devoting more time to particular tasks, discussing problems and expressing feelings to others, having a healthy home life, planning ahead and prioritizing, and recognizing one's own limitations (Kyriacou, 2001).

Novice teachers may be more susceptible to stress and burnout than more experienced teachers based on the nature of their coping processes. Early career teachers may have heavier or different demands placed upon them, may be more reactive to stressors that do occur, may construct less adaptive appraisals, may show less adaptive coping strategies, or may be less resilient in the face of negative events. To date, however, there is a dearth of research examining the development of coping during one's 
teaching career and there has been a call for more investigation of the role that successful coping plays in teachers' development as they progress through their respective careers (Kyriacou, 2001).

This study examined differences between novice and experienced teachers in the different steps in the process of coping with everyday stressors, including the demands teachers report, their emotional reactions to those demands, their appraisals and ways of coping, and what they are able to take away from stressful episodes. The long-term goal is to elucidate the coping strategies that can be utilized by teachers in order to constructively deal with stress, not only to reduce the negative outcomes associated with stress, but also to potentially promote teacher energy, vitality, and engagement with students and colleagues. In addition, it is a goal of this study to begin to map the processes through which adaptive coping strategies are developed over the course of one's teaching experiences, in the hope of making these strategies more salient to young teachers early in their careers.

In order to meet these objectives, this thesis proceeds in six chapters. Chapter 2 includes a review of current studies on teacher stress and coping, followed by a critique of the literature emphasizing aspects that are crucial to understanding the developmental process of acquiring coping strategies. Chapter 3 presents an emerging process model of teacher coping, with an explicit focus on the development of constructive strategies for dealing with the demands of teaching, and a set of research questions that follow from it. In Chapter 4, the methods for exploring these research questions are laid out, including the target sample and the methods utilized to capture the different steps in the coping process. Chapter 5 describes the results obtained from analyzing the data collected in 
ways that answer the research questions, and Chapter 6 concludes with a discussion of the strengths and limitations of the current study, and a few ideas for how it may help to guide future research. 


\section{CHAPTER 2}

\section{Review of the Literature on Teacher Stress and Coping}

To review what has been investigated with regards to teacher stress and coping, a search was conducted on PsychInfo Database by using the keywords teachers, stress, and coping in which more than 500 studies appeared. After eliminating studies that were either dissertations or non-peer reviewed articles, that number was reduced to a little over 200. Next, those studies that involved only elementary school teachers were eliminated, as this study was interested in stress for teachers at the secondary level and it is likely that elementary and secondary school teachers face different demands. The removal of these studies brought the number to just over 100. The next step was to review the abstracts of the final 100 studies and eliminate all those that were related to post-secondary schools. Finally, after reading the remaining 59 studies and choosing only those that had an explicit measure of coping, 33 studies meeting all of the above criteria were selected for further review. Eventually, two studies were dropped because one was looking at coping resources rather than coping itself (Betoret, 2006) and in the other, coping with changes and challenges were not represented as separate scales, rather, they were included in a measure of self efficacy (Skaalvik \& Skaalvik, 2007). Removing these two studies brought the final number reviewed to 31 .

All 31 studies were naturalistic in nature and most were cross-sectional and correlational, with only three using a longitudinal design (Freeman, 1987; Salo, 1995; Carmona, Buunk, Peiro, Rodriguez, \& Bravo, 2006). In addition, most of the data were collected via questionnaire, while 4 studies assessed teacher stress and coping by conducting interviews (Admiraal, Korthagen, \& Wubbels, 2000; Admiraal, Wubbels, \& 
Korthagen, 1996; Beach \& Pearson, 1998; Howard \& Johnson, 2004) and one study utilized both (Freeman, 1987). Further, the studies varied in sample size with the largest having a population of 8,158 (Schweitzer \& Dobrich, 2003) and the smallest 10 (Howard \& Johnson, 2004). Finally, there was considerable diversity with regards to the location of the studies with six being conducted in the U.S. (Beach \& Pearson, 1998; Blasé, 1986; Green \& Ross, 1996; Litt \& Turk, 1985; Mearns \& Cain, 2003; Seidman \& Zager, 1991), four in the Netherlands (Admiraal et al., 2000, 1996; Olff, Brosschot, \& Godaert, 1993; Verhoeven, Kraaij, Joekes, \& Maes, 2003), three in Australia (Howard \& Johnson, 2004; Innes \& Kitto, 1989; Parker \& Martin, 2009), three in China (Chan, 1998, 1994; Shen, 2009), and the remainder coming from a host of other countries such as Spain (Carmona et al., 2006; Pascual et al., 2003), Greece (Pomaki \& Anagnostopoulou, 2003) and Germany (Dick \& Wagner, 2001; Stoeber \& Rennert, 2008).

The following sections summarize findings from the studies on teacher stress and coping that are relevant to two questions: (1) what do teachers find stressful about teaching? And (2) how do they cope with these demands? In order to answer these two questions the most common measures used to assess teacher stress will be presented, followed by the most common stressors investigated in the studies. Next, the most common measures of coping will be described, followed by the most commonly investigated ways of coping, including some of the reported outcomes of these strategies.

\section{What Do Teachers Find Stressful About Teaching?}

\section{Common Measures of Teacher Stress}

In the 31 studies reviewed, the most common measure used to assess teacher stress was the Leiden Quality of Work Questionnaire for Teachers (LAKS-DOC; Maes 
and van der Doef, 1997), which was employed by five studies (Pascual et al., 2003; Griva \& Joekes, 2003; Pomaki \& Anagnostopoula, 2003; Rasku \& Kinnunen, 2003;

Verhoeven, Kraaij, Joekes, \& Maes, 2003) as part of the EUROTEACH project carried out in eleven European countries. In order to be included in the EUROTEACH project the sample had to be comprised of teachers working with 15-18 year olds in governmentsupported mixed secondary schools working a minimum of $2 / 3$ of the full-time contract hours.

The LAKS-DOC is an instrument that is derived from the Job Content Instrument (Karasek, 1985), the Questionnaire of Organizational Stress (Bergers et al., 1986), and the Structured Interview of Content and Organization of Work (Maes et al., 1989). This instrument assesses the following job characteristics: demands, control, social support, meaningfulness of teaching, physical exertion, environmental risks, and total working hours. Sample items for the demands section includes 16 items that assess time pressure (e.g., "I need more time to do my job well as a teacher"), role ambiguity (e.g., "I know exactly what my direct supervisor expects of me" reverse coded), and poor quality of interaction with students (e.g., "Students behave aggressively in this school"). The control section uses 12 items to assess task variety (e.g., "My job involves a variety of tasks"), decision authority (e.g., "I can choose the educational method I want to use in my course"), and further training (e.g., "My job requires that I undergo further training"). Social support is measured with 14 items concerned with support from school management (e.g., "The school management pays attention to what I say"), direct supervisors (e.g., "My direct supervisor values the work that I do"), and colleagues (e.g., "At my school, colleagues get on together well"). In addition, the following three scales 
of job characteristics are used: meaningfulness of teaching (e.g., "I get a lot in return from my students"), physical exertion ("The teaching profession requires a lot of physical effort"), and environmental risks ("The climatological conditions in our school are bad"). All these items are rated on a 4-point Likert scale $(1=$ strongly disagree, $4=$ strongly agree), and each measure is a simple sum of the items. Finally, teachers report the number of hours worked per week on the following tasks: teaching, preparation for teaching, correcting student's work, committees and meetings, and other job-related activities, which are then summarized into one category referred to as total work time. The reliability coefficients of the LAKS-DOC have been reported to be satisfactory with Cronbach's alpha of the subscales between .69 and .87 (Maes \& van der Doef, 1997).

The only other measure to be used in more than one study was the Teacher Stress Inventory (TSI) developed by Blasé (1986). The TSI is an open-ended instrument used to gather qualitative data indicating what teachers perceive as stressful. The first Teacher Stress Inventory (TSI) was administered to 63 teachers taking graduate courses at universities in the southwestern and northeastern U.S. It asked teachers to "identify, describe and illustrate the meanings of three major job-related stressors" (p. 15). Later, the TSI was administered to a sample of 392 teachers from all levels taking graduate courses in four major universities in northwestern, southeastern, mid-western, and southwestern regions of the U.S. during 1981-1983. The TSI is reported to have Cronbach alpha internal consistency coefficients between .85 and .93 (Fimian \&Fasteneau, 1990; Griffith et al., 1999).

In addition to the Blasé (1986) study, in which the measure was developed, two other studies used the TSI (Mearns \& Cain, 2003; Griffith, Steptoe, \& Cropley, 1999). In 
many of the other studies, much like Blasé (1986), the authors developed their own instruments to measure teacher stress, including the Leraren Stress Lijst (LSL; Olff et al., 1993), the Problems in Teaching Scale (PITS; Green \& Ross, 1996), and the Teacher Stressor Scale (TSS; Hui \& Chan, 1996). Further, some of the studies had no measure of stress as they either spoke in terms of general stress (Freeman, 1987; Seidman \& Zager, 1991) or left stressors out entirely (Chan, 1994; Shen, 2009). Finally, when reporting perceived teacher stress, some of the studies ranked demands according to how often they were mentioned by participants (e.g., Salo, 1995; Zurlo et al., 2007), while other studies simply listed stressors, giving no indication of how stressful they were viewed by teachers (e.g., Parker \& Martin, 2009; Howard \& Johnson, 2004; Schweitzer \& Dobrich, 2003).

Teacher Stressors

The stressors investigated in the 31 studies on teacher stress and coping were organized in Table 2.1 from the most commonly studied to the least commonly studied. Some of the stressors were separated into smaller subcategories to delineate the different terms used by the researchers. For example, the category problems with curriculum contained as many subcategories as the studies that investigated it (e.g., instructional problems, problems preparing for class, conflicts and tension relating to curriculum, and difficulties in organizing the lesson). The subcategories were place under the main heading if they appeared to be investigating the same phenomena (i.e., problems with curriculum include instructional problems). These categories and subcategories can be viewed in column 1 of the Stressor Table, along with the total number of studies that investigated the given stressor, written in parentheses next to the stressor category. 
Column 2 of the Table includes the number given to the study and is included in the appendix after the reference page. In all, more than a hundred variations of stressors were examined.

\section{Table 2.1}

Teacher Stressors Investigated in the Teacher Stress and Coping Literature

\begin{tabular}{ll}
\hline Stressor (Total \# of Studies) & Study \# \\
\hline Problems with students (13) & $2,4,7,11,18,23,24,25,29,30,31,32,33$ \\
Student misbehavior & $7,11,24,29,31,32$ \\
Low pupil achievement & $23,24,33$ \\
Unmotivated students & $2,23,24$ \\
Misbehavior of one pupil & 23,33 \\
Misbehavior of a group of pupils or class & 23,33 \\
Pupil on task behavior & 23,33 \\
Pupil apathy & 23,24 \\
Maintaining class/student discipline & 24,31 \\
Unmotivated and noncompliant students & 2 \\
Violent students & 2 \\
Students from disadvantaged and abusive & 2 \\
backgrounds & 18 \\
Problems with foreign students & 33 \\
Too many students & 11 \\
Lack of time to solve problems with students & 18 \\
Student absences & 24 \\
Guidance work & \\
Criticism of pupils & 29 \\
Mediocre pupils' efforts & 23 \\
\hline
\end{tabular}




\begin{tabular}{|c|c|}
\hline Problems with the classroom environment (11) & $8,9,10,12,13,15,18,22,23,32,33$ \\
\hline Environmental risks & $8,9,10,12,13$ \\
\hline Contextual and institutional & 15 \\
\hline Having to teach in overcrowded classrooms & 18 \\
\hline Teaching in many classes & 22 \\
\hline Shortage of equipment & 32 \\
\hline Material & 33 \\
\hline Administration / school policy (10) & $4,11,16,18,22,24,27,28,29,32$ \\
\hline Local school policy & 4 \\
\hline Mobbing by administration & 11 \\
\hline Poor leadership/supervision & 16 \\
\hline Authority induced changes & 22 \\
\hline Supervisor evaluation & 27 \\
\hline Bureaucratic interference & 28 \\
\hline School management & 29 \\
\hline Problems with colleagues (8) & $2,4,11,18,24,29,30,32$ \\
\hline Mobbing by colleagues & 11 \\
\hline Work relationships & 29 \\
\hline Workload (8) & $2,4,11,16,18,25,27,29$ \\
\hline Time and work load pressures & 2,29 \\
\hline Amount of work & 25 \\
\hline Too much paper work & 27 \\
\hline Role overload (feeling overloaded with work) & 27 \\
\hline Problems with curriculum (6) & $7,15,16,22,23,33$ \\
\hline Instructional problems & 23,33 \\
\hline Problems with preparing for class & 7 \\
\hline Conflicts and tension relating to curriculum & 15 \\
\hline
\end{tabular}




\begin{tabular}{|c|c|}
\hline Inadequate orientation & 16 \\
\hline Number of topics/curriculum & 22 \\
\hline Difficulties in organizing the lesson & 23 \\
\hline Demands (6) & $1,8,9,10,12,13$ \\
\hline Total work time (6) & $8,9,10,12,13,22$ \\
\hline Working hours per week & 22 \\
\hline Lack of control (5) & $8,9,10,12,13$ \\
\hline Lack of social support (5) & $8,9,10,12,13$ \\
\hline Physical exertion (5) & $8,9,10,12,13$ \\
\hline Lack of meaningfulness (5) & $8,9,10,12,13$ \\
\hline Low status (5) & $18,24,27,31,32$ \\
\hline Societies diminishing respect for profession & 18 \\
\hline Lack of value placed on teaching & 18 \\
\hline Professional recognition & 32 \\
\hline Problems with parents (5) & $11,18,24,25,30$ \\
\hline Lack of parental back-up on discipline & 18 \\
\hline Conflict and ambiguity (3) & $16,27,28$ \\
\hline Low salary (3) & $18,27,31$ \\
\hline Job stress (2) & 22,24 \\
\hline Setbacks and challenges & 1 \\
\hline Change & 2 \\
\hline Social comparison & 6 \\
\hline Problems with administrators/other teachers & 7 \\
\hline Public criticism & 11 \\
\hline Hectic work climate & 11 \\
\hline Interpersonal relationships & 15 \\
\hline Role & 15 \\
\hline
\end{tabular}




\begin{tabular}{|c|c|}
\hline Unclear institutional goals & 16 \\
\hline Lack of stimulation & 16 \\
\hline Scope of clients contacts & 16 \\
\hline Lack of autonomy & 16 \\
\hline Social isolation & 16 \\
\hline Unmet expectations & 16 \\
\hline Participation in decision making & 16 \\
\hline Distractive factors & 17 \\
\hline Intrusive thoughts & 17 \\
\hline Recognition and social support on the workplace & 18 \\
\hline Lack of support from the government & 18 \\
\hline Lack of information to implement change & 18 \\
\hline Knowing that absence will create problems for staff & 18 \\
\hline Lack of support from school governors & 18 \\
\hline Personal & 24 \\
\hline Negative public attitude & 24 \\
\hline Academic program & 24 \\
\hline Occupational & 24 \\
\hline Organizational & 24 \\
\hline The working community & 25 \\
\hline Social stressors & 25 \\
\hline Administrative work & 31 \\
\hline Time pressure & 31 \\
\hline Poor conditions for personal development & 31 \\
\hline Poor work conditions & 31 \\
\hline Work pressure & 32 \\
\hline Interpersonal relations and resources & 32 \\
\hline
\end{tabular}


Note. The stressors are organized from the most commonly studied to the least commonly studied in the teacher stress and coping literature.

The most common stressors investigated involved problems with students (13), classroom environment (11), school policy and administration (10), problems with colleagues (9), and workload (9). Interestingly, one common anticipated stressor, low salary (3), was rarely included in rating scales. This is somewhat surprising given that two of the three studies that did examine low salary found it to be very stressful for teachers (Litt \& Turk, 1985; Zurlo et al., 2007). In fact, Litt and Turk (1985) found low salary to be the biggest problem for teachers, while Zurlo, Pes, and Cooper (2007) found it to be the third greatest source of pressure. It may be that the point in time in which the study was done and the location where the study took place played key roles in how salary was ranked by teachers. The Litt and Turk (1985) study was done 25 years ago and teacher salaries have changed significantly since then. Further, Zurlo and colleagues did their study in Italy, so it may be that low salary is perceived as a greater problem for teachers there than in other countries. The five most common stressors are reviewed next.

\section{Problems with Students}

Investigations revealed that teachers rank student behavior as one of the main stressors associated with the teaching profession. For example, Innes and Kitto (1989) reported pupil misbehavior to be the top source of teacher stress, while Green and Ross (1996) found that teachers not only appraised students to be the greatest cause of stress,

but also the most recurrent one. Similarly, Griffith, Steptoe, and Cropley (1999) reported that teachers ranked student behavior as the second most prevalent source of stress behind only the category of work pressure and relationships. Finally, Chan (1998) 
reported student behavior management to be the second major cause of stress for teachers behind only workload/time pressure.

The group of stressors involving problems with students contained aspects involving pupil behavior (Admiraal, Korthagen, \& Wubbels, 2000; Admiraal, Wubbels, \& Korthagen, 1996; Blasé, 1986; Chan, 1998; Dick and Wagner, 2001; Green \& Ross, 1996; Griffith, Steptoe \& Cropley, 1999; Howard \& Johnson, 2004; Innes \& Kitto, 1989), unmotivated students (Admiraal et al., 2000; Blasé, 1986; Howard \& Johnson, 2004), pupil apathy (Admiraal et al., 2000; Blasé, 1986), and low pupil achievement (Admiraal et al., 2000, 1996; Chan, 1998). Other categories included student discipline, student absences (Blasé, 1996), violent students, students from disadvantaged and abusive backgrounds (Howard \& Johnson, 2004), students with emotional problems, students with learning problems (Chan, 1998), criticism from pupils, and mediocre pupil's efforts (Admiraal et al., 1996). In addition, some studies differentiated between pupil misbehavior and class misbehavior (Admiraal et al., 2000, 1996). One study even looked at pupil on task behavior as a possible stressor (i.e., "Pupil asks a question about an assignment"; Admiraal et al., 1996). With the high number of stressors coming from students, it is no surprise that teachers view problems with students as one of the most stressful aspects of teaching (Blasé, 1986; Kyriacou, 2001).

Qualitative studies reveal that teachers spontaneously report problems with students to be a source of stress. For example, in a qualitative analysis of sources of teacher stress, Blasé (1986) grouped all data linked to students and labeled it "student behavior”. From these data, four categories of stressors stemming from students were established: student discipline, student apathy, low student achievement, and student 
absences. Student discipline was the largest subcategory of student-generated stressors and referred to problems such as verbal abuse, fighting, screaming, damaging school property, teasing others, cheating, violent outbursts, and drug abuse. Blasé suggested that discipline problems appeared to be most stressful when they interfered with the teachers' ability to function and the students' ability to learn. He also posited that teachers felt pressure to play roles when imposing discipline (e.g., "babysitter," "heavy," "police"), which they found to be extremely unpleasant and incompatible with the kind of environment necessary for effective teaching and learning.

\section{Non-normative Student Problems}

Dealing with students' misbehavior can be difficult in it's own right, but when it has the potential of turning violent, the amount of stress increases. For example in a qualitative study on teacher stress and coping, Howard and Johnson (2004) depict a scene in which a teacher was physically assaulted by one of her students. In this example, the victim described the incident:

"I'd probably have to say my most stressful experience was on my 5th day here when I gave a student a consequence [a punishment for a misdemeanor] - which was only time out [being sent away from the class to a separate room for a specified period of time]. Obviously in 5 days you don't know the children perfectly and that child couldn't accept it. He was an ADD [a student with Attention Deficit Disorder] and autistic child and he grabbed me and pulled me basically to the ground and the force was so incredibly strong it was a matter of okay, how do I deal with this?" (p. 407) 
In the study mentioned above, teachers also described repeated refusal by students to conform to reasonable requests as well as incessant verbal abuse. To make matters worse, many of the problems associated with students are beyond the teachers' control. For example, some teachers mentioned various kinds of abuse and neglect endured by students at home as a major source of stress. Teachers are aware that many of their students come to school hungry and are poorly dressed. Dealing with the stress associated with the desire, and perhaps inability, to help these pupils can be overwhelming. As one teacher described:

"The worst things that I really find stressful are like, for example, I had a little girl come to me, her mouth was bleeding and she was screaming and mum was dragging her into class and you could see that she was still in the same clothes that she had on yesterday and no shoes on and things like that and her lip was bleeding. She was just hysterical and mum's just dumped her and run and those are the hard ones and getting to the bottom of the story and realizing that at 3 o'clock this woman is going to come and pick her up." (p. 408)

\section{Problems with the Classroom Environment}

Another commonly investigated source of teacher stress comes from the teaching environment. The category problems with the classroom environment includes several factors within the teaching domain that might prove stressful to even the most experienced educators, such as shortages of equipment like text books and supplies. Because of this abundance of contextual demands, researchers use a variety of descriptive terms in an attempt to differentiate them. For example, problems in the classroom environment have been described as environmental risks (Pascual et al., 2003; Griva \& 
Joekes, 2003; Pomaki \& Anagnostopoulou, 2003; Rasku \& Kinnunen, 2003; Verhoeven, Kraaij, Joekes, \& Maes, 2003), contextual and institutional stressors, (Beach \& Pearson, 1998), having to teach in overcrowded classrooms (Zurlo et al., 2007), teaching in many classes (Sweizer \& Dobrich, 2003), and a shortage of equipment (Griffith et al., 1999).

Although stressors from the teaching environment have often been studied, teachers rarely cite them as major sources of stress. For example, of the studies that reported rankings of major sources of stress for teachers, only Zurlo and colleagues (2007) found it to be listed as a major stressor, and even then teaching in over-crowded classrooms was only ranked as high as $10^{\text {th }}$. In another study, Blasé (1986) reported that lack of material (listed as a subcategory for an organizational stressor) was mentioned only 34 times out of 981 separate descriptions of work stress. In contrast, stress from students was mentioned 175 times, stress from administration was mentioned 166 times, and stress from colleagues was mentioned 92 times. Even stress from students' parents was mentioned 50 times. In addition, in a study on student teachers' behavior in response to daily hassles in the classroom, Admiraal and colleagues (1996) reported that even novice teachers do not perceive the classroom environment as being very stressful since the material category only accounted for $4 \%$ of the total hassles mentioned by the young teachers while student behavior accounted for over $80 \%$.

Even though the classroom environment is not typically viewed as stressful for teachers in and of itself, it may contribute to more stressful events later. For example, a teacher having difficulty dealing with classroom materials (such as a shortage of supplies) may soon experience an increase in disruptive student behavior. In this way, the teacher may experience stress due to pupil behavior, when in reality, the underlying cause 
of the disruptive behavior may be due to a disruption in the classroom environment itself. In support of this idea, Howard and Johnson (2004), who interviewed teachers depicted as resilient by their principals, described the setting of the teachers' work environment as "a highly disadvantaged area where issues of unemployment, poverty, family breakdown and interpersonal violence are common" (p. 401). This type of work setting generally includes shortages in the funding that pays for student supplies such as textbooks and other resource materials. In addition, the disadvantaged schools described above are identified as "hard-to-staff" because teachers generally do not live in those areas and typically choose not to work there (Howard \& Johnson, 2004). Because these schools are hard to staff, they may end up being populated by a high percentage of inexperienced teachers, further exacerbating the problems associated with the classroom environment as novice teachers are often ill-equipped to handle such disruptions in the work day.

\section{Problems with Administration/School Policy}

In addition to the stressors mentioned above, teachers tend to feel a great deal of pressure from their supervisors. Problems stemming from school administrators range from bureaucratic interference (Greenglass, Burke, \& Konarski, 1998) to unclear institutional goals (Burke \& Greenglass, 1996) to feeling pressure from being evaluated (Litt \& Turk, 1985). In contrast to problems with the classroom environment, teachers have consistently ranked problems associated with the administration as being highly stressful (Blasé, 1986; Chan, 1998; Green \& Ross, 1996; Griffith, Steptoe, \& Cropley, 1999; Zurlo et al., 2007). For example, in his analysis of sources of teacher stress, Blasé (1986) found it to be the third greatest stressor reported by teachers. The educators in this sample mentioned aspects such as unclear expectations, lack of knowledge or expertise, 
lack of support, inconsistency, unreasonable expectations, and poor evaluation procedures (among others) all relating to problems associated with the administration. Further, Chan (1998) reported school management to be ranked the $3^{\text {rd }}$ greatest cause of teacher stress, while Griffith and colleagues (1999) found it to be the most prominent source of teacher stress, although when listing it in their figure depicting sources of teacher stress, it was combined with relationships, making it unclear as to how it ranked on it's own (see Figure 1, p. 522).

\section{Problems with Colleagues}

Another common problem experienced by teachers results from interactions with colleagues. Salo (1995) reported problems with other teachers to be ranked the $3^{\text {rd }}$ major cause of teacher stress, while Blasé (1986) and Chan (1998) both reported problems with colleagues to be ranked $4^{\text {th }}$. Zurlo and colleagues (2007) reported problems with colleagues to be rated as the fourth highest stressor as well. However, when they listed it in a group of the top 10 sources of pressure experienced by teachers, it was described as, "knowing that my absence will create problems for other staff" making it difficult to compare with findings of other studies since no other study reported it in this manner (see Table III, p. 235). In another study, problems with colleagues were combined with problems with administrators so there is no way to discern how this category compares with categories from other studies (Green \& Ross, 1999). It is interesting to note that even though these two subcategories were combined, Green and Ross (1999) reported that teachers still rated them to be slightly less stressful than problems with student behavior. Finally, Dick and Wagner (2001) used the term "mobbing” to describe certain kinds of "terrorizing" by colleagues that can occur in the workplace and included sample 
items like "colleagues often spread rumors about me," and "I am often excluded from social activities, like parties or informal meetings.” Again, because no other study used this concept as a means of investigating teacher stress associated with colleagues, it makes the results from this study difficult to compare with others.

Problems with Workload

Workload was the next most commonly studied stressor for teachers and it was assessed by using descriptive terms such as time and workload pressures (Chan, 1998; Howard \& Johnson, 2004), amount of work (Salo, 1995), too much paper work, and role overload (Litt \& Turk, 1985). Because of the wide array of different responsibilities placed on teachers, such as grading papers, preparing lessons, incorporating district mandated requirements, tutoring students before and after class, attending meetings, and contacting parents, the total amount of work can be experienced as very stressful. For example, Chan (1998) reported workload and time pressure to be ranked number one, while Salo (1995) reported the content of work (i.e., amount of work) to be the second greatest stressor for teachers. In addition, Litt and Turk (1985) reported too much paperwork to be the third greatest stressor, although this is only one aspect of work requirements placed on teachers.

Although workload can be a major source of stress for teachers, with the exception of the studies mentioned above, workload is not typically reported as being as difficult as the other stressors mentioned thus far. For example, it was not even reported as one of the top 10 stressors for teachers by Zurlo and colleagues (2007) and, in the studies that did report workload as one of the top stressors, the researchers generally combined it with other sources of stress. Griffith and colleagues (1999), for example, 
reported work pressure and student misbehavior as the most important sources of stress, but in looking at the sample items for work pressure one can see that not only is administrative work included, but so is pressure from head-teachers and educational officers. Pressure from colleagues has already been shown to be stressful in it's own right (e.g., Blasé, 1984; Chan, 1998; Salo, 1995) and can be quite different than pressure from the amount of work one has to do. Combining these two stressors into the same category may lead to an exaggerated view of how stressful workload actually is for teachers.

It may be that teachers find workload to be less stressful than working with students, colleagues, and administrators, as well as the classroom environmental factors described earlier, because they believe they have more control over the amount of work they put in versus other aspects of teaching. Indeed, Green and Ross (1996) found that problems with administrators and other teachers were reported as more stressful than problems with preparing for class, and teachers generally believed that problems for classroom preparation were of their own creation. Unfortunately for teachers, however, most of the stressors described thus far may be out of their control. Because teachers must deal with such a wide array of stressors on a daily basis, their physical and emotional health may be placed in jeopardy, as perceiving one's job as stressful may be a factor in burnout and employee turnover.

How Do Teachers Cope with these Demands?

\section{Common Measures of Coping used by Teachers}

In order to deal with the many demands associated with the profession, teachers must have effective strategies that enable them to manage stress. In the teacher stress and coping literature, these strategies have been measured in a variety of ways. In the 31 
studies reviewed, the most commonly used measure to assess coping was the CISS-S-2, which is a 21-item shortened version of the Coping Inventory for Stressful Situations (Endler \& Parker, 1990) that was employed in 5 studies (i.e., Pascual et al., 2003; Griva \& Joekes, 2003; Pomaki \& Anagnostopoula, 2003; Rasku \& Kinnunen, 2003;

Verhoeven, et al., 2003). Endler and Parker (1990) divided coping strategies into three categories: task-oriented, emotion-oriented, and avoidance-oriented ones. The taskoriented portion of the measure involves strategies that attempt to change the stressful situation and remove it's effects (e.g., "determine a course of action and follow it"). Emotion-oriented coping involves the use of cognitive activities that reduce or remove the effects of the stress and involve regulating emotions. Interestingly, the only example item included for emotion-oriented coping by any of the five studies mentioned above was “become very upset” (see Rasku \& Kinnunen, 2003). Avoidance-oriented coping involves methods of turning one's thoughts away from the stressful event (e.g., "go out for a snack or meal"). The three coping categories contained 7 items each and teachers indicated (on a 5-point scale: $1=$ not at all, 5 = very much) how often they used that particular strategy. The CISS is reported to have very good reliability and validity with internal consistencies at or above .85 and the short version is expected to have comparable levels of reliability (Verhoeven et al., 2003).

The next most commonly used measure of teacher coping was the COPE (Carver et al., 1989), and was utilized by 3 studies (i.e., Griffith et al., 1999; Mearns \& Cain, 2003; Shen, 2009). The COPE is a 53-item measure designed to assess 14 different ways of coping with stressful events, that are combined into three overarching categories: (1) problem-focused coping (e.g., active coping, planning, suppression of competing 
activities, restraint coping, and seeking of instrumental social support), (2) emotionfocused coping (e.g., seeking of emotional social support, positive reinterpretation, acceptance, denial, turning to religion), and (3) maladaptive coping (e.g., focus on and venting of emotions, behavioral disengagement, mental disengagement, and alcohol-drug disengagement). Examples of problem-focused coping items were, "I take additional action to try to get rid of the problem," and "I try to come up with a strategy about what to do". Examples of emotion-focused coping were, "I talk to someone about how I feel," and "I look for something good in what is happening," and examples of maladaptive coping were, "I turn to work or other substituting activities to take my mind off things," "I go to movies or watch TV to think about it less" and "I drink alcohol or take drugs in order to think about it less". Participants rated each item using a 4-point scale from 1 ("I don't do this at all") to 4 ("I usually do this a lot"), after reading the following orienting instructions:

We are interested in how people respond when they confront difficult or stressful events in their lives. There are lots of ways to try to deal with stress. This questionnaire asks you to indicate what you generally do and feel when you experience stressful events. Obviously, different events bring out somewhat different responses, but think about what you usually do when you are under a lot of stress.

Most of the subscales in the COPE scale had sufficient alphas with the exception of mental disengagement (.45) and alcohol-drug disengagement (which had an alpha of .0). In an attempt to improve upon the internal consistencies of the scale, each of the three studies utilizing the COPE measure modified the instrument in some way. For example, 
Mearns and Cain (2003) modified the instructions so that participants reported on how they generally dealt with stress that is associated with their teaching job. In addition, they divided the subscales into the three higher order coping dimensions: active, emotionfocused, and avoidant coping. According to the authors, this revision helped ameliorate the problems with the internal consistencies of the original COPE scale. They reported the COPE alphas in their study to be .85 for active coping, .84 for emotion-focused, and .66 for avoidant coping.

Shen (2009) attempted to solve the reliability problem by combining items that were part of the original factors (i.e., active coping, planning, positive reinterpretation and growth, and acceptance) to load on one factor (i.e., active coping and positive thinking), while items from the original component "focus on and venting of emotions" were incorporated into the component "seeking social support for emotional reasons". The following nine subscales were then utilized: (1) active coping and positive thinking; (2) suppression of competing activities; (3) restraint coping; (4) behavioral disengagement; (5) mental disengagement; (6) denial; (7) seeking social support for instrumental reasons; (8) seeking social support for emotional reasons; and (9) turning to religion. According to the author, the total variance explained by the nine factors was just over 54 percent with an average internal consistency of .82 .

In their attempt to resolve the internal consistency problems of the COPE, Griffith and colleagues (1999) selected specific items that assessed responses like active planning, seeking social support, suppression of competing activities, and mental and behavioral disengagement as a means of assessing a variety of coping strategies distinct to teachers. In addition, the researchers indicated that in order to diminish the likelihood of 
confounding emotion-focused coping with psychological distress, most items chosen were behavioral-oriented coping. Finally, after a factor analysis of the coping scale, the researchers settled on four coping dimensions: coping by seeking support $(\alpha=.87)$, coping by active planning $(\alpha=.84)$, coping by cognitive and behavioral disengagement $(\alpha=.65)$, and coping by suppressing competing activities $(\alpha=.69)$.

The only other coping measure used in more than two studies was the Ways of Coping Questionnaire (WCQ; Folkman \& Lazarus, 1988), which was also employed by 3 studies (i.e., Chan, 1994; 1998; Peklaj \& Puklek, 2001), and the TSI, described in the section on teacher stress. The WCQ is a 66 -item instrument that measures strategies utilized by individuals when coping with stressful events and contains eight subscales: confrontive coping (e.g., "I expressed my feelings"), distancing (e.g., "I behaved as if nothing would have happened," and "I tried to forget everything), self-control (e.g., "I tried to keep my opinion for myself" [sic]), seeking social support (e.g., "I tried to find professional help"), accepting responsibility (e.g., "I recognized that I give rise to the problem myself"), escape-avoidance (e.g., "I hoped that a miracle will happen; I have slept more than usually" [sic]), planful problem solving (e.g., "I focused on the problem"), and positive reappraisal (e.g., "I have changed and became more mature"). The WCQ had marginal Cronbach's reliability coefficients for the subscales ranging from .61 to .79 (Folkman \& Lazarus, 1988). The only modification made in any of the studies was to translate the scale to Chinese (Chan, 1994; 1998) and Slovene (Peklaj \& Puklek, 2001).

It is interesting to note that one of the measures used to determine what teachers find as stressful, the Teacher Stress Inventory (TSI) described earlier, was also used as a 
coping measure (e.g., Blasé, 1986). The second version of the TSI was modified to reflect emergent categories identified in the first questionnaire and distributed to 47 teachers taking courses at a major university located in southwestern U.S. The TSI was modified to give more emphasis on coping. Strategies identified as "direct action" and "palliative" were distinguished from each other and questions relating to perceived effectiveness were included. The final revision was administered to 35 teachers taking courses at a southwestern university. The phrase "if any" was added to the questionnaire items 3 (e.g., "List and describe the most important typical approaches (if any) you use to deal with stress factor identified above and indicate the degree of effectiveness (or ineffectiveness) of each approach." [sic]) and 5 (e.g., "List and describe the most important approaches (if any) you use to deal with your feelings identified in number 4 and indicate the degree of effectiveness (or ineffectiveness) of each approach").

\section{Ways Teachers Cope with the Demands of Teaching}

Table 2.2 contains a list of the coping strategies most commonly investigated in studies of teacher stress and coping. The first column includes all the ways of coping as described by the researchers in the studies, including the total number of studies investigating the given way of coping which is written in parentheses after the way of coping category. Again, like the Stressor Table, some of the ways of coping were separated into smaller subcategories to delineate the different terms used by the researchers. The second column includes either a general definition or sample items listed in the studies cited (in some cases both were provided). If there were no sample items or definition provided, this was noted by the phrase "Not mentioned". The third column includes the number listed along with the study (or studies) utilizing this term, which can 
be found in the appendix after the reference section of the thesis paper.

Table 2.2

Ways of Coping Investigated in the Teacher Stress and Coping Literature

\begin{tabular}{|c|c|c|}
\hline Ways of Coping & General Definition & Study \\
\hline $\begin{array}{l}\text { Problem-Focused Coping } \\
\text { (19) }\end{array}$ & $\begin{array}{l}\text { Problem-focused coping is defined as tackling a } \\
\text { problem directly (Lazarus \& Folkman, 1984). } \\
\text { Described as rational problem solving (e.g., "went over } \\
\text { in mind what to say/do, prepared for the worst, knew } \\
\text { what to do and doubled efforts and changed and grew } \\
\text { as a person"; Chan, 1998) and active problem solving, } \\
\text { which "involves strategies such as direct intervention, } \\
\text { considering different solutions to the problem, and } \\
\text { considering problems as a challenge" (Olff et al., } \\
\text { 1993). }\end{array}$ & $\begin{array}{l}4,5,7,8,9,10 \\
12,13,14,17 \\
19,22,25,27 \\
29,30,31,32,33\end{array}$ \\
\hline $\begin{array}{l}\text { Seeking Social } \\
\text { Support for } \\
\text { instrumental } \\
\text { reasons }\end{array}$ & Not mentioned & 19 \\
\hline $\begin{array}{l}\text { Coping by } \\
\text { Education }\end{array}$ & $\begin{array}{l}\text { E.g., "Participating in teacher training," "Searching } \\
\text { for literature which gives me advice," and "Talking } \\
\text { about it in a supervision group." }\end{array}$ & 22 \\
\hline Active Behavioral & $\begin{array}{l}\text { "Active-behavioural strategies refer to overt } \\
\text { behavioural attempts to deal directly with the event } \\
\text { and its effects; for example, one might talk with a } \\
\text { professional person about the situation" (Innes \& } \\
\text { Kitto, 1989, p. 304). }\end{array}$ & 31 \\
\hline Intervening & $\begin{array}{l}\text { The attempt to change the state of affairs (e.g., } \\
\text { "Teacher walks along the benches and urges the pupils } \\
\text { to be quiet"). }\end{array}$ & 33 \\
\hline Avoidant Coping (19) & $\begin{array}{l}\text { The attempt to change the classroom context without } \\
\text { being directed toward the classroom event (e.g., } \\
\text { "Teacher invites pupils to answer, while others are } \\
\text { talking"; Admiraal, Wubbels, \& Korthagen, 1996). }\end{array}$ & $\begin{array}{l}4,5,7,8,9,10 \\
12,13,14,17 \\
19,25,26,27 \\
29,30,31,32,33\end{array}$ \\
\hline $\begin{array}{l}\text { Resigned } \\
\text { Distancing }\end{array}$ & $\begin{array}{l}\text { E.g., "went on as if nothing had happened," "went } \\
\text { along with fate," "tried to forget the whole thing," and } \\
\text { "got away in rest of vacation" (Chan, 1998). }\end{array}$ & 14,29 \\
\hline $\begin{array}{l}\text { Passive Wishful } \\
\text { Thinking }\end{array}$ & $\begin{array}{l}\text { E.g., "Had fantasies or wishes about outcome, } \\
\text { daydreamed a better time or place, wished the situation } \\
\text { would go away, and wished could change feeling or } \\
\text { event" (Chan, 1998). }\end{array}$ & 14,29 \\
\hline Distancing & $\begin{array}{l}\text { E.g., "I behaved as nothing would have happened," } \\
\text { and "I tried to forget everything." }\end{array}$ & 17 \\
\hline Denial & Not mentioned & 19 \\
\hline $\begin{array}{l}\text { Behavioral } \\
\text { Disengagement }\end{array}$ & Not mentioned & 19 \\
\hline $\begin{array}{l}\text { Mental } \\
\text { Disengagement }\end{array}$ & Not mentioned & 19 \\
\hline $\begin{array}{l}\text { Avoidance of } \\
\text { Thinking }\end{array}$ & Not mentioned & 25 \\
\hline
\end{tabular}




\begin{tabular}{|c|c|c|}
\hline Displacement & $\begin{array}{l}\text { E.g., "think of other things," "blame others," "deny } \\
\text { that the problem exists," "avoidance," and "try to carry } \\
\text { on." }\end{array}$ & 26 \\
\hline $\begin{array}{l}\text { Think of other } \\
\text { things }\end{array}$ & Not mentioned & 27 \\
\hline Mental and & E.g., "turn to other activities," "stop trying," & 32 \\
\hline Behavioral & "daydream," "give up," "sleep," "give up attempt," & \\
\hline Disengagement & "watch TV," and "reduce effort." & \\
\hline Ignoring & $\begin{array}{l}\text { The student teacher's attempt to continue the behaviour } \\
\text { that s/he showed before the event started (e.g., } \\
\text { "Teacher goes on with the lesson"). }\end{array}$ & 33 \\
\hline $\begin{array}{l}\text { Emotion-Focused Coping } \\
\text { (15) }\end{array}$ & $\begin{array}{l}\text { Emotion-focused coping refers to expressing or } \\
\text { dealing with the emotions in a stressful event. }\end{array}$ & $\begin{array}{l}4,5,7,8,9,10 \\
12,13,17,19 \\
22,26,27,31,32\end{array}$ \\
\hline $\begin{array}{l}\text { Seeking Social } \\
\text { Support for } \\
\text { Emotional Reasons }\end{array}$ & $\begin{array}{l}\text { Shen (2009) integrated the factor "focus on and } \\
\text { venting emotions" into the factor of seeking support } \\
\text { for emotional reasons. }\end{array}$ & 19,32 \\
\hline $\begin{array}{l}\text { Comforting } \\
\text { Cognitions }\end{array}$ & $\begin{array}{l}\text { This strategy includes positive reframing, self- } \\
\text { encouragement, and considering the problem in a } \\
\text { relative way. According to the author, it could be } \\
\text { argued that the measure in this component reflects } \\
\text { cognitive defense. }\end{array}$ & 4 \\
\hline $\begin{array}{l}\text { Expressing } \\
\text { Emotions }\end{array}$ & $\begin{array}{l}\text { Demonstrating an expressive emotional reaction } \\
\text { towards the problems of the stressful event. }\end{array}$ & 4 \\
\hline $\begin{array}{l}\text { Positive } \\
\text { Reappraisal }\end{array}$ & E.g., "I have changed and became more mature." & 17 \\
\hline $\begin{array}{l}\text { Find an Emotional } \\
\text { Prop }\end{array}$ & $\begin{array}{l}\text { E.g., "express feelings," "talk to others to get } \\
\text { emotional support," "smoke more," "relax," "take a } \\
\text { day off to sort yourself out," and "resort to pills." }\end{array}$ & 26 \\
\hline Active Cognitive & $\begin{array}{l}\text { This coping strategy involves an appraisal of the } \\
\text { stressful event or situation (e.g., "trying to see the } \\
\text { positive side"). }\end{array}$ & 31 \\
\hline $\begin{array}{l}\text { Seeking Social Support } \\
\text { (8) }\end{array}$ & $\begin{array}{l}\text { Undetermined whether emotion-focused or problem- } \\
\text { focused coping (e.g., "I tried to find professional help; } \\
\text { Peklaj \& Puklek, 2001). Seek Support (e.g., "try to get } \\
\text { advice," "discuss feelings," "talk to someone to find } \\
\text { out..." "get emotional support"; Griffith et al., 1999). }\end{array}$ & $\begin{array}{l}4,14,17,22,25 \\
27,29,32\end{array}$ \\
\hline $\begin{array}{l}\text { Coping by drawing } \\
\text { on professional } \\
\text { support }\end{array}$ & $\begin{array}{l}\text { E.g., "Turning to external authorities," and "Turning to } \\
\text { the psychological service of the school." }\end{array}$ & 22 \\
\hline $\begin{array}{l}\text { Express feelings } \\
\text { and seek support }\end{array}$ & Not mentioned & 27 \\
\hline $\begin{array}{l}\text { Seek support and } \\
\text { ventilation }\end{array}$ & $\begin{array}{l}\text { E.g., "talked to someone about feelings, talked to } \\
\text { someone to find out more, let feelings out, and asked } \\
\text { advice from a relative/friend." }\end{array}$ & 29 \\
\hline Palliative Coping (5) & $\begin{array}{l}\text { Palliative coping is said to occur when an individual's } \\
\text { main motivation behind putting forth effort is to avoid } \\
\text { negative consequences associated with failure, such as } \\
\text { in the case of avoidance and self handicapping (Parker } \\
\& \text { Martin, 2009). It does not deal with the source of the } \\
\text { stress but is an attempt to reduce the effect of the } \\
\text { stressor (Howard \& Johnson, 2004). }\end{array}$ & $1,2,4,6,24$ \\
\hline
\end{tabular}




\begin{tabular}{|c|c|c|}
\hline Direct Coping (4) & $\begin{array}{l}\text { Using master orientation and forward planning } \\
\text { demonstrating high levels of "effort, process, mastery } \\
\text { and development" (Parker \& Martin, 2009, p 69). } \\
\text { Direct coping involves attempts to eliminate the source } \\
\text { of the stress (Howard \& Johnson, 2004). }\end{array}$ & $1,2,6,24$ \\
\hline $\begin{array}{l}\text { Suppression of } \\
\text { Competing Activities (2) }\end{array}$ & $\begin{array}{l}\text { E.g., "prevent distraction," "focus," "prevent } \\
\text { interference," and "concentrate" (Griffith, Steptoe \& } \\
\text { Cropley, 1999). }\end{array}$ & 19,32 \\
\hline Internal Control (2) & $\begin{array}{l}\text { A coping strategy, which depends on one's own efforts } \\
\text { to change the situation (Burke \& Greenglass, 1996). }\end{array}$ & 16,28 \\
\hline \multicolumn{3}{|l|}{ Used in Only 1 Study } \\
\hline Depressive Reaction & $\begin{array}{l}\text { E.g., "being overwhelmed by the problem" and "being } \\
\text { pessimistic about the outcome." }\end{array}$ & 4 \\
\hline Level I & $\begin{array}{l}\text { Attempts to avoid, deny, mask over, or rationalize the } \\
\text { conflict and give reasons for it but fail to discuss } \\
\text { strategies for coping. }\end{array}$ & 15 \\
\hline Level II & $\begin{array}{l}\text { Consists of references to short-term expedient } \\
\text { strategies or survival techniques. }\end{array}$ & 15 \\
\hline Level III & $\begin{array}{l}\text { Involves the consideration and/or implementation for } \\
\text { long-term change in one's theories or beliefs. Here } \\
\text { they go beyond a short-term focus to reflect on } \\
\text { conflicts and tensions in terms of implications for their } \\
\text { theories of teaching. }\end{array}$ & 15 \\
\hline Preventive Coping & $\begin{array}{l}\text { Includes coping techniques aimed at promoting one's } \\
\text { well-being and reducing the likelihood of anticipated } \\
\text { or potential problems (e.g., "planning for the future"). }\end{array}$ & 16 \\
\hline Existential Coping & $\begin{array}{l}\text { Includes ways of coping that attempt to maintain a } \\
\text { sense of meaning and coherence or an attitude of } \\
\text { acceptance in dealing with general conditions of life. }\end{array}$ & 16 \\
\hline Confrontive Coping & $\begin{array}{l}\text { E.g., "I expressed my feelings," "stood my ground and } \\
\text { fought for what I wanted" and "tried to get the person } \\
\text { responsible to change his or her mind." }\end{array}$ & 17 \\
\hline Self-Control & $\begin{array}{l}\text { E.g., "I tried to keep my opinion for myself," "I tried to } \\
\text { keep my feelings to myself" and "kept others from } \\
\text { knowing how bad things were." }\end{array}$ & 17 \\
\hline Accepting Responsibility & $\begin{array}{l}\text { E.g., "I recognized that I give rise to the problem } \\
\text { myself," "criticized or lectured myself," and "realized I } \\
\text { brought the problem on myself." }\end{array}$ & 17 \\
\hline $\begin{array}{l}\text { Active Coping and } \\
\text { Positive Thinking }\end{array}$ & $\begin{array}{l}\text { According to the author, this dimension was made up } \\
\text { of active coping, planning, and acceptance and positive } \\
\text { reinterpretation from the original COPE scale by } \\
\text { Carver. }\end{array}$ & 19 \\
\hline Turning to Religion & Not mentioned & 19 \\
\hline Restraint Coping & Not mentioned & 19 \\
\hline Maladaptive Coping & $\begin{array}{l}\text { E.g., "Substance abuse," and "watch } 3 \text { or more hours } \\
\text { of TV." }\end{array}$ & 21 \\
\hline Adaptive Coping & $\begin{array}{l}\text { E.g., "Seeking social support, attending workshops, } \\
\text { exercising, meditation, and deep breathing." }\end{array}$ & 21 \\
\hline $\begin{array}{l}\text { Coping by Seeking } \\
\text { Support and Initiating } \\
\text { Change }\end{array}$ & $\begin{array}{l}\text { E.g., "Talking about it with colleagues," "Asking the } \\
\text { school authority for advice and help," and "Trying to } \\
\text { change the conditions at school with..." }\end{array}$ & 22 \\
\hline
\end{tabular}




\begin{tabular}{|c|c|c|}
\hline $\begin{array}{l}\text { Active-Passive } \\
\text { Dimension }\end{array}$ & $\begin{array}{l}\text { The degree of intensity of the student teacher's actions } \\
\text { when transferring verbal messages. }\end{array}$ & 23 \\
\hline $\begin{array}{l}\text { Agitation-Harmony } \\
\text { Dimension }\end{array}$ & $\begin{array}{l}\text { The degree of tension the student teacher arouses in } \\
\text { the interaction with the students. }\end{array}$ & 23 \\
\hline $\begin{array}{l}\text { Thinking about work } \\
\text { alone }\end{array}$ & Not mentioned & 25 \\
\hline $\begin{array}{l}\text { Devoting oneself to free- } \\
\text { time activities }\end{array}$ & Not mentioned & 25 \\
\hline $\begin{array}{l}\text { The use of food, alcohol, } \\
\text { or tobacco }\end{array}$ & Not mentioned & 25 \\
\hline $\begin{array}{l}\text { Being rational and } \\
\text { problem solving }\end{array}$ & $\begin{array}{l}\text { E.g., "put things into perspective," "humor," "plan," } \\
\text { "support and advise seeking," "rationalize," and } \\
\text { "problem-solving." }\end{array}$ & 26 \\
\hline $\begin{array}{l}\text { Let off steam but get } \\
\text { stuck into work }\end{array}$ & $\begin{array}{l}\text { E.g., "head down and work harder," "be irrational," } \\
\text { "drink," "take it out on others," "resignation," and } \\
\text { "plan lesson by lesson.” }\end{array}$ & 26 \\
\hline $\begin{array}{l}\text { Think positively whilst } \\
\text { allowing yourself } \\
\text { diversions }\end{array}$ & $\begin{array}{l}\text { E.g., "positive comparison with others," "prayer," "be } \\
\text { physical," "think positively," "early problem solving," } \\
\text { "try not to worry," "hobbies," and "improve skills." }\end{array}$ & 26 \\
\hline Waiting & $\begin{array}{l}\text { Staying with the situation for a period of time (e.g., } \\
\text { "Irritated teacher waits in front of the classroom"). }\end{array}$ & 33 \\
\hline
\end{tabular}

As can be seen, the most frequently studied strategies were problem-focused coping and avoidant coping (19 studies each), followed by emotion-focused coping (15), and seeking social support (8). The only other coping strategies investigated in more than two studies included palliative coping (5) and direct coping (4), although a case could be made that direct coping, defined as using mastery orientation and forward planning demonstrating high levels of "effort, process, mastery and development" (Parker \& Martin, 2009, p 69), fits under the category of problem-focused coping, which has been described as tackling the problem directly (Lazarus \& Folkman, 1984). Palliative coping, on the other hand, appears to be a combination of avoidant and emotion-focused coping as it is said to occur when an individual's main motivation behind putting forth effort is to avoid negative consequences associated with failure, such as in the case of avoidance and self handicapping (Parker \& Martin, 2009). In addition, much like emotion-focused 
coping, it does not deal with the source of the stress but is an attempt to reduce the emotional impact of the stressor (Howard \& Johnson, 2004).

\section{Problem-Focused Coping}

As mentioned earlier, problem-focused coping is defined as tackling a problem directly (Lazarus \& Folkman, 1984). In the teacher literature, problem-focused coping has been described in many ways. For example, Olff and colleagues (1993) used the term "active problem solving" to describe how one might utilize strategies such as considering various solutions to address the problem directly, coming up with a direct intervention to solve the problem, and perceiving the problem as challenging. Presumably, viewing the problem as a challenge leads to more active problem-solving techniques, whereas viewing the problem as a threat may lead to avoiding dealing with the problem all together. In a similar vein, Innes and Kitto (1989) used the term "active behavioral strategies" to describe dealing directly with the event and its consequences through the use of overt behavioral strategies such as seeking professional help to deal with a problem. Further, when describing problem-focused coping techniques, Chan (1994) used the term "rational problem solving" and listed the items "went over in mind what to say/do," "prepared for the worst," and "knew what to do and doubled efforts" (p.153). Finally, Admiraal and colleagues (1996) described problem-focused coping in terms of "intervening" as an attempt to change the situation, such as when a teacher approaches students to urge them to work quietly.

Problem-focused coping is typically associated with positive outcomes for teachers, as it tends to alleviate psychological distress (Chan, 1998) and teachers themselves report it to be the most effective coping strategy (Litt \& Turk, 1985). In addition, higher 
amounts of task-oriented coping predicted a stronger sense of personal accomplishment (Griva \& Joekes, 2003; Pascual et al., 2003; Pomaki \& Anagnostopoulou, 2003; Rasku \& Kinnunen, 2003), and lower levels of depersonalization (Griva \& Joekes, 2003; Pascual et al., 2003; Pomaki \& Anagnostopoulou, 2003; Rasku \& Kinnunen, 2003), whereas lower amounts of task-oriented coping has been found to lead to more physical symptoms related to burnout (Griva \& Joekes, 2003; Innes \& Kitto, 1989). Further, problem-focused coping has been found to be negatively associated with disengagement (Griffith et al., 1999 ) and somatic complaints (Rasku \& Kinnunen, 2003), and positively associated with job satisfaction (Griva \& Joekes, 2003; Pomaki \& Anagnostopoulou, 2003). Together, these findings suggest that problem-focused coping may have salutary effects for teachers, or, the reverse could be true since the results are based largely on correlations. Avoidant Coping

In the teacher literature, avoidant coping has been conceptualized as attempting to withdraw from a stressful event without dealing directly with the problem. Many descriptive terms have been utilized to measure avoidance-oriented coping, including avoidance and passive expectancies (e.g., "resigning oneself to the situation," "trying to avoid difficult situations," and "awaiting the consequences"; Olff et al., 1993), passive wishful thinking (e.g., "had fantasies or wishes about outcome," "daydreamed a better time or place," "wished the situation would go away," and "wished could change feeling or event"; Chan, 1994; 1998), distancing (e.g., "I behaved as nothing would have happened," or "I tried to forget everything"; Peklaj \& Puklek, 2001), displacement (e.g., "think of other things," "blame others," "deny that the problem exists," "avoidance," and "try to carry on"; Freeman, 1987), avoidance of thinking (Salo, 1995), denial (Shen, 
2009), mental and behavioral disengagement (e.g., "turn to other activities," "stop trying," "daydream," "give up," "sleep," "give up attempt," "watch TV," and "reduce effort"; Griffith, et al., 1999), and ignoring (e.g., "Teacher goes on with the lesson"; Admiraal et al., 1996). Regardless of how many terms are used to describe avoidance, it all seems to come down to turning one's attention away from the stressful event and/or hoping the situation will resolve itself. It may be that, due to this failure to act to resolve the situation, avoidance is typically viewed as a maladaptive coping strategy.

In the teaching literature avoidant coping tends to be associated with negative outcomes. For example, Chan (1998) reported that, in contrast to problem-focused coping, avoidant coping tends to exacerbate psychological distress. In addition, teachers who use more avoidant coping are reported to be less satisfied with the outcome and tend to view problems as recurrent (Green \& Ross, 1996). Further, avoidant coping has been found to be positively associated with somatic complaints (Pomaki \& Anagnostopoulou, 2003) and emotional exhaustion (Rasku \& Kinnunen, 2003). Finally, two studies found that not only does avoidant coping contribute to an increase in physical symptoms, but also is predictive of more burnout in teachers (Griva \& Joekes, 2003; Innes \& Kitto, 1989). However, it could once again be the reciprocal effect since the results are based largely on correlations.

\section{Emotion-Focused Coping}

Emotion-focused coping can be conceptualized as attempting to express or deal with emotions arising during a stressful situation. Similar to the ways of coping described thus far, strategies involving emotion-focused coping have been investigated in a variety of ways. Examples include seeking social support for emotional reasons (Shen, 2009; 
Griffith et. al., 1999), expressing emotions (e.g., "showing an emotional expressive reaction towards problems"; Olff et al., 1993), find an emotional prop (e.g., "express feelings," "talk to others to get emotional support," "relax"; Freeman, 1987), positive reappraisal (e.g., "I have changed and became more mature"; Peklaj \& Puklek, 2001), and active cognitive coping (e.g., "trying to see the positive side"; Innes \& Kitto, 1989). In addition, Olff and colleagues (1993) used the term "comforting cognitions," describing it as including self-encouragement, positive reframing, and thinking about the problem in a reasonable way. This seems to fit under the umbrella of emotion-focused coping, as it appears to be using thought processes to regulate emotions aroused by the stressful experience.

Much like avoidant coping, emotion-focused coping is typically associated with negative outcomes for teachers attempting to deal with stress in this manner. For example, higher levels of emotion-focused coping have been reported to be a predictor of somatic complaints and emotional exhaustion (Griva \& Joekes, 2003; Pascual et al., 2003; Pomaki \& Anagnostopoulou, 2003; Rasku \& Kinnunen, 2003; Verhoeven et al., 2003). In addition, in contrast to problem-focused coping, emotion-focused coping lead to more depersonalization (Pascual et al., 2003; Rasku \& Kinnunen, 2003; Verhoeven et al., 2003) and had a negative association with personal accomplishment (Pascual et al., 2003; Rasku \& Kinnunen, 2003) and job satisfaction (Pascual et al., 2003; Pomaki \& Anagnostopoulou, 2003; Rasku \& Kinnunen, 2003). It should be noted, however, that in one study low levels of emotion-focused coping have been found to be associated with high personal accomplishment (Verhoeven et al., 2003) which may actually lead to an increase in job satisfaction. 


\section{Social Support}

As can be seen in Table 2.2, social support is often included in problem-focused coping or emotion-focused coping measures, depending upon what aspect of support one is utilizing. For example, seeking social support for instrumental reasons is included in the category of problem-focused coping, as the individual is going to another as a direct attempt at changing the circumstances of the stressful event. In contrast, seeking social support for emotional reasons sometimes falls under the classification of emotion-focused coping, as the individual is seeking emotional support from another individual or group of individuals.

The descriptive terms provided above gave a clear indication as to which category each type of support seeking would fall under. Other terms utilized in the studies gave no such indication, and were placed in a separate category in the Ways of Coping Table under the heading Seeking Social Support. Examples of such terms were, coping by drawing on professional support (e.g., "Turning to external authorities," and "Turning to the psychological service of the school"), coping by education (e.g., "Participating in teacher training," "Searching for literature which gives me advice," and "Talking about it in a supervision group"), express feelings and seek support, and seek support and ventilation (e.g., "talked to someone about feelings," "talked to someone to find out more," "let feelings out," and "asked advice from a relative or friend"). In all, eight studies used some form of seeking support without determining whether it was for emotional or instrumental reasons.

Much like problem solving, social support is typically associated with positive outcomes in the teacher stress and coping literature. It has been suggested that support 
from colleagues can assist in coping in two ways, first, through the enactment of formal roles, and second, through developing camaraderie with colleagues by uniting in the struggle with the large number of difficult students (Freeman, 1987). Indeed, an increase in social support has been shown to lead to the use of more adaptive coping strategies and less maladaptive ones. For example, Shen (2009) reported that the use of more social support was predictive of a greater use of active coping and positive thinking. In contrast, less use of social support has been found to be associated with an increase in disengagement (Griffith et al., 1999; Shen, 2009), including both mental and behavioral disengagement (Shen, 2009). Together, these results indicate that social support can have salutary effects for teachers who are attempting to cope with stress.

Some studies have indicated that social support has been associated with positive outcomes for teachers, regardless of whether it is perceived or sought out by the individual. For example, Dick and Wagner (2001) reported that perceiving greater principal support can reduce the perception of both workload and mobbing (described as certain kinds of terrorizing at the workplace by colleagues or principals), and the perception of more global social support turned out to be a moderator between stress and strain, suggesting that social support may help to reduce physical symptoms associated with stress. Similarly, seeking social support has been found to be negatively associated with negative affect and disengagement (Griffith et al., 1999), and teachers who attended workshops as a means of social support reported lower levels of burnout. In addition, Schweitzer and Dobrich (2003) found that there was a strong positive correlation between self-reported health and both coping by seeking support and coping by education. Interestingly, no such correlation was found between self reported health and coping by 
drawing on professional support.

Although the studies mentioned above indicate social support is associated with positive outcomes, some studies have shown otherwise. For example, in spite of the finding that teachers reported seeking support as one of the most effective means of coping (Litt \& Turk, 1985), teachers who reported discussing difficulties with colleagues and friends more often were more burned out (Seidman \& Zager, 1991). Similarly, Salo (1995) reported that teachers who made greater use of the support of friends had more depressed moods and exhaustion in December than at the start of the school year. It may be that teachers who had more problems at work or were more depressed and exhausted were also more likely to turn to friends for social support.

\section{Critiques of the Research on Teacher Stress and Coping}

Although there is a growing body of research on teacher stress and coping, the conclusions that can be drawn from this research as a whole are limited based on the design of most of the studies reviewed, including their reliance on survey methods and their focus on narrow bands of stress and categories of coping. Most importantly, few studies took a developmental perspective on coping. Each of these issues is considered in turn, highlighting findings from the few studies that did not share these shortcomings.

\section{Method of Gathering Data.}

Most of the studies on teacher stress and coping were based on data gained through closed-ended questionnaires, resulting in several limitations in the kinds of conclusions that can be drawn. These limitations were apparent when attempting to interpret the meaning of results about stress, coping, and the processes that connect them.

Stress. The use of checklists and questionnaires to capture teachers' perspectives on 
what they found stressful about teaching both constrained the kinds of stressors that teachers could report and introduced sets of stressors that might not have otherwise been salient to teachers. For example, as mentioned earlier, five of the studies employed the LAKS-DOC to measure teacher stress, and 8 categories were utilized, each containing between 4 and 16 items. Five of these categories contained more than 12 items each. Because there are so many categories containing a varied amount of items, there are also more stressors for teachers to rate, some of which may not have even occurred to the teachers had they not read them in the questionnaire.

In contrast, Blasé (1986) developed the TSI to gather qualitative data indicating what teachers perceive as stressful. Allowing teachers to list and describe what they view as stressful might avoid the possibility of teachers rating demands that they never even perceived as stressful in the first place. In addition, with closed-ended questionnaires some of the stressors perceived by teachers may not even be included, therefore they would be left out of the data altogether. This problem might be avoided with data gathered from open-ended interviews such as the TSI.

Coping. Similarly, the coping data gained from the closed-ended questionnaires were limited due to the constraints of the method utilized to acquire this information. For example, the CISS-S-2 was the most common measure used for coping and because it was closed-ended, commonly used strategies of coping may have been left off the questionnaire entirely, which appears to be the case with regards to seeking social support. Although seeking social support is commonly reported by teachers as a method of coping in open-ended interviews (see Admiraal et al., 2000; 1996; Beach \& Pearson, 1998; Howard \& Johnson, 2004; Freeman, 1987), and is often included in other closed- 
ended studies (e.g., Chan, 1994; 1998; Griffith et al., 1999; Mearns \& Cain, 2003; Shen, 2009), it was apparently not included as an option in the CISS-S-2 as none of the sample items listed by any of the five studies using the measure indicated that seeking social support was an option for coping.

Instead, the studies using the CISS-S-2 (e.g., Griva \& Joekes, 2003; Rasku \& Kinnunen, 2003; Verhoeven et al., 2003) described the following three ways of coping (1) task-oriented, (2) emotion-oriented, and (3) avoidance-oriented coping, while listing social support as a job condition and included the items ("The school management pays attention to what I say," "My direct supervisor values the work that I do," and "At my school, colleagues get on together well"). In this way, the researchers were looking at support as a resource rather than as a way of coping with stress. In other words, the researchers appear to have chosen to investigate social support in relationship to coping, rather than as a method of coping. Because this approach is significantly different than that of the other studies, combining the results of the studies to interpret the meaning becomes difficult.

Coping process. Another issue associated with data gathered from closed-ended questionnaires is their limitations with respect to capturing the process utilized by teachers to cope with stressful events. Typically, teachers are asked to review a list of stressors and then rate them on a 5-point Likert type scale as to how stressful they perceive each one to be. Next, teachers are asked to review a list of ways of coping, rating them in a similar fashion. However, in this way, the steps of how the teacher gets from the stressor to the way of coping with the stressful event are left out.

In contrast, data from open-ended interviews can be collected in a way that allows 
the researcher to examine the process of coping by asking about the episodic events occurring between the stressor and the actual ways of coping utilized by the teacher. For example, in the TSI, teachers are first asked to identify, describe and explain the meaning of three stressors associated with the profession, allowing the teachers themselves to choose what they perceive as stressful. Next, teachers are asked to provide an example to help clarify this meaning. The teachers are then asked to explain why the stressor identified causes them stress. In addition, teachers are asked to identify their typical approaches used in order to deal with the stress that was identified and to indicate the level of effectiveness (or ineffectiveness) of each approach. Finally, teachers are asked to identify the feelings associated with the stress factors and explain how they deal with those feelings, indicating once again the perceived level of effectiveness (or ineffectiveness) of each approach.

As can be seen by the comparison between open-ended versus closed-ended methods of data gathering described above, open-ended interviews can provide more information about the process of coping. Not only are teachers allowed to choose which demands they perceive as stressful, but they are also allowed to explain why it is viewed as stressful, which might provide a hint as to why they respond to it the way they do. In addition, teachers are allowed to describe how they cope with the stressful situation, providing them with the opportunity to spontaneously choose the coping method that comes to mind, and preventing them from having to look at a list and simply choosing the best one provided, regardless of whether they use it or not. Further, teachers are allowed to describe how they feel about the stressors and how they deal with those feelings. Coping with one's feelings and coping with the stressor itself might be different aspects 
of the coping process.

\section{Categories of Coping}

Another area that appears to be in need of attention is the inconsistency across studies in the ways of coping that are examined. The lack of consistency in describing the strategies employed by teachers to deal with stress makes it difficult to compare or aggregate results from the various studies. As can be seen in Table 2.2, across the 31 studies, only three ways of coping were used in more than half: problem-focused (19 studies), avoidant coping (19 studies), and emotion-focused coping (15 studies). Only two other categories were used in 5 or more studies: seeking social support ( 8 times) and palliative coping (5 times). Moreover, of the 56 different categories used to capture ways of coping, 24 were used by only one study.

Heterogeneity of categories. In addition to lack of consistency across studies, many of the systems used to categorize ways of coping do not show the properties of a good classification system (Skinner et al. 2003). Good categories are functionally homogenous, meaning that all the ways of coping they include have the same kinds of effects on coping outcomes. However, in studies of teacher coping, some of the categories of coping were heterogeneous in nature. One of the most heterogeneous categories was "emotionfocused" coping, which included an array of ways of coping that were used to deal with the emotional consequences of stressful encounters. For example, Freeman (1987) listed "find an emotional prop" as a way of coping and included the sample items "talk to others to get emotional support," "relax," "smoke more," and "resort to pills". Choosing relaxation or talking to others to get emotional support as ways of coping with stress are generally viewed as adaptive, whereas smoking more and resorting to pills would 
typically be viewed as maladaptive. Including both adaptive and maladaptive coping methods in the same category can make it difficult to interpret the meaning of the results.

Emotion-focused coping was not the only category that was heterogeneous in nature. The category of seeking social support also included a variety of coping strategies. For example, Chan (1998) used the category "seek support and ventilation" and included items such as "talked to someone about feelings," "talked to someone to find out more," "let feelings out," and "asked advice from a relative/friend" (see Table 3, p. 153). However, talking to someone to find out more and asking advice from others are categorized by other researchers as problem-focused coping, whereas talking to someone about one's feelings and letting one's feelings out is considered emotion-focused coping. Similarly, Griffith and colleagues (1999) listed seeking support as a method of coping but included items belonging to both problem-focused (e.g., "try to get advice," "talk to someone to find out," and "ask people"), and emotion-focused coping (e.g., "discuss feelings," "get emotional support," "get sympathy \& understanding," and "talk about how I feel"), making it difficult to decipher which type of coping is being utilized (see Table 2, p. 521). It may be that the individual is seeking emotional support, or it may be instrumental support, or, both reasons might apply. Much like grouping adaptive and maladaptive coping together, combining emotion-focused coping and problem-focused coping in the same category makes it difficult to draw conclusions about the meaning of the findings, or to compare them to findings from studies in which they were distinguished.

Other studies failed to provide any examples of items, making it impossible to decipher what type of social support is being assessed. For example, Olff and colleagues 
(1993) listed "seeking social support" as a subscale of "habitual coping strategies" but included no examples (p. 83). In addition, Litt and Turk (1985) included the items "express feelings and seek support" but failed to provide further information. It may be that the individual is seeking support in order to express feelings, which would belong under the category of emotion-focused coping or the individual may be seeking support for advice, which would fall under the category of problem-focused coping. Further, Peklaj and Puklek (2001) included the item "I tried to find professional help," leaving it unclear as to why the individual is seeking the professional support (p. 11). Similarly, Schweizer and Dobrich (2003) listed the coping strategy of drawing on professional support and included the items "turning to external authorities" and "turning to the psychological service of the school” (p. 96). Although intuitively it makes sense that getting psychological support from the school fits under the emotional support category, this cannot be determined conclusively given the information provided. In addition, turning to external authorities provides no indication as to the kind of support for which external authorities are being sought.

Different definitions. Another problem associated with the categories of coping is that different definitions were used across studies. For example, palliative coping was used in 5 of the studies but researchers were not always in agreement with how this way of coping should be conceptualized. Blasé (1986), for example, simply described it as attempting to reduce one's feelings of discomfort, leaving it open to the reader's interpretation as to whether this includes adaptive, and/or maladaptive coping techniques. Olff and colleagues (1993), on the other hand, listed both adaptive and maladaptive items (e.g., "seeking distraction, "trying to feel better by smoking, drinking, or relaxation") 
when attempting to explain the meaning of palliative coping. In contrast, other researchers alluded that palliative coping is generally maladaptive because it includes strategies such as failure avoidance and self-handicapping in which the individual is attempting to avoid the negative outcomes through excessive drinking, smoking, and avoidance behavior (Howard \& Johnson, 2004; Parker \& Martin, 2009). Finally, Carmona and colleagues (2006) described palliative coping similarly to the other studies (i.e., ignoring or riding the situation, becoming less involved or avoiding the situation) but were the only researchers to include "utilizing colleague support" as a descriptive term for palliative coping. Using different definitions for the same term makes it confusing when one is attempting to understand the meaning of the coping strategy being investigated.

Comprehensiveness of category systems. With such a wide array of describing ways of coping for teachers, comparing results across studies can be quite difficult. In addition to problems of comparability, the use of different numbers and combinations of coping categories makes it difficult to discern the list of ways of coping that must be included in a study for its system to be considered comprehensive. Beyond consensus that the most common ways of coping, such as problem-solving and avoidance, must be included, none of the systems used in these studies could accommodate the entire range of strategies used by teachers to cope with stress. As mentioned previously, most of the studies utilized a closed-ended questionnaire method of data gathering, which limited the teachers' coping responses to those offered by the researchers. However, none of the category systems used in these studies can be considered exhaustive, that is, considered to include all the ways of coping needed to cover the relevant domain. Researchers 
provided varying combinations of ways of coping that teachers could choose from. For example, Salo (1995) included seven ways of coping: avoidance of thinking; problem solving; social support; thinking about work alone; devoting oneself to free-time activities; and the use of food, alcohol or tobacco, while Chan (1998) included four ways of coping (i.e., rational problem solving, resigned distancing, seeking support and ventilation, and passive wishful thinking), and Stoeber and Rennert (2008) included only two (i.e., active and avoidant coping).

Some researchers created their own unique list of coping strategies, making it difficult to detect consensus across studies. For example, Freeman (1987) described ways of coping in terms of 5 "clusters" that, according to the author, "appeared to be part of a continuum rather than discrete groups of responses" (p. 7) and were described as (1) being rational and problem-solving, (2) displacement, (3) find an emotional prop, (4) let off steam but get stuck into work, and (5) think positively whilst allowing yourself diversions. In addition, Admiraal and colleagues (1996) used four categories adapted from the Farell (1983) study, including intervening (e.g., "Teacher walks along the benches and urges the pupils to be quiet"), waiting (e.g., "Irritated teacher waits in front of the classroom"), avoiding (e.g., "Teacher invites pupils to answer, while others are talking"), and ignoring (e.g., "Teacher goes on with the lesson"). Further, Burke and Greenglass (1996) described coping in terms of internal control, preventative coping, and existential coping. Internal control was described as "a coping strategy, which depends on one's own efforts to change the situation" (p. 50). Preventive coping included coping strategies to promote one's own well-being and reduce the likelihood of anticipated problems (e.g., planning for the future), while existential coping included an attitude of 
acceptance in coping with life's events and to maintain a sense of meaning.

Other researchers described coping in terms of levels. For example, Beach and Pearson (1998) identified coping strategies as Level I, II, and III. Level I was described as attempting to avoid, deny, mask over, or rationalize the conflicts and tensions. Teachers would describe the conflict and give reasons for it but fail to discuss strategies for coping. Level II was said to entail survival techniques that were convenient, shortterm strategies, and Level III involved the contemplating and/or implementing long-term change in one's beliefs system. In this case teachers went beyond short-term coping strategies to consider the stressors in terms of ramifications for their beliefs' about teaching. Similarly, Schweitzer and Dobrich (2003) described ways of coping in terms of three "components": Component 1 was labeled Coping by Education (e.g., "Participating in teacher training," "Searching for literature which gives me advice," and "Talking about it in a supervision group"). Component 2 was labeled Coping by Seeking Support and Initiating Change (e.g., "Talking about it with colleagues," "Asking the school authority for advice and help," and "Trying to change the conditions at school with..."). Component 3 was denoted Coping by Drawing on Professional Support (e.g., "Turning to external authorities," and "Turning to the psychological service of the school"). No other researchers described coping in terms of components and this was the only study to recognize Coping by Education as a way of coping.

In contrast to the categories mentioned above, only one category, namely, "problem-focused coping" appears to be homogeneous and consistent across all 19 studies that examined this way of coping. For example, the category of problem-focused coping includes only direct problem solving (e.g., direct intervention and considering 
different solutions to the problem) and instrumental actions such as seeking support for instrumental reasons or searching literature to gain advice (see Table 2). Because of the homogeneity and consistency across the literature in teacher stress and coping in this particular category, problem-focused coping can more readily be compared across the different studies.

\section{Developmental Perspective}

In addition to the shortcomings mentioned above, few studies have looked at coping from a developmental perspective. In order to find out whether more experienced teachers cope more effectively and to understand how teachers develop coping strategies, one must examine not only what teachers find stressful and how they cope with it, but also what is done after the coping has occurred and how this experience plays into the process of adapting, elaborating, or abandoning these coping strategies.

Experience. Most studies of teacher stress and coping include teachers with a variety of experience, ranging from student teachers and teachers just entering the profession to veteran teachers who have been teaching for 20 or more years. Few studies, however, have looked at teacher coping as a function of years of experience in the profession. Those that have investigated the association between years of teaching and coping have generally reported there to be a connection (Griva \& Joekes, 2003; Pascual et al., 2003; Seidman \& Zager, 1991). For example, research has demonstrated that younger teachers not only perceive more social support than older teachers (Griva \& Joekes, 2003), they also seek it more as a coping strategy (Seidman \& Zager, 1991). In addition, younger teachers have been found to use exercise more as a way of coping with daily stress (Seidman \& Zager, 1991), while at the same time, to rely more on avoidance 
coping and substance use than their older colleagues (Griva \& Joekes, 2003; Pascual et al., 2003). In contrast, older teachers have been found to use more meditation and deep breathing exercises than younger teachers (Seidman \& Zager, 1991).

Although the studies mentioned above have all indicated that experience plays a part in coping, other studies have shown there to be no differences in coping as a function of experience (Dick \& Wagner, 2001; Stoeber \& Rennert, 2008). Therefore, further investigation is warranted. Specifically, because some studies suggest that novice teachers have yet to develop the coping strategies of their more experienced counterparts, more investigation into the process of developing these ways of coping is justified.

Stress and the coping process. Because most of the literature is based on correlational and cross-sectional data, very little is known about the process of coping for teachers. However, the few studies that did examine the connections between steps in the coping process suggest that this might be a useful endeavor. They show, for example that both the nature of the stressor and the teachers' appraisals of stress shape how they cope.

Most of the studies that have examined links between steps in the coping process have focused on the connections between levels of stress and coping. In the teacher literature, the level of stress has been shown to be a factor when it comes to coping strategies employed by the individual. For example, a higher level of stress has been shown to be associated with more reliance on avoidant and emotion-focused coping (Chan, 1994; Mearns \& Cain, 2003; Shen, 2009). Additionally, Schweitzer and Dobrich (2003) reported a negative correlation between stress and all three of the coping components they investigated, namely: Coping by education (e.g., "Participating in teacher training," "Searching for literature which gives me advice," and "Talking about it 
in a supervision group"), coping by drawing on professional support (e.g., "Turning to external authorities," and "Turning to the psychological service of the school"), and coping by seeking support and initiating change (e.g., "Talking about it with colleagues," "Asking the school authority for advice and help," and "Trying to change the conditions at school with..."). Finally, teachers who were least stressed did not use a wider range of strategies; rather, they generally relied on their own resources (i.e., only one of the teachers in the least stressed group relied on professional support, while none of them relied on the school's organization for support; Freeman, 1987).

Salo (1995) conducted one of the rare longitudinal studies of stress and coping and suggested that the level of stress teachers report relates to the coping strategy they call upon. In this study a longitudinal follow-up design was utilized, involving 66 teachers who completed questionnaires during four repeated assessments of stress and coping indicators in the fall term of 1991. The four stress variables (i.e., depression, anxiety, exhaustion, and work satisfaction) were formed based on a factor analysis of the fivepoint rating scales of the subjects' mood during the week. The reliability coefficients for the stress scales varied between the measurements from 0.61 and 0.86 respectively. In addition, two stressors were studied (amount of work and different social stressors) because, according to the authors, "a teacher's work environment is very social in its nature, and these two stressors are common in educational work" (p. 209). Further, different coping resources (e.g., social support, competence, work ability, and effectiveness of coping) were studied using interviews with the participants. Finally, coping behavior was investigated by reviewing the different ways of coping (i.e., avoidance of thinking, problem solving, social support, thinking about work alone; 
devoting oneself to free-time activities, and the use of food, alcohol or tobacco) employed by teachers to cope with various problems at work.

To analyze the results, individual differences in stress were examined by cluster analysis using hierarchical clustering and Euclidean similarities. Additionally, a MANOVA was used to determine changes in stress and coping variables over time. Further, multiple-regression analyses were carried out for each of the different group variables, as well as for the variables that demonstrated recurrent significant associations with the observed stress variables. Finally, separate multiple regression analyses were formed for the repeatedly measured source of stress and ways of coping, as well as the singly measured coping resource variables.

Salo (1995) reported that teachers whose stress increased considerably also increased their attempts at problem solving and showed a reduced interest in hobbies. In addition, teachers with exhausting stress thought about work alone more often and they used more stimulants than teachers with lower levels of stress. Further, teachers with moderate levels of stress used different coping strategies quite moderately. These findings suggest that teachers' with different levels of stress may rely on different ways of coping.

In addition to looking at the connection between stress level and coping, some of the studies in the teacher literature examined the association between the level of stress and appraisals. In these studies stress level has been shown to be a factor with teacher appraisals. For example, in the study mentioned above, Salo (1995) reported that teachers with exhausting stress rated their working abilities the lowest and considered their lives to be only fairly satisfactory, whereas teachers without stress rated their working abilities 
more positively and were the most satisfied with their lives. Further, teachers who reported lower levels of stress, assessed pupils' motivation and conduct more favorably than teachers with higher levels of stress. These findings suggest that the teachers' ability to educate students may be influenced by their stress level, as teachers with lower stress are not only more confident about their ability to teach, they also seem to believe that the students are more willing to learn. This belief, in effect, may lead the teacher to a higher level of engagement with the students, thereby leading to more effective instruction.

The studies mentioned above indicate that teacher appraisals are associated with stress level. Other studies have indicated that teacher appraisals are related to the way they cope with stress. One such study attempted to examine a direct relationship between appraisal and coping. In their study, Schweitzer and Dobrich (2003) assessed appraisal using four items (e.g., "I can meet the professional demands," "I avoid quarrels with colleagues," "I experience professional problems as a challenge rather than as a burden," and "I feel overstrained by the pupils," reverse scored). In this study, researchers found a strong positive association between appraisal and coping by education, and between appraisal and coping by seeking support. Interestingly however, no such relationship was found between appraisal and coping by drawing on professional support. It may be that drawing on professional support was viewed by the teachers as a weakness as they would be turning to the psychological services of the school or from outside sources, rather than simply discussing issues with colleagues or reading helpful literature.

The study mentioned above seems to indicate that how teachers feel about their ability to cope with the stressful situation matters. In fact, according to Freeman (1987), teachers felt that their personal qualities contributed the most to their ability to cope with 
stress at work. This idea appears to be supported by the finding that higher expectancies of negative mood regulation were associated with more use of active coping strategies (Mearns \& Cain, 2003), while negative affect was positively associated with disengagement (Griffith et. al., 1999). In addition, Shen (2009) reported that a higher general self-efficacy was predictive of the use of more active coping, positive thinking, suppression of competing activities, and restraint coping, and less reliance on seeking social support for emotional reasons, coping by turning to religion, and coping through behavioral disengagement. Indeed, according to Olff and colleagues (1993), individuals who believe they have control of aspects of their life are more likely to use problemfocused coping, which reveals their assumption that these actions will be beneficial to them in some way.

In another study, perceived pressure from colleagues, students, and students' parents was positively correlated with avoidant coping (Stoeber \& Rennert, 2008). However, perceived pressure from colleagues and students also had a positive association with active coping. Apparently, teachers feel compelled to either actively cope with the situation or to avoid it when it comes to perceived pressure from colleagues and students, but when it comes to perceived pressure from parents, all teachers want to do is to avoid the situation. It may be that the teacher feels more pressure to try to change the situation when that pressure is coming from those within the work setting (e.g., colleagues and students), but the same cannot be said when it comes to those outside the work environment (e.g., parents).

Developmental mechanism. An aspect of coping that seems to be lacking in the literature is what is done after the coping has occurred. It makes intuitive sense that 
teachers might learn through experience and adjust their techniques of coping after reflecting on the effectiveness of the strategy employed, adopting those that appear beneficial, and abandoning those that seem ineffective. In this way, teachers would develop new coping skills as a function of experience, and these new skills might result in changes in coping behavior over the course of the teacher's career. Despite the simplicity of this concept, such post coping assessment was not investigated by any of the studies reviewed for the purpose of this study.

In sum, due to the reliance on survey methods and their limited view on stress and categories of coping, the conclusions that can be drawn from the findings in the teacher stress and coping literature are limited. Moreover, this narrow band of stress and coping has failed to capture the process of coping that occurs during a stressful event. In turn, a developmental perspective has not been thoroughly investigated thus far in the teacher stress and coping literature. These issues are addressed in the current study. 


\section{CHAPTER 3}

\section{Purpose of the Study}

Teaching is considered to be an extremely stressful occupation. Teachers face a myriad of demands daily, such as motivating students, maintaining discipline, adapting to changes, and being evaluated by administration, amongst the many other responsibilities that must be mastered to become effective teachers. Such demands can have a major impact on teachers' health and well-being, making them more susceptible to physical and emotional problems associated with burnout. These problems, in turn, may lead to losses in teachers' motivation and detract from their ability to educate students. Novice teachers seem to be especially vulnerable to the kinds of physical and emotional exhaustion that lead to burnout. Coping is a potential resource that may buffer teachers from the harmful effects of stress, and may be especially important to teachers who are new to the profession. However, little is known about how adaptive coping strategies are developed over the course of a teacher's career.

The purpose of the study was to help illuminate the coping strategies utilized by teachers at different stages of their career. More specifically, its aim was to explore how early career teachers differ from more experienced teachers in the multiple steps that comprise the process of coping, including recognizing and appraising everyday demands, actually dealing with stressors in their daily lives, and most importantly, learning from these stressful encounters. The goal was to contribute to our understanding of the development of teachers' coping so that training programs and interventions can intentionally support early career teachers in constructing the repertoire of strategies they need to become engaged and effective teachers. If the information provided by the 
current study can provide a better understanding of the coping strategies utilized by teachers at different points in their careers, it may eventually contribute to interventions and preparation programs that support active engagement in teaching, prevent burnout, and reduce the attrition rate of teachers early in their careers, thereby saving time and money and leading to improvements in the overall quality of teaching and in student motivation and learning.

The following sections summarize the current research on teacher stress and coping, as well as some of its shortcomings, and then describe how each of these limitations is addressed in the current study. In order to guide the design of this study, a new developmental model of teacher stress and coping is presented, followed by a description of a recently developed system for classifying ways of coping. Finally, the research questions on which the current study focuses are enumerated.

\section{Review of the Shortcomings of the Teacher Literature}

Several decades of research have revealed much about teacher stress and coping. Collectively, these studies found that the most common stressors experienced by teachers were problems with students, school administration, and colleagues, as well as issues with the classroom environment, and workload. To cope with these demands, teachers typically rely on problem-focused coping, emotion-focused coping, seeking social support, and avoidant coping. Despite these consistent findings, however, this literature as a whole suffers from several shortcomings, including the use of closed-ended questionnaires, the lack of consistency in describing ways of coping, and the lack of a developmental perspective. 
Closed-ended questionnaires. Most of the studies of teacher stress and coping relied on data gathered via closed-ended questionnaires. Such data impose constraints on both the kinds of stressors reported by teachers and the ways in which they reported coping with these stressors. Closed-ended questionnaires also suggest stressors and ways of coping that might not be salient to teachers. In addition, the use of closed-ended questionnaires imposes limits on developing a clear understanding of the processes and steps teachers take, starting with facing the demands placed upon them to actually coping with these stressful events.

Lack of consistency. Another area that appears to be problematic in the teacher literature is the lack of consistency in describing ways of coping used by teachers. In general, the typical categories of coping are heterogeneous in nature, including both adaptive and maladaptive coping techniques in the same categories. In addition, most categories have varying definitions, making it difficult to compare results across studies. Further, none of the category systems used in the studies can provide a list of ways of coping that is comprehensive enough to include all the strategies utilized by teachers. All of these inconsistencies lead to difficulties in comparing studies and deciphering the meaning of their findings.

Lack of a developmental perspective. Most importantly, none of the studies in the teacher literature provided a developmental perspective on the coping process. Having a developmental view of coping is essential to determining the role that experience plays in the coping process. In addition, the lack of a developmental perspective limits the understanding that can be gained about how links between different steps in the process 
of coping might change over time. Further, a developmental outlook is needed to understand the mechanisms involved in how teachers learn to cope more adaptively. Model of Teacher Stress and Coping

The current study on teacher stress and coping uses open-ended assessments to examine the process of coping as a function of years of experience, and explores mechanisms that might play a part in the development of coping skills. To accomplish this task, the study relies on a process-oriented developmental model of teacher stress and coping (see Figure 3.1). As the shaded portion of the model suggests, the coping episodes begin with demands being placed on the teacher. These demands can range from disruptive students to responsibilities handed down by the school authority figures (i.e., administrators). The teacher then appraises the stressor to determine if a course of action is required. Next, if the teacher surmises that steps must be taken, the coping strategy that seems appropriate for the given situation is employed, resulting in some sort of outcome. The teacher then has a basis to assess the effectiveness of the chosen strategy during the post coping assessment phase of the event. At this point the individual has the opportunity to learn from the experience and adjust the strategy in a way that seems most likely to improve upon the coping methods employed when confronted with a similar event in the future. 
Figure 3.1

Teacher Stress \& Coping Model
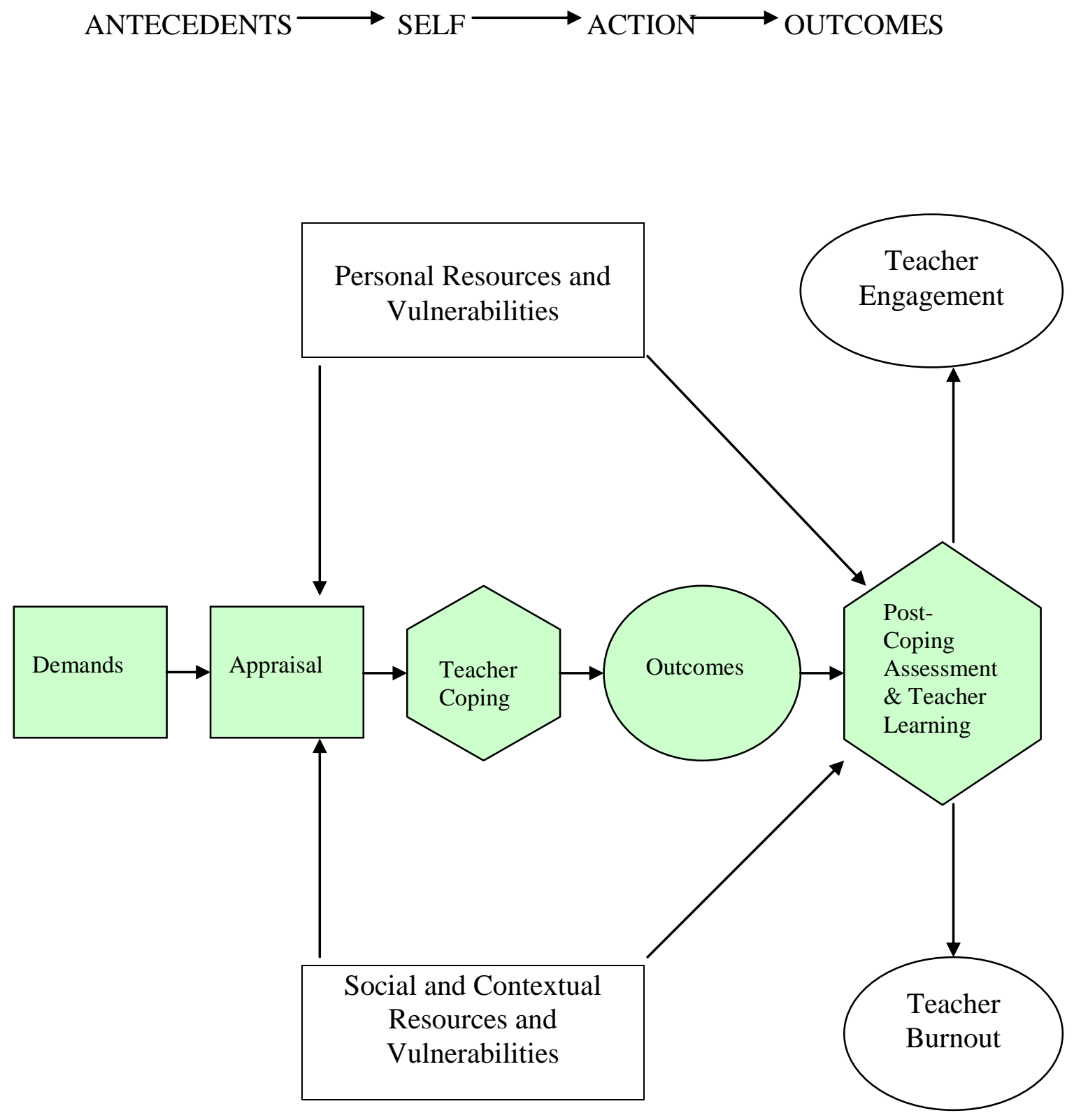
By building on this model, the current study was able to make several contributions to the existing research on teacher stress and coping. First, it utilized an open-ended interview method. Secondly, the study relied on a classification system that was relatively comprehensive with consistently defined homogeneous categories of coping. Moreover, an important goal of the study was to develop category systems to classify each of the steps in the coping process. Thirdly, and most importantly, this study took a developmental perspective to attempt to gain a better understanding of the process of developing coping strategies over the course of one's teaching career. These contributions are explained more fully in the following paragraphs.

Open-ended interviews. Open-ended interviews were utilized in this study to determine the kinds of stressors that teachers think of spontaneously. In this way, the stressors faced by teachers were not limited to a pre-determined list from which individuals would be forced to choose. Similarly, open-ended interviews allowed teachers to report any of the ways they cope with these stressors, without being limited by the list of methods provided on a questionnaire. By utilizing open-ended interviews, this study was able to gather information about multiple steps in the process of coping depicted in the developmental model, including teachers' perceptions about the demands of their profession, their emotional reactions, the ways teachers cope with stressful events, the typical resolutions of the ways of coping utilized by teachers, and their reflections on a coping episode after it is over.

Uniform classification of ways of coping. In order to address the problems associated with inconsistencies in describing ways of coping, this study relied on a uniform classification system that is homogeneous, comprehensive, and consistently 
defined. This type of uniform system is necessary because the troublesome aspects of measuring ways of coping described previously make it difficult to determine which coping strategies are likely to be adaptive and which are likely to be maladaptive. Because different ways of coping are often placed in broad categories that at times overlap with each other, understanding the consequences of coping strategies becomes difficult. Utilizing the 12 coping families posited by Skinner and colleagues (2003) to classify ways of coping used by teachers has the potential to ameliorate the difficulties associated with the inconsistencies in reporting ways of coping in the teacher stress and coping literature.

Recent work on the development of coping has identified 12 families of coping (see Table 3.1) that include the most common strategies utilized by individuals, including problem-solving, support-seeking, distraction, and escape (Skinner et al., 2003). These higher order categories were devised after analyzing 100 assessments of coping and compiling a list of 400 ways of coping, providing a comprehensive list of strategies that are fundamentally different from one another. This list may be able to provide a means of organizing all the strategies utilized by teachers when faced with the many demands placed on them from the teaching profession, into categories that are functionally homogeneous and functionally distinct. This category system encompasses all the ways of coping that have been studied in the literature on teacher stress and coping.

Because a key goal was to examine multiple steps in the coping process, an important aim of the study was to develop coding categories, not only for ways of coping, 
Table 3.1

Twelve Families of Coping and Their Adaptive Processes

\begin{tabular}{ll}
\hline Family of Coping & $\begin{array}{l}\text { Family Function in Adaptive } \\
\text { Process }\end{array}$ \\
\hline $\begin{array}{l}\text { 1. Problem-Solving (e.g., Strategizing, } \\
\text { Instrumental action, Planning) }\end{array}$ & Adjust actions to be effective \\
$\begin{array}{l}\text { 2. Information Seeking (e.g., Reading, } \\
\text { Observation, Asking others) }\end{array}$ & Find additional contingencies \\
$\begin{array}{l}\text { 3. Helplessness (e.g., Confusion, Cognitive } \\
\text { interference, Cognitive exhaustion) }\end{array}$ & Find limits of actions \\
$\begin{array}{l}\text { 4. Escape (e.g., Behavioral avoidance, Mental } \\
\text { withdrawal, Denial, Wishful thinking) }\end{array}$ & Escape noncontingent environment \\
$\begin{array}{l}\text { 5. Self-reliance (e.g., Emotion regulation, } \\
\text { Behavior regulation, Emotional expression, } \\
\text { Emotion approach) }\end{array}$ & Protect available social resources \\
$\begin{array}{l}\text { 6. Support Seeking (e.g., Contact seeking, } \\
\text { Comfort seeking, Instrumental aid, Social }\end{array}$ & Use available social resources
\end{tabular}
referencing)

7. Delegation (e.g., Maladaptive help-seeking, Find limits of resources Complaining, Whining, Self-pity)

8. Social Isolation (e.g., Social withdrawal, Withdraw from unsupportive Concealment, Avoiding others) context

9. Accommodation (e.g., Distraction, Cognitive Flexibly adjust preferences to restructuring, Minimization, Acceptance) options

10. Negotiation (e.g., Bargaining, Persuasion, Find new options Priority-setting)

11. Submission (e.g., Rumination, Rigid Give up preferences perseveration, Intrusive thoughts

12. Opposition (e.g., Other blame, Projection, Remove constraints Aggression

Note. Adapted from Skinner, Edge, Altman, \& Sherwood, 2003. 
but also for the steps prior to coping (i.e., demands and appraisals), as well as the steps after coping (i.e., resolutions and post-coping assessment). To do this, all of the information from previous research on teacher stress and coping was used to create a menu of categories for each construct.

Developmental perspective of the current study. The most important contribution of this study was to incorporate a developmental perspective on the study of teacher stress and coping. In order to conceptualize the developmental perspective outlined above, the current study relied upon the standard theory of coping effectiveness in the development of coping competence (Lazarus \& Folkman, 1984). This theory suggests that as an individual becomes more competent in coping with stress, fewer stressful events will be experienced and there will be less intense emotional reactions in relation to those stressful events. In addition, the individual will tend to choose more constructive ways of coping with the stressful event leading to resolutions that are better for all partners involved in the episode. Finally, the stressful episode would likely be followed by an openness and receptivity to learn from the mistakes made while coping with the stressful event.

As can be seen by the process described above, the current study relied on the learning hypothesis to explain the development of coping competence. The learning hypothesis suggests that more experienced educators are better teachers because they have developed more adaptive coping strategies by becoming more aware of the process of coping and improving their capacity to self regulate. In turn, fewer demands are experienced, emotional reactions are less severe, more adaptive coping strategies are utilized, and increased learning is acquired. By developing more effective coping 
strategies, teachers are able to become more stress resistant and remain in the profession. Those teachers who fail to learn these more adaptive ways of coping are likely to experience more stress and leave the profession early.

In contrast, the selection hypothesis suggests that more experienced educators tend to cope better because they are more stress resistant and are, therefore, the survivors. From this perspective, it is not as if the more experienced teachers cope better because they learned how to deal more adaptively with stress over time. Instead, teaching is a process of selection, in which only the stress resistant survive to continue teaching for 18 years or more. This idea would suggest that the surviving teachers were more stress resistant from the beginning and already possessed the skills necessary to effectively cope with the demands placed on them. In contrast, those who were not stress resistant were not able to cope with the demands so they left the profession early. Both the learning hypothesis and the selection hypothesis are consistent with the evidence that suggests stress is a major cause of desistance in the teaching profession.

If coping is going to eventually reduce burnout and promote teacher effectiveness, it must do more than simply ameliorate distress. There must also be an opportunity to learn from stressful encounters and increase one's coping resources. In order for this to take place, one must first reflect on the outcome of the coping episode and then conceptualize ways for improvement. This post-coping assessment may play a large part in teacher learning and promote the development of the coping skills necessary to become a more effective teacher.

In order to examine this learning process, a developmental perspective was incorporated into the current study in three ways. First, this study examined how all the 
steps in the coping process differ as a function of teaching experience. Second, this study examined the links between the steps in the process of coping by examining, for example, whether different demands lead to different coping strategies for teachers, and whether different ways of coping result in different resolutions of stressful events. Third, the current study included questions in the interview about post-coping assessment examining, for example, whether different outcomes of the stressful episodes result in different kinds of learning and reflection, and whether the ways that teachers cope with stressful episodes result in different kinds of learning and reflection. These research questions are summarized below.

\section{Research Questions}

The first set of research questions focuses on what teachers perceive as stressful about teaching and whether these perceptions differ according to years of teaching experience. The next set of questions focuses on the appraisals of the demands in teaching. The third set investigates the ways teachers cope with stressful events and whether these strategies differ according to years of teaching experience. The fourth set of questions addresses the typical resolutions of stressful episodes and whether these resolutions differ according to years of experience. The last set of research questions center on post-coping assessment and teacher learning. This set investigates whether teachers utilize their experiences with stressful events to learn effective strategies for dealing with difficult situations in the future, and whether this learning differs according to years of experience.

\section{Demands in Teaching}

a. What do teachers perceive as stressful? 
b. Do perceptions of demands differ according to years of teaching experience?

\section{Appraisals of Teaching Demands}

a. How do teachers react emotionally to the demands of teaching?

b. Does emotional reactivity differ according to years of teaching experience?

c. Do different demands lead to different kinds of emotional reactions?

\section{Teacher Coping}

a. What are the ways teachers cope with stressful events?

b. Do the ways teachers cope with stressful events differ according to years of teaching experience?

c. Do the different appraisals lead to different ways of coping?

d. Does the nature of the demand of the stressful event lead to different coping strategies for teachers?

4. Resolution of Stressful Episodes

a. How are stressful events typically resolved?

b. Do the resolutions differ according to years of experience?

c. Do the ways teachers' cope result in different resolutions of stressful events?

\section{Post-Coping Assessment and Teacher Learning}

a. Do teachers incorporate their experiences with stressful events into learning effective strategies for dealing with difficult situations in the future?

b. Do teachers' reflections and learning differ according to years of experience?

c. Does the way that stressful episodes are resolved result in different kinds of learning and reflection? 
d. Do the ways that teachers cope with stressful episodes result in different kinds of learning and reflection? 


\section{CHAPTER 4}

\section{Methods}

\section{Sample}

Sixty participants were recruited to take part in the study. The participants were all teachers employed with the Vancouver, British Columbia School Board during the 2009 calendar year, teaching in grades 4 to 12 . The participants had a median age of 47 years (ranging from 28-63) and were 90\% female $(N=54)$. The sample included $65 \%$ Elementary School Teachers $(N=39)$ and 35\% Secondary School Teachers $(n=21)$. The participants were comprised of $67 \%$ European-Canadian $(N=40), 18 \%$ Asian-Canadian $(N=11)$, and $15 \%$ other ethnicities $(N=9)$. The participants ranged in years of teaching from 3 to 35 years of experience.

Design

The current study utilized a portion of the baseline interview of a randomized waitlist control study conducted to explore the feasibility, outcomes, and acceptability of a mindfulness-based teacher development program for both primary and secondary teachers in Vancouver, British Columbian, Canada. The intervention program utilized in the study was the Stress Management and Relaxation Techniques (SMART). SMART is based on research and practice from the Mindfulness Based Stress Reduction (MBSR Kabat-Zin, 1990), emotions and stress (Ekman, 2007), and forgiveness (Luskin, 2002). The program runs for 8 weeks, including 11 sessions that occur both during the week and on the weekends, resulting in 36 hours of developmental practice in mindfulness techniques. The techniques (taught by Margaret Cullen, an experienced instructor trained in MBSR) include practices of mindfulness meditation and mindful yoga, instruction and 
reflection on topics such as stress reactivity and recovery, coping skills, and forgiveness. The goal of the program was to help teachers manage occupational stress and develop skills that assist them in providing a classroom environment that promotes academic and social-emotional learning, as well as civic responsibility.

Procedures

After the baseline assessment, teachers were assigned to an immediate intervention condition (SMART), or a waitlist control group. Data were gathered at three time points: baseline, post-intervention, and 3 month follow-up, and the control group was assessed along with the treatment group at all three time points. The teachers were interviewed by graduate students attending the University of British Columbian in Vancouver, BC as part of the baseline assessment for the SMART-in-Education program in the spring of 2009. The Vancouver School Board, as well as The Impact Foundation funded the program, and the teachers were not charged to participate. All participants received a stipend at the completion of the program to help compensate them for their time.

Measures

In interviews (lasting approximately 30-40 minutes), teachers were asked a series of questions about different aspects of their job in the framework of how they viewed "a really good day in the classroom" and "a really bad day in the classroom." More specifically, teachers were asked to describe which aspects they find to be the most demanding. In addition, the teachers were asked to describe a particular coping episode, and in reference to that episode, they were asked about their appraisals, ways of coping, and what they had learned. The coping episode is the portion of the interview the current 
study focuses on, and the specific questions asked in reference to this coping episode appear in Table 4.1 below. All interviews were tape recorded and transcribed by trained graduate students.

Table 4.1

Coping Episode Interview Questions

\begin{tabular}{|c|c|}
\hline Construct & Interview Question \\
\hline Demand & $\begin{array}{l}\text { "Can you give me a specific example of a stressful } \\
\text { experience in your job?" }\end{array}$ \\
\hline Ways of Coping & "What did you do?" \\
\hline Appraisal & "How did it make you feel?" \\
\hline Resolution & "How did it turn out?" \\
\hline $\begin{array}{l}\text { Post Coping } \\
\text { Assessment }\end{array}$ & "What would you do differently if you could?" \\
\hline
\end{tabular}

\section{Coding Data}

In order to examine whether and how each aspect of the coping process differed for teachers with differing years of experience, the participants answers to the interview questions were coded by trained graduate students and then analyzed. Before the data was analyzed, the teachers were categorized into groups based on years of experience. Next, answers to each question in the open-ended interviews were coded. Finally, scores were generated from the codes. Each of these aspects will be discussed further in the following paragraphs. 
Creation of groups based on years of experience. To help distinguish between teachers of differing experience, the participants were divided into three groups based on years they had been teaching (see Table 4.2 below). Three criteria were considered when dividing the teachers into groups, namely, homogeneity within groups, differences between groups, and comparable group size.

Table 4.2

Teacher Groups Based on Years Experience

\begin{tabular}{lll}
\hline Group Name & Years of experience & Number of teachers \\
\hline Early Career Teachers & $1-8$ & 19 \\
Middle Career Teachers & $9-19$ & 18 \\
Late Career Teachers & 20 or more years & 18 \\
\hline
\end{tabular}

Developing the Coding System for the Open-ended Interviews. In the current study the information provided by the participants was in the form of interviews, therefore the answers needed to be coded before the data could be analyzed. In order to develop a coding system, a coding menu that applies to each of the constructs in Table 4.1 was created. The process of developing this coding menu involved several steps. First, all of the information from previous research on teacher stress and coping was used to create a menu of categories for each construct. For example, as described earlier, the most common problems facing teachers according to the literature on teacher stress and coping involve interactions with students. Examples of such problems mentioned by teachers were student misbehavior, low pupil achievement, and working with unmotivated students. These demands were categorized under the heading of "problems 
with students." Finally, the same approach was utilized for all of the demands mentioned by teachers during the interviews. In this way, the many demands described by teachers could be classified in order to add clarity to what teachers perceive as stressful about their profession.

Extracting coping episode. Next, a coping episode was extracted from the interview to isolate a single event in which the teacher described the coping process in detail. In order to extract the single episode a group of trained graduate students were given the following directions: "Choose the coping episode example that is most complete (i.e., all five of the constructs can be most easily identified). If it is too difficult to decide between two, choose the first one mentioned, as it is typically more spontaneous. Be sure that each step described by the teacher applies directly to the coping episode being examined" (see Appendix B). After the episodes were extracted they were discussed and agreed upon by the trained coders. These single coping episodes were then utilized to code the categories discussed in detail below.

Coding the demands reported by teachers. Much research has been done on what teachers find stressful about their profession. As mentioned previously, the five most frequently mentioned teacher stressors in the teacher stress and coping literature were problems with students, problems with the administration, problems with colleagues, overall workload, and problems with the work environment. In addition, problems with parents have often been mentioned as a major source of stress in teaching. Together, these six categories were utilized to create the demands category. In turn, this list could be referred to when coding the responses provided by the teachers as to what they find 
stressful. The demands category was then coded as follows: $1=$ students, $2=$ environment, 3=administration/policy, 4=colleagues, 5=workload, and 5=parents.

Coding teacher appraisals of the stressful event. For the category of appraisals, a list of words signifying negative emotions was created and agreed upon by independent raters. This list was then referred to when coding the teachers' appraisals of the coping episodes. The appraisal portion of the coping episode was then coded as follows: $0=$ no negative emotion mentioned, 1 = negative emotion (e.g., frustrated, upset, anxious, sad), and $2=$ extreme negative emotion (e.g., furious, overwhelmed, angry). In addition, if the emotional description was preceded by an exclamatory word such as "very," or “extremely," it was coded as an extreme negative emotion. Further, any example of a physical response (e.g., headache, rash, stomachache) to a stressor was considered an extreme negative emotion. In turn, clarity could be gained as to whether teachers become less emotionally reactive about the demands faced in teaching as they acquire experience in the profession.

Coding ways of coping reported by teachers. Because there was already a comprehensive list for families of coping, that list was utilized when constructing the coding menu for ways of coping by teachers (see Table 3.1). To adapt the list for families of coping to the current study, submission was listed as rigid cognition (e.g., rumination rigid perseveration, and intrusive thoughts). In addition, the term "submission" was incorporated into the family of coping listed as "helplessness" (e.g., confusion, cognitive interference, cognitive exhaustion, giving up, resignation, and submission). Finally, to help delineate between effective and ineffective ways of coping by teachers, the 12 families of coping were divided into two categories, Adaptive Coping (i.e., problem 
solving, information seeking, self-regulation, support seeking, cognitive accommodation, and negotiation), and Maladaptive Coping (i.e., helplessness, escape, delegation, social isolation, rigid cognition, and opposition).

Next, coping utterances were extracted from the single coping episode to create a list of all the ways of coping described by the teachers when explaining what they did in response to the demand placed upon them (see Appendix C). Independent raters then coded these utterances according to the coping family with which they belong (e.g., if the coping involved strategizing, instrumental action, or planning it was coded as problem solving: see Categories of Coping Strategies in Appendix B).

Coding resolution of the stressful event. For the next construct, the resolution of the coping episodes, the outcome of the way in which the teacher chose to deal with the event was coded as follows: $1=$ in process of being resolved, $2=$ unsuccessful, and $3=$ successful. The resolution of each episode was coded as "in process of being resolved" if the teacher indicated that the issue had not yet been resolved (e.g., "I guess it hasn't been resolved yet"). If the teacher indicated that the resolution did not turn out as desired, it was coded as "unsuccessful." In addition, if the teacher indicated that the situation was handled in a satisfactory way, it was coded as "successful." Finally, if the interviewer did not ask the question, and/or the teacher did not indicate whether the episode was successful or unsuccessful, the column was left blank.

Coding post-coping assessment. The final construct investigated in this study was post-coping assessment. To the researcher's knowledge, this construct is new to the teacher stress and coping literature. Therefore, an entirely new coping scheme was designed for the purpose of this study with regards to this construct. Post-coping 
assessment is the term used to describe whether the teacher incorporated learning into the coping episode. In the interviews, teachers were asked whether they would do anything differently, if they could. To assess whether teachers learned from the stressful encounter, the answers to this question were coded as follows: $1=$ No when the outcome was favorable (If the teacher simply said "No," without elaborating on whether the outcome was favorable or not, this information was deduced from the previous interview question, "How did it turn out?"); 2 = No when the outcome was unfavorable (i.e., the teacher shows rigidity to change, either in a stubborn or confused way, including responses like "I don't know what I could have done differently" because of the rigid component of the response); $3=$ Yes when the teacher would try an effective strategy or stop and ineffective one (e.g., "Next time I will try to look at the other teacher's point of view" or "I'll stop losing my temper with the student"); and $4=$ Yes when the teacher would try an ineffective strategy (This includes wishful thinking and unrealistic examples such as "I would wave a magic wand to make state testing go away"). Again, if this question was not asked by the interviewer, and/or not indicated by the teacher it was left blank.

\section{Determining Interrater Reliability}

After the preliminary development of coding categories was complete, ten percent of the interviews were coded to improve and finalize the system. The interviews chosen for the initial coding were randomly selected with two interviews coming from each of the three groups (i.e., early, middle, and late career teachers). Next, two raters independently categorized the data from the transcriptions by marking coding units corresponding to the construct being measured. The coded data from the six interviews were then examined to determine interrater reliability. Where there was disagreement 
between the first and second raters, consensus was reached through discussion and the coding system modified or elaborated as needed. The kappa coefficient for agreement between the two raters for the five categories were as follows: Demands $=.79$, Appraisal $=.77$, Coping $=.88$ (see Table 4.3 below for the complete list of families of coping), Resolution $=.69$, and Post Coping Assessment $=.70$.

Table 4.3

\section{Coping Kappas}

\begin{tabular}{ll}
\hline Coping Family & Kappa \\
\hline Problem Solving & .87 \\
Information Seeking & 1.00 \\
Helplessness & 1.00 \\
Escape & 1.00 \\
Self Regulation & .61 \\
Support Seeking & .77 \\
Delegation & 1.00 \\
Social Isolation & 1.00 \\
Cognitive Accommodation & .68 \\
Negotiation & .82 \\
Rigid Cognition & 1.00 \\
Opposition & .85 \\
Overall Coping Agreement & .88 \\
\hline
\end{tabular}




\section{Scoring Coding Categories}

Once the coding system was finalized and the interviews were all coded, each teacher received a "score" for each category based on whether or not they mentioned an item from that category (i.e., $1=$ yes, $0=$ no). For example, Research Question 1 asks, "What do teachers perceive as stressful?" Each teacher received a mark based on whether or not they had mentioned stressors from each category (e.g., problems with students,

problems with classroom environment, etc.) Each teacher's "score" for each category was recorded according to the construct and coding categories involved.

Then the coded responses to each question were totaled across all teachers in the sample to determine the total frequency with which each category was mentioned. For example, for Demands, total scores were calculated for each of the categories (e.g., a total score was calculated for problems with students, problems with classroom environment, etc.). This process was repeated for each category of constructs listed in Table 4.1 above. 


\section{CHAPTER 5}

\section{Results}

\section{Overview}

Analyses of the data were organized around the three kinds of issues addressed in the research questions: (1) descriptive questions, examining whether there are differences in the relative frequency with which teachers mention constructs in each coding category; (2) group differences questions, examining whether there are differences in each step of the coping process as a function of teachers' years of experience; and (3) connection questions, examining whether there are links between the steps in the coping process.

Descriptive analysis. There were five descriptive research questions: (1) Demands in Teaching: 1a. What do teachers perceive as stressful?; (2) Appraisals of Teaching Demands: 2a. How do teachers react emotionally to the demands of teaching?; (3) Teacher Coping: 3a. What are the ways teachers cope with stressful events?; (4) Resolution (outcomes) of Stressful Episodes: 4a. What are the typical resolutions?; (5) Post-Coping Reflection and Teacher Learning: 5a. Do teachers incorporate their experiences with stressful events into learning effective strategies for dealing with difficult situations in the future?

Data coded using the procedure described in the methods section provided information about the total frequency of teachers' responses in each category. To analyze these data, a frequency analysis was conducted by entering each category into SPSS and computing the total frequency score. Next, to determine whether the frequency scores occurred significantly differently than could be expected by chance, a Chi-square analysis was conducted. For example, for research question 1a, the Chi-square analysis compared 
the number of times the teachers mentioned a particular demand (e.g., problems with students; yes $=1$, no=0) with the number expected due to chance (e.g., since there were six categories of demands, the odds were $1 / 6$ or .17). These steps were repeated for each demand variable (e.g., students, administration, workload, etc.). Then, the same procedure was repeated for the other four constructs investigated in the study (i.e., appraisal, coping, resolution, and assessment).

Differences as a function of teacher experience. As described earlier, the second kind of question addressed by the open-ended interviews was to examine whether each step in the coping process differed as a function of teaching experience. There were five research questions like this: (1) Demands in Teaching: 1b. Do perceptions of demands differ according to years of teaching experience?; (2) Appraisals of Teaching Demands: 2b. Does emotional reactivity differ according to years of teaching experience?; (3) Teacher Coping: 3b. Do the ways teachers cope with stressful events differ according to years of teaching experience?; (4) Resolution (outcomes) of Stressful Episodes: 4b. Do the resolutions differ according to years of experience?; (5) Post-Coping Reflection and Teacher Learning: 5b. Do teachers' reflections and learning differ according to years of experience?

One set of analyses was conducted for each question. In order to explore whether teachers who have different levels of experience (early, middle, and late career teachers) differed in how often they named each category, a Chi-square analysis was conducted. First, middle and late career teachers were combined to form one group referred to as "other." Next, level of experience (early $=1$, other $=0$ ) was paired with the demand "students" $(1=$ yes, no=0). Then, level of experience (early=1, other $=0)$ was paired with 
each of the other possible demand variables (e.g., workload, parents, etc.). The same steps were applied to middle versus other and late versus other teachers. Finally, the above procedure was applied to the other four constructs (i.e., appraisals, coping, etc.).

Connections between steps in the coping process. In addition to differences in the coping process as a function of years of experience, this study examined the links between the steps in the process of coping and included questions in the interview about post-coping assessment. There are six research questions focusing on links in the coping process: (2) Appraisals of Teaching Demands: 2c. Do different demands lead to different kinds of emotional reactions?; (3) Teacher Coping: 3c. Do the different appraisals lead to different ways of coping?; $3 \mathrm{~d}$. Does the nature of the demand of the stressful event lead to different coping strategies for teachers?; (4) Resolution (outcomes) of Stressful Episodes: 4c. Do the ways teachers' cope result in different resolutions of stressful events?; (5) Post-Coping Reflection and Teacher Learning: 5c. Do the outcomes of the stressful episodes result in different kinds of learning and reflection?; 5d. Do the ways that teachers cope with stressful episodes result in different kinds of learning and reflection?

One set of analyses was conducted for each question. To explore whether there was an association between how the teachers responded to the different questions, a series of Chi-square analyses was conducted. For example, each teacher was classified for each demand (e.g., did they report the demand: yes=1, no=0). Next, the emotion variables "extreme negative" and "no emotion" were combined to form one group. Then, the emotion variable (e.g., negative $=1$, other $=0$ ) was paired with the demand variable (e.g., students mentioned: yes $=1$, no=0) and a Chi-square analysis was conducted to 
determine the extent of the relationship between the two variables. This process was repeated for each of the constructs being investigated.

The results of the above data analysis are presented below in the following order: (1) demands in teaching (e.g., "What do you find stressful?"), (2) teacher appraisal (e.g., “How does it make you feel?”), (3) teacher coping (e.g., “What did you do?”), (4) resolution (e.g., "How did it turn out?"), and (5) teacher learning (e.g., "What would you do differently, if anything?").

\section{Demands in Teaching}

Question 1a. What do teachers perceive as stressful? A frequency analysis was conducted to determine what kinds of demands teachers find stressful. The demand variables included the following six categories: students, environment, administration, colleagues, workload, and parents. As can be seen in Table 5.1, the most frequently mentioned demand by all the teachers $(N=55)$ was students, which was mentioned by $40 \%$ of the teachers. The demand mentioned next most frequently was workload (18\%), followed by parents (15\%), colleagues (13\%), administration (9\%), and environment $(6 \%)$.

Next, a series of pairwise comparisons were conducted to assess which demands were mentioned significantly differently than could be expected by chance (i.e., 1/6 or .17). In the first comparison, the student variable ( $0=$ no, $1=y e s)$ was mentioned significantly more often than could be expected by chance, $\chi^{2}(1, N=55)=20.62, p<.05$. In the next comparison, the environment variable $(0=$ no, $1=y e s)$ was mentioned significantly less often than expected, $\chi^{2}(1, N=55)=5.20, p<.05$. No other demand variables were mentioned significantly differently than would be expected by chance. 
Table 5.1

Reported Demands by Teachers

\begin{tabular}{|c|c|c|c|}
\hline Demands & Total & Percentage & $p$ value \\
\hline Students & 22 & $40 \%$ & $p<.05$ \\
\hline Workload & 10 & $18 \%$ & ns \\
\hline Parents & 8 & $15 \%$ & ns \\
\hline Colleagues & 7 & $13 \%$ & ns \\
\hline Administration & 5 & $9 \%$ & ns \\
\hline Environment & 3 & $6 \%$ & $p<.05$ \\
\hline Sample Size & $N=55$ & $100 \%$ & \\
\hline
\end{tabular}

Question 1b. Do perceptions of demands differ according to years of teaching

experience? To assess the relationship between teacher groups (i.e., early, middle, and late) and their perceived demands (i.e., students, workload, parents, colleagues, administration, and environment), a series of $2 \times 3$ contingency table analyses were conducted. In the first analysis, the group variable was significantly related to the student variable $($ no $=0$, yes $=1), \chi^{2}(2, N=55)=5.79, p=.05$, Cramer's V $=.33$. Sixty-one percent of the late career teachers mentioned students as stressful, while $37 \%$ of early career teachers and only $22 \%$ of middle career teachers mentioned students as stressful (see Table 5.2 below). In order to determine where the group differences in demands occur, a series of 2x2 Chi-square analyses were conducted. Results indicated that the group variable (late $=1$, other $=0)$ was significantly related to the student variable, $\chi^{2}(1$, $N=55)=4.97, p<.05, \mathrm{Phi}=.30$. Late career teachers mentioned students significantly 
more often than the other teachers. In addition, the group variable (late $=1$, other $=0$ ) was significantly related to the parent variable, $\chi^{2}(1, N=55)=4.55, p<.05$, Phi $=-.29$. Late career teachers mentioned parents as stressful significantly less often than the other teachers.

In the second analysis the group variable was significantly related to the environment variable, $\chi^{2}(2, N=55)=6.01, p=.05$, Cramer's $\mathrm{V}=.33$. Sixteen percent of the early career teachers mentioned the environment as stressful while no teachers in either of the other groups did so. In order to determine where the group differences in demands occur, a series of 2x2 Chi-square analyses were conducted. Results indicated that the group variable (early $=1$, other=0) was significantly related to the environment variable $(\mathrm{yes}=1, \mathrm{no}=0), \chi^{2}(1, N=55)=6.01, p<.05, \mathrm{Phi}=.33$. Early career teachers Table 5.2

Reported Demands according to Levels of Teaching Experience

\begin{tabular}{|c|c|c|c|c|}
\hline \multirow[b]{2}{*}{ Demands } & \multicolumn{3}{|c|}{ Levels of Experience } & \multirow[b]{2}{*}{$p$ value } \\
\hline & $\begin{array}{c}1 \\
(1-8 \mathrm{yrs}) \\
\end{array}$ & $\begin{array}{c}2 \\
(9-19 \text { yrs }) \\
\end{array}$ & $\begin{array}{c}3 \\
(20+y r s) \\
\end{array}$ & \\
\hline Students & $\begin{array}{c}7 \\
(37 \%)\end{array}$ & $\begin{array}{c}4 \\
(22 \%)\end{array}$ & $\begin{array}{c}11 \\
(61 \%)\end{array}$ & $p<.05$ \\
\hline Workload & $\begin{array}{c}2 \\
(11 \%)\end{array}$ & $\begin{array}{c}5 \\
(28 \%)\end{array}$ & $\begin{array}{c}3 \\
(17 \%)\end{array}$ & $n s$ \\
\hline Parents & $\begin{array}{c}4 \\
(21 \%)\end{array}$ & $\begin{array}{c}4 \\
(22 \%)\end{array}$ & $\begin{array}{c}0 \\
(0 \%)\end{array}$ & $n s$ \\
\hline Colleagues & $\begin{array}{c}2 \\
(11 \%)\end{array}$ & $\begin{array}{c}3 \\
(17 \%)\end{array}$ & $\begin{array}{c}2 \\
(11 \%)\end{array}$ & $n s$ \\
\hline Administration & $\begin{array}{c}1 \\
(6 \%)\end{array}$ & $\begin{array}{c}2 \\
(11 \%)\end{array}$ & $\begin{array}{c}2 \\
(11 \%)\end{array}$ & $n s$ \\
\hline Environment & $\begin{array}{c}3 \\
(16 \%)\end{array}$ & $\begin{array}{c}0 \\
(0 \%)\end{array}$ & $\begin{array}{c}0 \\
(0 \%)\end{array}$ & $p<.05$ \\
\hline Sample Size & $N=19$ & $N=18$ & $N=18$ & \\
\hline
\end{tabular}


mentioned environment as stressful significantly more often than the other teachers (i.e., middle and late). No other group differences were found in the demands variable. Appraisals of Teaching Demands

Question 2a. How do teachers react emotionally to the demands of teaching?

In order to determine how teachers react to the demands they face in the profession, a frequency analysis was conducted. As can be seen in Table 5.3 below, the most frequently mentioned appraisal was extreme negative emotion, which was indicated by $44 \%$ of the teachers $(N=55)$. The next most frequently mentioned appraisal was negative emotion, indicated by $42 \%$ of the teachers. Finally, no negative emotion was mentioned by only $15 \%$ of the teachers.

Table 5.3

Teacher Reported Appraisals of the Stressful Event

\begin{tabular}{lccc}
\hline Appraisal & Total & Percentage & $p$ value \\
\hline Extreme negative emotion & 24 & $44 \%$ & $n s$ \\
Negative emotion & 23 & $42 \%$ & $n s$ \\
No negative emotion mentioned & 8 & $15 \%$ & $p<.05$ \\
$\quad$ Sample Size & $N=55$ & $100 \%$ & \\
& & & \\
\end{tabular}

Next, a series of pairwise comparisons were conducted to determine which types of appraisals (i.e., extreme negative, negative, or no negative emotion) were mentioned significantly differently than could be expected by chance (i.e., 1/3 or .33). In the first analysis, no negative emotion was mentioned significantly less often than the expected, $\chi^{2}$ $(1, N=55)=8.47, p<.05$ (see Table 5.3 above). No statistical significance was found with 
either negative or extreme negative emotions mentioned. It appears that teachers react negatively to the demands placed on them in the profession.

\section{Question 2b. Does emotional reactivity differ according to years of teaching}

experience? In order to determine whether teachers' emotional reactions differ according to years of experience, a $3 \times 3$ Chi-square analysis was conducted. The variables considered were group (early $=1$, middle $=2$, and late $=3$ ) and appraisal (no negative $=0$, negative $=1$, and extreme negative $=2$ ). Results indicated that there is a significant difference in how teachers appraise the demand according to years of experience, $\chi^{2}(4$, $N=55)=9.29, p=.05$, Cramer's $\mathrm{V}=.29$.

Next, to determine where the difference in appraisal occurs, a series of $2 \times 2$ Chisquare analyses were conducted. In the first analysis, the group variable (early=1 and other $=0$ ) was significantly related to the appraisal variable "extreme negative emotion" $\left(\right.$ yes $=1$, no=0), $\chi^{2}(1, N=55)=4.50, p<.05$, Phi $=.29$ (see Table 5.4 below $)$. When compared to the other teachers, early career teachers mentioned extreme negative emotions significantly more often. In the second analysis, the group variable (early=1 and other $=0$ ) was significantly related to the appraisal variable "no negative emotion" (yes=1, no $=0), \chi^{2}(1, N=55)=4.94, p<.05, \mathrm{Phi}=-.30$. When compared to the other teachers, early career teachers mentioned no negative emotions significantly less often (see Table 5.4 below). In the third analysis, the group variable (late $=1$, other $=0$ ) was significantly related to the appraisal variable "no negative emotion (yes $=1, \mathrm{no}=0), \chi^{2}(1, N=55)=7.60$, $p<.05, \mathrm{Phi}=.37$. When compared to the other teachers, late career teachers mentioned "no negative emotions" significantly more often. No other group differences were found with regards to teacher appraisals. 
Table 5.4

Teacher Appraisal by Levels of Experience

\begin{tabular}{lcccc}
\hline \multirow{2}{*}{ Appraisal } & \multicolumn{3}{c}{ Levels of Experience } & \\
\cline { 2 - 4 } & 1 & 2 & 3 & $p$ value \\
\hline Extreme negative emotion & $(1-8 \mathrm{yrs})$ & $(9-19 \mathrm{yrs})$ & $(20+\mathrm{yrs})$ & \\
\multirow{2}{*}{ Negative emotion } & $(58 \%)$ & $(39 \%)$ & $(33 \%)$ & $p<.05$ \\
No negative emotion mentioned & 8 & 9 & 6 & $n s$ \\
& $(42 \%)$ & $(50 \%)$ & $(33 \%)$ & \\
\multicolumn{1}{c}{ Sample Size } & $(0 \%)$ & $(11 \%)$ & $(33 \%)$ & \\
& $N=19$ & $N=18$ & $N=18$ & \\
& & & & \\
\end{tabular}

Question 2c. Do different demands lead to different kinds of emotional reactions?

In order to determine whether different demands led to different kinds of emotional reactions, a series of $2 \times 2$ Chi-square analyses were conducted. In the first analysis, the workload demand variable (yes $=1$ and no=0) was significantly related to the negative emotion variable $\left(\mathrm{yes}=1\right.$ and no=0), $\chi^{2}(1, N=55)=3.99, p<.05$, Phi $=.27($ see Table 5.5 below). Teachers were more likely to describe the emotional reaction brought on by the amount of work as negative. In the second analysis, the parent demand variable (yes=1 and no $=0$ ) was significantly related to the extreme negative emotion variable (yes=1 and no=0), $\chi^{2}(1, N=55)=3.74, p=.05$, Phi $=.26$. Teachers were more likely to describe their emotional reaction to stress brought on by parents as extremely negative. In the third analysis, the administration demand variable (yes $=1$ and no=0) was significantly related to the negative emotion variable $(\mathrm{yes}=1$ and no $=0), \chi^{2}(1, N=55)=3.95, p<.05$, Phi $=-$ .27. Teachers were less likely to describe their emotional reaction brought on by the 
administration as negative. No other demand variables were significantly related to teacher appraisals.

Table 5.5

Interaction Between Demands and Emotional Reaction

\begin{tabular}{|c|c|c|c|c|}
\hline \multirow[b]{2}{*}{ Demands } & \multicolumn{3}{|c|}{ Appraisal } & Total \\
\hline & $\begin{array}{c}\text { No } \\
\text { Negative }\end{array}$ & $\begin{array}{l}\text { Negative } \\
\text { Emotion }\end{array}$ & $\begin{array}{l}\text { Extreme } \\
\text { Negative }\end{array}$ & \\
\hline Students & 5 & 8 & 9 & 22 \\
\hline Workload & 1 & 7 & 2 & 10 \\
\hline Parents & 0 & 2 & 6 & 8 \\
\hline Colleagues & 1 & 4 & 2 & 7 \\
\hline Administration & 1 & $\mathbf{0}$ & 4 & 5 \\
\hline Environment & 0 & 2 & 1 & 3 \\
\hline Total & 8 & 23 & 24 & 55 \\
\hline
\end{tabular}

Note. Bold face indicates significance at $p<.05$.

\section{Teacher Coping}

Question 3a. What are the ways teachers cope with stressful events? In order to determine how teachers cope with stressful events, a frequency analysis was conducted. As can be seen in the Table 5.6 below, the most common way for teachers to deal with the demands placed on them was problem solving, which was mentioned by $65 \%$ of the teachers. The next most commonly mentioned way of coping was support seeking, which was indicated by $35 \%$ of the teachers. Self-regulation was the third most commonly mentioned way of coping (22\%) followed by opposition (20\%), helplessness and cognitive accommodation (18\%), negotiation (13\%), rigid cognition (11\%), and 
delegation (4\%). No teachers mentioned escape, information seeking, or social isolation as a way of coping with the demands placed on them in teaching.

Next, in order to determine whether there was an overall $F$ for the ways of coping, a repeated measures MANOVA was conducted. Results indicated a significant effect for the ways of coping, $F(11,42)=29.90, p<.001$. Then, a series of pairwise comparisons were conducted to determine whether teachers mentioned the ways of coping significantly differently than could be expected by chance (1/12 or .08). In the first analysis, problem solving (yes $=1$ and no=0) was mentioned significantly more often than could be expected by chance, $\chi^{2}(1, N=55)=100.09, p<.05$ (see Table 5.6 below). In the next analysis, support seeking (yes $=1$ and no=0) was also mentioned significantly more often than could be expected by chance, $\chi^{2}(1, N=55)=14.08, p<.05$. In the next analysis, delegation (yes $=1$ and no=0) was mentioned significantly less often than could be expected by chance, $\chi^{2}(1, N=55)=6.26, p<.05$. In addition, three ways of coping were not mentioned by any teachers (i.e., escape, information seeking, and social isolation). These three ways of coping were mentioned significantly less often than could be expected by chance. No other way of coping was mentioned significantly differently than could be expected by chance.

Question 3b. Do the ways teachers cope with stressful events differ according to years of teaching experience? In order to determine whether the ways in which teachers cope with stressful events differ according to years of experience a series of $2 \times 2$ Chisquare analyses were conducted. In the first analysis, years of experience (late career teachers $=1$ and other $=0$ ) was significantly related to self regulation (yes $=1$ and no $=0), \chi^{2}$ $(1, N=55)=4.15, p<.05, \mathrm{Phi}=-.28$ (see Table 5.7 below). Late career teachers were 
significantly less likely than the other groups to use self-regulation to cope with stress. In the second analysis, years of experience (late $=1$ and other $=0$ ) was significantly related to cognitive accommodation (yes $=1$ and no $=0), \chi^{2}(1, N=55)=4.13, p<.05$, Phi $=.27$. Late career teachers were significantly more likely than the other groups to use cognitive accommodation to cope with stress. In the third analysis, years of experience (middle career teachers $=1$ and other $=0$ ) was significantly related to delegation (yes $=1$ and no=0), $\chi^{2}(1, N=55)=4.27, p<.05, \mathrm{Phi}=.28$. Middle career teachers were significantly more likely than the other groups to use delegation as a way of coping with the demands in teaching. No other group differences were found.

Question 3c. Do the different appraisals lead to different ways of coping? In order to determine whether different appraisals lead to different ways of coping a series of Chisquare analyses were conducted. There were no significant differences found. It appears there is no relation between how the teachers appraise the demand (i.e., no emotion, negative emotion, and extreme negative emotion) and the way they choose to cope with it (see Table 5.8 below). 
Table 5.6

Teacher Reported Ways of Coping

\begin{tabular}{|c|c|c|c|}
\hline Ways of Coping & Total & Percent & $p$ value \\
\hline Problem Solving & 36 & $65 \%$ & $p<.05$ \\
\hline Support Seeking & 19 & $35 \%$ & $p<.05$ \\
\hline Self Regulation & 12 & $22 \%$ & $n s$ \\
\hline Opposition & 11 & $20 \%$ & $n s$ \\
\hline Helplessness & 10 & $18 \%$ & $n s$ \\
\hline Cognitive Accommodation & 10 & $18 \%$ & $n s$ \\
\hline Negotiate & 7 & $13 \%$ & $n s$ \\
\hline Rigid Cognition & 6 & $11 \%$ & $n s$ \\
\hline Delegation & 2 & $4 \%$ & $p<.05$ \\
\hline Escape & 0 & $0 \%$ & $*$ \\
\hline Information Seeking & 0 & $0 \%$ & $*$ \\
\hline Social Isolation & 0 & $0 \%$ & $*$ \\
\hline
\end{tabular}

Note. The * indicates Chi-square analysis could not be conducted. 
Table 5.7

Interaction between Ways of Coping and Levels of Experience

\begin{tabular}{lccc}
\hline \multirow{2}{*}{ Ways of Coping } & \multicolumn{3}{c}{ Levels of Experience } \\
\cline { 2 - 4 } & $\begin{array}{c}1 \\
(1-8 \mathrm{yrs})\end{array}$ & $\begin{array}{c}2 \\
(9-19 \mathrm{yrs})\end{array}$ & $\begin{array}{c}3 \\
(20+\mathrm{yrs})\end{array}$ \\
\hline Problem Solving & $12(63 \%)$ & $12(67 \%)$ & $12(67 \%)$ \\
Support Seeking & $6(32 \%)$ & $6(33 \%)$ & $7(39 \%)$ \\
Self Regulation & $6(32 \%)$ & $5(28 \%)$ & $\mathbf{1}(\mathbf{6 \%})$ \\
Opposition & $5(26 \%)$ & $5(28 \%)$ & $1(6 \%)$ \\
Helplessness & $3(16 \%)$ & $4(22 \%)$ & $3(17 \%)$ \\
Cognitive Accommodation & $3(16 \%)$ & $1(6 \%)$ & $\mathbf{6}(\mathbf{3 3 \%})$ \\
Negotiate & $3(16 \%)$ & $2(11 \%)$ & $2(11 \%)$ \\
Rigid Cognition & $4(21 \%)$ & $2(11 \%)$ & 0 \\
Delegation & 0 & $\mathbf{2 ( 1 1 \% )}$ & 0 \\
Escape & 0 & 0 & 0 \\
Information Seeking & 0 & 0 & 0 \\
Social Isolation & 0 & 0 & 0 \\
$\quad$ Sample Size $=55$ & 0 & 0 & 0 \\
\hline
\end{tabular}

Note. Bold face indicates significant at $p<.05$. 
Table 5.8

Interaction between Ways of Coping and Appraisals

\begin{tabular}{lccc}
\hline \multirow{2}{*}{ Ways of Coping } & \multicolumn{3}{c}{ Appraisal } \\
\cline { 2 - 4 } & $\begin{array}{c}\text { No } \\
\text { Negative }\end{array}$ & Negative & $\begin{array}{c}\text { Extreme } \\
\text { Negative }\end{array}$ \\
\hline Problem Solving & 5 & 18 & 13 \\
Support Seeking & 4 & 6 & 9 \\
Self Regulation & 2 & 3 & 7 \\
Opposition & 1 & 5 & 5 \\
Helplessness & 1 & 2 & 7 \\
Cognitive Accommodation & 2 & 4 & 4 \\
Negotiate & 0 & 3 & 4 \\
Rigid Cognition & 0 & 3 & 3 \\
Delegation & 1 & 1 & 0 \\
Escape & 0 & 0 & 0 \\
Information Seeking & 0 & 0 & 0 \\
Social Isolation & & & 0 \\
\hline
\end{tabular}

Question 3d. Does the nature of the demand of the stressful event lead to different coping strategies for teachers? In order to determine whether the nature of the demand lead to different coping strategies for teachers a series of Chi-square analyses were conducted. The variables were demands (yes=1 and no=0) and ways of coping (yes=1 and no=0). In the first two analyses, administration was significantly related to support seeking, $\chi^{2}(1, N=55)=5.03, p<.05$, Phi $=.30$, and delegation, $\chi^{2}(1, N=55)=4.20, p<$ 
.05, Phi $=.28$ (see Table 5.9 below). Teachers who mention administration as a demand in education are more likely to use support seeking and/or delegation to cope with the stress. In the next analysis environment was significantly related to opposition, $\chi^{2}(1$, $N=55)=4.32, p<.05, \mathrm{Phi}=.28$. Teachers who mention environment as a demand in education were more likely to mention the use of opposition as a way of coping with the stress. In the next analysis, workload was significantly related to helplessness, $\chi^{2}(1$, $N=55)=3.91, p<.05$, Phi $=.27$. Teachers who mention workload as a demand were more likely to use helplessness to cope with the stress. In the next analysis, the demand variable parents was significantly related to self-regulation, $\chi^{2}(1, N=55)=4.36, p<.05$, Phi $=.28$. Teachers who mention parents as a demand were more likely to use selfregulation to cope with the stress. No other differences were found between the demands variable and the way teachers cope with the stress.

\section{Resolution of Stressful Episodes}

Question 4a. How are stressful events typically resolved? In order to determine how stressful events are typically resolved, a Frequency Analysis was conducted. As can be seen in Table 5.10 below the most frequent resolution of the stressful event was successful (51\%), followed by unsuccessful (40\%) and in process of being resolved (9\%). Teachers were most likely to have a successful resolution when attempting to resolve a stressful event. 
Table 5.9

Interaction Between Ways of Coping and Demands

\begin{tabular}{|c|c|c|c|c|c|c|}
\hline & & & Demands & & & \\
\hline Ways of Coping & Student & Environ. & Admin. & Colleagues & Workload & Parents \\
\hline Problem Solving & 14 & 1 & 2 & 5 & 8 & 6 \\
\hline Support Seeking & 6 & 0 & 4 & 3 & 1 & 5 \\
\hline Delegation & 0 & 0 & 1 & 0 & 1 & 0 \\
\hline Opposition & 2 & 2 & 1 & 1 & 2 & 3 \\
\hline Helplessness & 4 & 0 & 0 & 1 & 4 & 1 \\
\hline $\begin{array}{l}\text { Cognitive } \\
\text { Accommodation }\end{array}$ & 5 & 1 & 1 & 2 & 1 & 0 \\
\hline Negotiate & 4 & 0 & 1 & 1 & 0 & 1 \\
\hline Rigid Cognition & 2 & 0 & 1 & 1 & 2 & 0 \\
\hline Self Regulation & 4 & 1 & 1 & 2 & 0 & 4 \\
\hline Escape & 0 & 0 & 0 & 0 & 0 & 0 \\
\hline Information Seeking & 0 & 0 & 0 & 0 & 0 & 0 \\
\hline Social Isolation & 0 & 0 & 0 & 0 & 0 & 0 \\
\hline
\end{tabular}

Note. Bold face indicates significant at $p<.05$. 
Table 5.10

Teacher Reported Resolutions of the Stressful Event

\begin{tabular}{lccc}
\hline Resolution & Total & Percent & Sign. \\
\hline Successful & 28 & $51 \%$ & $p<.05$ \\
Unsuccessful & 22 & $40 \%$ & $n s$ \\
In Process of Being Resolved & 5 & $9 \%$ & $p<.05$ \\
$\quad$ Total Sample Size & $N=55$ & $100 \%$ & \\
& & & \\
\hline
\end{tabular}

Next, in order to determine whether the stressful events were resolved significantly differently than could be expected by chance (i.e., $1 / 3$ or .33), a series of $2 \times 2$ Chi-square analyses were conducted. In the first analysis, successful resolution occurred significantly more often than could be expected by chance, $\chi^{2}(1, N=55)=7.98, p<.05$ (see Table 5.10 above). In the second analysis the variable "in process of being resolved" occurred significantly less often than expected, $\chi^{2}(1, N=55)=14.22, p<.05$. The final variable (unsuccessful) did not occur differently than would be expected by chance. It appears teachers were typically successful when attempting to resolve a stressful event.

Question $4 b$. Do the resolutions differ according to years of experience? In order to determine whether the resolution of stressful events differ according to years of experience a series of $2 \times 2$ Chi-square analyses were conducted. No significant differences were found (see Table 5.11 below). Experience seems to have little effect when it comes to the resolution of the stressful episode. 
Table 5.11

Resolutions According to Levels of Experience

\begin{tabular}{|c|c|c|c|}
\hline \multirow[t]{2}{*}{ Resolution } & \multicolumn{3}{|c|}{ Levels of Experience } \\
\hline & $\begin{array}{c}1 \\
(1-8 \mathrm{yrs})\end{array}$ & $\begin{array}{c}2 \\
(9-19 \mathrm{yrs})\end{array}$ & $\begin{array}{c}3 \\
(20+y r s)\end{array}$ \\
\hline Successful & $\begin{array}{c}11 \\
(58 \%)\end{array}$ & $\begin{array}{c}10 \\
(56 \%)\end{array}$ & $\begin{array}{c}7 \\
(39 \%)\end{array}$ \\
\hline & $n s$ & $n s$ & $n s$ \\
\hline Unsuccessful & $\begin{array}{c}6 \\
(32 \%)\end{array}$ & $\begin{array}{c}7 \\
(39 \%)\end{array}$ & $\begin{array}{c}9 \\
(50 \%)\end{array}$ \\
\hline & $n s$ & $n s$ & $n s$ \\
\hline In Process of Being Resolved & $\begin{array}{c}2 \\
(11 \%)\end{array}$ & $\begin{array}{c}1 \\
(6 \%)\end{array}$ & $\begin{array}{c}2 \\
(11 \%)\end{array}$ \\
\hline Sample Size & $\begin{array}{l}n s \\
N=19\end{array}$ & $\begin{array}{l}n s \\
N=18\end{array}$ & $\begin{array}{l}n s \\
N=18\end{array}$ \\
\hline
\end{tabular}

Question 4c. Do the ways teachers cope result in different resolutions of stressful events? In order to determine whether the ways teachers cope with stress result in different resolutions, a series of $2 \times 2$ Chi-square analyses were conducted. In the first analysis, self-regulation (yes $=1$ and no=0) was significantly related to a successful resolution $($ success $=1$ and other $=0), \chi^{2}(1, N=55)=6.46, p<.05$, Phi $=.34($ see Table 5.12 below). Teachers who mentioned the use of self-regulation to cope with stress were more likely to have a successful resolution of the event. In the next analysis, helplessness $(y e s=1$ and no=0) was significantly related to an unsuccessful resolution (unsuccessful=1 and other $=0), \chi^{2}(1, N=55)=4.58, p<.05$, Phi $=.29$. Teachers who mentioned using helplessness as a way of coping with stress were typically unsuccessful in resolving the stressful event. No other differences were found between ways of coping and the resolution of the stressful event. 
As a further analysis, a total coping score was calculated by totaling up all the adaptive ways of coping (i.e., problem solving, information seeking, self regulation, support seeking, cognitive accommodation, and negotiation) mentioned by each teacher and subtracting the number of maladaptive ways of coping (i.e., helplessness, escape, delegation, social isolation, rigid cognition, and opposition). This score captured whether the teacher used more adaptive or maladaptive ways of coping when attempting to resolve the stressful event.

Next, in order to determine whether the overall way teachers cope with stress was related to the resolution of the stressful event, a 2x3 Chi-square analyses was conducted. Results indicated that the teachers total coping (adaptive $=1$, neutral $=0$, and maladaptive $=$ -1) was significantly related to the resolution of the event (unsuccessful $=1$ and other $=0$ ), $\chi^{2}(2, N=55)=6.25, p<.05$, Cramer's $\mathrm{V}=.34$. No differences were found between the total ways teachers cope and having a successful resolution, or between total coping and the resolution still being in process.

Next, in order to determine where the difference lies, a series of $2 \times 2$ Chi-square analyses were conducted. In the first analysis, the resolution "unsuccessful" was significantly related to maladaptive coping (yes $=1$, no $=0), \chi^{2}(1, N=55)=6.06, p<.05$, Phi $=.33$ (see Table 5.13 below). Teachers who reported using more maladaptive ways of coping were significantly more likely to report having an unsuccessful resolution. No other differences were found between total coping and resolution of the stressful event. 
Table 5.12

Interaction Between Ways of Coping and Resolution

\begin{tabular}{|c|c|c|c|}
\hline \multirow[b]{2}{*}{ Ways of Coping } & \multicolumn{3}{|c|}{$\underline{\text { Resolution }}$} \\
\hline & Successful & Unsuccessful & In Process \\
\hline Problem Solving & 19 & 13 & 4 \\
\hline Support Seeking & 12 & 5 & 2 \\
\hline Self Regulation & 10 & 0 & 2 \\
\hline Opposition & 5 & 5 & 1 \\
\hline Helplessness & 3 & 7 & 0 \\
\hline Cognitive Accommodation & 6 & 2 & 2 \\
\hline Negotiate & 4 & 2 & 1 \\
\hline Rigid Cognition & 4 & 2 & 0 \\
\hline Delegation & 1 & 1 & 0 \\
\hline Escape & 0 & 0 & 0 \\
\hline Information Seeking & 0 & 0 & 0 \\
\hline Social Isolation & 0 & 0 & 0 \\
\hline
\end{tabular}

Note. Bold face indicates significant at $p<.05$ 
Table 5.13

Interaction Between Total Coping and Resolution

\begin{tabular}{lccc}
\hline & & \multicolumn{2}{c}{ Resolution } \\
Total Coping & Successful & Unsuccessful & In Process \\
\hline Adaptive & 16 & 11 & 5 \\
Maladaptive & 4 & 9 & 0 \\
Neutral & 3 & 2 & 0 \\
\hline
\end{tabular}

\section{Post-Coping Reflection and Teacher Learning}

Question 5a. Do teachers incorporate their experiences with stressful events into learning? A Frequency Analysis was conducted in order to determine how teachers assess their learning from experiences with stressful events. In the interviews, teachers were asked whether they would do anything differently, if they could, to resolve the stressful event. Because the teachers' answers varied according to whether the outcome was favorable or not (e.g., some teachers indicated they would not try anything differently even though the outcome was unfavorable, whereas other teachers indicated they would not do anything differently and the outcome was favorable), the variables were described as "No Unfavorable" and "No Favorable." In addition, at times teachers mentioned unrealistic ways of handling the situation differently (e.g., "Yes, if I had a magic wand...”). In order to capture the difference between realistic and unrealistic ideas as to what could be done differently, the yes response was divided between "Yes Effective" (i.e., the teacher suggested an effective strategy), and "Yes Ineffective" (i.e., the teacher suggested and unrealistic or ineffective strategy). As can be seen in Table 
5.14 below, the most common answer provided by teachers was "Yes Effective," which was mentioned by $54 \%$ of the teachers. The next most frequently mentioned assessment was no when the outcome was unfavorable (19\%), followed by no when the outcome was favorable (15\%). Finally, twelve percent of the teachers mentioned that they would try a strategy that was ineffective (e.g., wishful thinking).

Table 5.14

Frequency Count of Teacher Assessment

\begin{tabular}{|c|c|c|c|}
\hline Assessment & Total & Percent & $p$ value \\
\hline Yes Effective & 22 & $54 \%$ & $p<.05$ \\
\hline No Unfavorable & 8 & $19 \%$ & $n s$ \\
\hline No Favorable & 6 & $15 \%$ & $n s$ \\
\hline Yes Ineffective & 5 & $12 \%$ & $n s$ \\
\hline Sample Size & $N=41$ & $100 \%$ & \\
\hline
\end{tabular}

Note: 14 teacher interviews could not be coded on the assessment variable because they were not asked what they would do differently and/or it could not be determined by the teacher's answer.

In order to determine whether the assessment variables (yes effective, no unfavorable, no favorable, and yes ineffective) occurred significantly more than could be expected by chance (i.e., $1 / 4$ or .25 ) a series of pairwise comparisons were conducted. In the first analysis "Yes Effective" (yes $=1$ and no=0) was mentioned significantly more than could be expected, $\chi^{2}(1, N=41)=17.96, p<.05$ (see Table 5.14 above). No other assessment variables occurred significantly different than could be expected by chance. It 
appears teachers demonstrated learning from the stressful event by suggesting effective strategies for future situations.

Question 5b. Do teachers' reflections and learning differ according to years of experience? A series of Chi-square analyses were conducted to determine whether teachers' reflections and learning differed according to years of experience. In the first analysis, teacher assessment (yes effective $=1$ and other $=0$ ) was significantly related teacher experience $($ early $=1$ and other $=0), \chi^{2}(1, N=41)=5.31, p<.05$, Phi $=.36$ (see Table 5.15 below). Early career teachers were more likely to suggest effective strategies for future stressful events. In the next analysis, teacher assessment (yes effective $=1$ and other $=0)$ was significantly related to teacher experience (late $=1$ and other $=0), \chi^{2}(1$, $N=41)=5.60, p<.05, \mathrm{Phi}=-.37$. In contrast to other teachers, late career teachers were less likely to suggest effective strategies for dealing with stressful events in the future. No other significant differences were found between teacher assessment and years of experience.

Question 5c. Does the way in which stressful episodes are resolved result in different kinds of learning and reflection? In order to determine whether the resolution of the stressful episodes resulted in different kinds of learning and reflection, a series of $2 \times 2$ Chi-square analyses were conducted. In the first analysis the resolution variable (successful=1 and other=0) was significantly related to the assessment variable (no favorable $=1$ and other $=0), \chi^{2}(1, N=41)=6.07, p<.05$, Phi $=.39$ (see Table 5.16 below $)$. When the resolution was successful teachers typically mentioned they would not do anything differently. No other relationship was found between the resolution of the stressful event and teacher assessment. 
Table 5.15

Interaction Between Teacher Assessment and Levels of Experience

\begin{tabular}{|c|c|c|c|}
\hline \multirow[b]{2}{*}{ Assessment } & \multicolumn{3}{|c|}{ Levels of Experience } \\
\hline & $\begin{array}{c}1 \\
(1-8 \mathrm{yrs}) \\
\end{array}$ & $\begin{array}{c}2 \\
(9-19 \mathrm{yrs}) \\
\end{array}$ & $\begin{array}{c}3 \\
(20+y r s) \\
\end{array}$ \\
\hline Yes Effective & $\begin{array}{c}11 \\
(79 \%)\end{array}$ & $\begin{array}{c}8 \\
(53 \%)\end{array}$ & $\begin{array}{c}\mathbf{3} \\
(25 \%)\end{array}$ \\
\hline Yes Ineffective & $\begin{array}{c}0 \\
(0 \%)\end{array}$ & $\begin{array}{c}2 \\
(13 \%)\end{array}$ & $\begin{array}{c}3 \\
(25 \%)\end{array}$ \\
\hline No Favorable & $\begin{array}{c}2 \\
(14 \%)\end{array}$ & $\begin{array}{c}2 \\
(13 \%)\end{array}$ & $\begin{array}{c}2 \\
(17 \%)\end{array}$ \\
\hline No Unfavorable & $\begin{array}{c}1 \\
(7 \%)\end{array}$ & $\begin{array}{c}3 \\
(20 \%)\end{array}$ & $\begin{array}{c}4 \\
(33 \%)\end{array}$ \\
\hline Sample Size & $N=14$ & $N=15$ & $N=12$ \\
\hline
\end{tabular}

Note. Bold face indicates significant at $p<.05$.

Table 5.16

Interaction Between Teacher Assessment and Resolution of the Stressful Event

\section{$\underline{\text { Resolution }}$}

Assessment Successful Unsuccessful In Process

\begin{tabular}{lccc}
\hline Yes Effective & 13 & 6 & 3 \\
No Unfavorable & 1 & 5 & 2 \\
No Favorable & $\mathbf{6}$ & 0 & 0 \\
Yes Ineffective & 2 & 3 & 0 \\
\hline
\end{tabular}

Note. Bold face indicates significant at $p<.05$. 
Question 5d. Do the ways that teachers cope with stressful episodes result in different kinds of learning and reflection? In order to determine whether the ways that teachers cope with stressful episodes result in different kinds of learning and reflection, a series of Chi-square analyses were conducted. In the first analysis, delegation (yes=1 and no $=0$ ) was significantly related to assessment (no unfavorable $=1$ and other $=0), \chi^{2}(1$, $N=41)=4.23, p<.05$, Phi $=.32$ (see Table 5.17 below). Teachers who mentioned the use of delegation as a way to cope with stress were more likely to say they would not do anything different even though the outcome was unfavorable. No other differences were found between the way teachers cope with stress and their assessment of future events. 
Table 5.17

Interaction Between Ways of Coping and Teacher Learning

\begin{tabular}{|c|c|c|c|c|}
\hline & & Teacher & Learning & \\
\hline Ways of Coping & $\begin{array}{c}\text { Yes } \\
\text { Effective }\end{array}$ & $\begin{array}{c}\text { No } \\
\text { Unfavorable }\end{array}$ & $\begin{array}{c}\text { No } \\
\text { Favorable }\end{array}$ & $\begin{array}{c}\text { Yes } \\
\text { Ineffective }\end{array}$ \\
\hline Problem Solving & 14 & 6 & 3 & 2 \\
\hline Support Seeking & 9 & 2 & 4 & 1 \\
\hline Self Regulation & 7 & 1 & 3 & 0 \\
\hline Opposition & 3 & 3 & 1 & 1 \\
\hline Helplessness & 4 & 3 & 0 & 1 \\
\hline Cognitive Accommodation & 3 & 2 & 1 & 1 \\
\hline Negotiate & 2 & 2 & 2 & 0 \\
\hline Rigid Cognition & 4 & 1 & 0 & 1 \\
\hline Delegation & 0 & 1 & 0 & 0 \\
\hline Escape & 0 & 0 & 0 & 0 \\
\hline Information Seeking & 0 & 0 & 0 & 0 \\
\hline Social Isolation & 0 & 0 & 0 & 0 \\
\hline
\end{tabular}

Note. Bold face indicates significant at $p<.05$. 


\section{CHAPTER 6}

\section{Discussion}

Teaching has been shown to be one of the most stressful professions, ranking $2^{\text {nd }}$ in terms of poor physical health associated with stress (Johnson et al., 2005). Teachers have reported that the sources of this stress include working with working with unmotivated students, time pressure and workload, dealing with administration and colleagues, and poor working conditions (Kyriacou, 2001). The demands placed on teachers have been shown to have deleterious effects on their mental and physical health such as higher rates of cardiovascular disease, depression, and poor interpersonal relationships (Mearns \& Cain, 2003; Rubino et al., 2009). In addition, these healthrelated outcomes have been shown to lead to emotional exhaustion and burnout (Greenglass et al., 1998) causing a higher attrition rate in teaching than in other careers (Jalongo \& Heider, 2006).

Early career teachers. Because they are new to the profession, early career teachers seem to be especially vulnerable when it comes to dealing with the stress associated with teaching. Indeed, the teacher attrition rate in the U.S. is said to be as high as $46 \%$ within the first five years of teaching (Jalongo \& Heider, 2006). In order to deal with the demands place on them, young teachers must learn how to cope with stress in effective ways, affording them the opportunity to work successfully with students on a daily basis. Indeed, teachers with more access to coping resources reported less burnout than those with limited access to such resources (Betoret, 2006). In addition, learning effective coping strategies has been said to contribute to a mastery orientation toward teaching, which significantly predicts enjoyment of work (Parker \& Martin, 2009). If 
teachers are to be supportive to the students they work with, they must gain an understanding of the process of coping and learn to make adjustments along the way that allow them to manage the stress associated with the profession.

Purpose and procedure of the study. The purpose of the current study was to elucidate the processes through which teachers cope in order to gain a better understanding of how, with increasing levels of experiences, teachers can develop effective coping strategies to deal with the demands they face on a daily basis. To do this, the interview portion prior to a mindfulness training program for teachers (SMART) was utilized by analyzing teacher's responses to questions designed to tap five steps in the coping process: (1) demands (i.e., "Can you give me a specific example of a stressful experience in your job?”); (2) appraisal (i.e., "How did it make you feel?”); (3) coping (i.e., "What did you do?”); (4) resolution (i.e., "How did it turn out?”); and (5) postcoping assessment (i.e., "What would you do differently if you could?"). After coding the data from these interviews, a series of Chi-square analyses were conducted to determine the relationship between the constructs (i.e., demands, appraisal, coping, resolution, and post-coping assessment), as well as the relationship between levels of experience (i.e., early, middle, and late career teachers) and the constructs. The results from these analyses will be summarized below (see Appendix D).

\section{Summary of the Results}

Demands in teaching. In order to determine what teachers find stressful and whether their perceptions of demands differ according to years of teaching experience, a series of Chi-square analyses were conducted. The results indicated that teachers reported students as a source of stress more often than any of the other demands they face. Forty 
percent of the teachers mentioned students as stressful. The next most frequently mentioned teacher stressor was workload (18\%), followed by parents (15\%), colleagues (13\%), administration (9\%) and the work environment (6\%).

In addition, the demands reported by teachers differed according to levels of experience. Specifically, early career teachers mentioned environment significantly more often than the other groups (i.e. middle and late). In addition, late career teachers mentioned students significantly more often and parents significantly less often than the other groups (i.e., early and middle). It appears that as teachers gain experience, they focus more on the demands presented by their students, whereas some other demands weigh less heavily on them.

Appraisals of teaching demands. The second set of analyses examined (1) how teachers react emotionally to the demands of teaching, (2) whether the emotional reactivity differed according to years of experience, and (3) whether different demands lead to different kinds of emotional reactions. Results indicated that the highest percentage of teachers (44\%) appraised the emotion associated with the demands they described in the interview as "extreme negative." The next most common appraisal was "negative" (42\%), followed by "no negative emotion" (15\%). Interestingly, only the first two groups (extreme negative and negative) were mentioned significantly differently than could be expected by chance. It appears the demands teachers face evoke emotions that teachers perceive as being either negative or extremely negative.

With regards to levels of experience, the results indicated that early career teachers mentioned no negative emotion significantly less than the other groups. In addition, early career teachers mentioned extreme negative significantly more often than 
the other groups. Finally, late career teachers mentioned no negative emotion significantly more often than the other groups. It appears that teachers experience fewer negative emotions as they gain experience in teaching.

In the final analysis of teacher appraisals, results indicated that different demands did indeed lead to different kinds of emotional reactions. For example, teachers were more likely to appraise the demands presented by parents as provoking extreme negative emotions. In addition, teachers were more likely to appraise the demands presented by the administration and the amount of work as producing negative emotions.

Teacher coping. The third set of analyses focused on coping in order to determine (1) how teachers cope with stressful events, (2) whether teachers cope differently according to levels of experience, and (3) whether different demands and appraisals lead to different ways of coping. Results indicated that teachers mentioned the use of problem-solving more often than other strategies, as sixty-five percent of the teachers mentioned the use of this strategy. The next most common way of coping was support seeking (35\%), followed by self-regulation (22\%) and opposition (20\%). Interestingly, teachers did not mention the use of escape, information seeking, or social isolation when reporting how they cope with stressful events in their jobs.

With regards to whether the ways in which teachers cope with stress differed according to years of experience, findings indicated that middle career teachers were significantly more likely than the other groups to use delegation. In addition, late career teachers reported using self-regulation and cognitive accommodation significantly more often than the other groups. It appears that teachers may change the way they cope with stressful events as they gain experience in teaching. 
The next question investigated in teacher coping was whether the nature of the demand led to different ways of coping. Results indicated that the demand variable "parents" was significantly related to the use of self-regulation. In addition, administration was significantly related to support seeking. Finally, environment was significantly related to opposition, and workload was significantly related to helplessness. Interestingly, the demands involving inter-personal relationships (i.e., parents and administration) led to more adaptive coping (i.e., self-regulation and support seeking), whereas the demands involving the amount of work or the place it is conducted led to more maladaptive coping (i.e., opposition and helplessness). It appears that the nature of the demand does lead to different ways of coping.

Interestingly, although there was an association found between the type of demand and the way teachers cope, the appraisals of those demands did not relate to how teachers cope with them. It may be that because the question, "How did it make you feel?" was asked after the question, "What did you do?" that this particular association was not captured. For example, it may be that the teachers were reporting how they felt about the way they coped with the demand, or they may have reported how they felt about the demand itself. Because there is no way to determine which aspect of the coping episode the teachers were referring to, further investigation is warranted.

Resolution of the stressful episodes. The fourth set of analyses focused on the resolution of the stressor in order to determine (1) how stressful events are typically resolved, (2) whether the resolutions differ according to years of experience, and (3) whether the ways teachers cope result in different resolutions. Results indicated that the resolutions of the stressful event are most often successful. Indeed, fifty-one percent of 
the teachers reported the outcome to be successful, while forty percent of the teachers reported the outcome to be unsuccessful, and only nine percent of the stressful episodes were unresolved. In addition, the resolutions differed according to the ways in which teachers coped with the stressful event. For example, self-regulation typically led to a successful resolution, while helplessness typically led to an unsuccessful resolution. However, there was no difference found in the way in which the stressful events were resolved as a function of their level of teaching experience.

Post-coping reflection and teacher learning. The fifth set of analyses focused on post-coping reflection in order to determine (1) whether teachers incorporate their experiences with stressful events into learning effective strategies in the future, (2) whether there are differences according to levels of experience, and (3) whether the way in which they cope and the outcome led to different kinds of learning. Results indicated that teachers reported that they would indeed try a different effective technique to deal with a similar episode in the future most often (54\%), followed by reports that (1) they would not try a different approach even though the outcome was unfavorable (19\%); (2) no they would not try a new approach because the outcome was favorable (15\%); and (3) yes they would try a new strategy, even though coders viewed it as ineffective (12\%).

In addition, teachers' assessments differed according to years of experience. For example, early career teachers reported that they would try a new effective strategy significantly more than the other groups. Interestingly, in contrast to early career teachers, late career teachers reported that they would try a new effective strategy significantly less often than the other groups. It appears that teachers may become more rigid when it comes to trying different strategies in the future as they acquire experience 
in teaching, or it may be that they are already doing what works so they feel no need to change their approach.

Further, teachers who reported a successful resolution were significantly more likely to report that they would not try anything different, indicating that they found no need to try a new strategy because the outcome was favorable. Finally, the only way of coping that was related to teacher assessment was delegation (i.e., placing the blame elsewhere), which was significantly related to reports that teachers would not do anything different even though the outcome was unfavorable. It appears that teachers may have felt there is no need to change because they did not feel responsible for the episode in the first place.

Findings in Relation to Previous Literature on Teacher Stress and Coping

In the teacher stress and coping literature, nearly all of the studies investigated what teachers find to be stressful and how they choose to cope with it. Much can be gained by comparing the findings of the current study with what has been found in previous research. In the following paragraphs, findings from the current study that were consistent with the literature reviewed will be presented. In addition, findings that are new to the teacher stress and coping literature will be summarized.

Demands reported by teachers. Previous literature has indicated that the most common stressors reported by teachers are problems associated with students (e.g., student misbehavior, low achievement, unmotivated students, etc., see Table 2.1). Similarly, findings in the current study indicated that teachers reported problems with students more often than any other demand. This finding is not that surprising given that teachers spend most of their work day interacting with students. In addition, because of 
their youth, students are typically much less mature than the teachers, making them more challenging interaction partners. Therefore, teachers must have a comprehensive understanding of how their younger and less experienced interaction partners think and behave in order to effectively deal with the demands associated with them. Because teachers typically invest a great deal of time and energy in working with students, it is likely that their energy is depleted after engaging with students over extended periods of time. In turn, when teachers are asked to reflect on what they find to be stressful, the first set of issues that comes to mind are those that related to students.

Workload. The next most common stressor reported in the current study was workload, reported by $18 \%$ of the teachers. Similarly, previous literature has indicated that workload is often cited as a common demand placed on teachers. Indeed, workload was number four on the list of demands investigated by the studies examined in the literature review, after only that of students, classroom environment, and administration. However, if combined with total work time (investigated in 6 studies) workload would be the most often investigated teacher stressor (see Table 2.1).

Again, this finding is not too surprising given that teachers are expected to evaluate the performance of 25-35 students in multiple different subjects such as Math, English, Science, and Reading in elementary schools, and up to 180 or more students in secondary schools. In addition, much of what was traditionally viewed as a role and responsibility of parents (e.g., sex education, morality, social responsibility, proper hygiene, etc.) has been delegated to teachers. Further, new state guidelines and government regulations (e.g., state testing requirements, no student left behind, etc.) impose continually increasing expectations and added work upon teachers. Collectively, 
these responsibilities can make the teaching profession exhausting work and add stress to an already busy workday.

Parents. The third most commonly reported demand in the current study was from parents, mentioned by $15 \%$ of the teachers. Interestingly, although this demand was among the stressors most frequently mentioned in the current study, only 6 studies examined in the literature review investigated parents as a stressor. As described earlier, this could be due to the nature of the studies themselves. Because most of the studies reviewed were in the form of questionnaires, teachers were forced to choose from a list rather than speak freely about what they find stressful. It could be that the extent of the demand placed on teachers by parents was not captured because of this restriction.

Certainly it makes intuitive sense that parents would be viewed as stressful to teachers for several reasons: (1) Parents typically only meet with teachers when the parent is unhappy with the teacher, or the teacher is unhappy with the student; (2) Parents have high expectations for their children and may attempt to impose their will on their children's teachers; (3) Because parents view the classroom education from the lens of their own child, they tend to disregard the fact that teachers have many other students to work with as well; (4) Because the parents were educated during a different era, they are often unaware of the changing reforms of education and can simply not relate to what the teacher experiences in the classroom on a daily basis. Together, these differing viewpoints can create tension between the teacher and parent, leading to an increase in the level of stress faced by the teacher. Indeed, the demand placed on teachers by parents was the only teacher stressor to be significantly related to experiencing extreme negative 
emotions. Based on this relationship, it appears that teachers find dealing with parents to be extremely stressful.

Colleagues. The fourth most commonly reported demand in the current study was colleagues, mentioned by $13 \%$ of the teachers. In the studies reviewed here, the demand placed on teachers by colleagues have often been cited as a source of stress, and was tied with workload as the fourth most commonly investigated teacher stressor. It could be that colleagues are not as stressful as the first three demands mentioned thus far because teachers are typically isolated from their colleagues throughout the workday and only interact with them in passing and/or during meetings. In addition, colleagues are often a resource for teachers in dealing with stress, as they often turn to colleagues when seeking support. In turn, the positive influence and support from colleagues could reduce the negative effect of stress associated with them. Still, much like the tension created from a lack of understanding between teacher and parent, teachers have differing views of what is best for students and these differences could create tension between them, leading to an elevated level of stress. In addition, there are times when teachers must make joint decisions on what is best for the students and attempting to collaborate in this way could place a strain on the relationship.

Administration. The fifth most frequently reported demand in the current study was from the administration. This finding is consistent with the previous literature, investigated by nearly a third of the studies reviewed. Moreover, as stated earlier, teachers consistently rank problems associated with the administration as being highly stressful (Blasé, 1986; Chan, 1998; Green \& Ross, 1996; Griffith, Steptoe, \& Cropley, 1999; Zurlo et al., 2007). Although the administration has decision-making power over 
the teachers and can affect their workday in a multitude of ways, they are not typically mentioned as being any more stressful than working with colleagues. It may be that, just as teachers spend less time with colleagues than students, they spend even smaller amounts of time with the administration, leading to lower levels of stress than all of the other demands mentioned thus far. However, the administration is still reported to be stressful by many teachers and seems to create hard feelings. Indeed, the demand placed on teachers by the administration was significantly related to the teachers experiencing negative emotions. This relationship could be partially explained by the lack of control felt by teachers when working with the administration.

Environment. The least frequently mentioned demand was from problems associated with the classroom environment (e.g., overcrowded classrooms, lack of supplies, etc.), reported by only $6 \%$ of the teachers in the current study. Interestingly, although problems associated with the classroom environment are often studied, they are rarely cited as a source of major stress for teachers. Indeed, of all the studies that reported the rankings of stress for teachers, only one listed environment as a stressor, and that was only ranked as high as $10^{\text {th }}$ (Zurlo, et al., 2007). It was suggested previously in this thesis that the classroom environment may contribute to more stressful events later, such as a teacher experiencing a shortage of equipment might, as a result, face an increase in disruptive student behavior. In turn, when asked to describe a stressful event, the teacher may describe an event involving a student, when the underlying cause of the stress was actually due to factors relating to the classroom environment. This perception may help to explain why the classroom environment is often studied but rarely reported as a major source of stress for teachers. 
Appraisals of the demands reported by teachers. In the current study, teachers most frequently reported that the demands they face led to extreme negative emotion (44\%), followed by negative emotion (42\%), and finally, no negative emotion (15\%). It makes intuitive sense that teachers would typically report that the demands they face led to either extreme or negative emotions because if they didn't, there would be no cause for stress. Indeed, of the three possible appraisals, only no negative emotion was mentioned significantly less often than could be expected by chance (the .33 expected outcome), indicating that teachers typically associate the demands placed on them with negative feelings. This, of course, is of no great surprise given that the teachers were asked to talk about a stressful situation and if they had no negative emotions they would not be very likely to find the event stressful.

In comparing these findings to the larger literatures on teacher stress and coping, it is important to note that in this work "appraisals" refer not only to negative emotions, but also to perceptions about the nature and controllability of the demand. Typically, appraisal is viewed as coming in two phases, primary and secondary. According to Lazarus \& Folkman (1987), initial appraisal is when an individual assesses the demand as a harm, threat, or challenge, while secondary appraisal is when the individual assesses his or her ability to cope with the demand. However, because the current study measured appraisal in terms of emotional arousal experienced by the teacher (i.e., no negative emotion, negative emotion, and extreme negative emotion), it is difficult to compare it with the previous literature. Moreover, although appraisals are a common target in research on stress and coping more generally, in the work focusing specifically on 
teachers, none of the studies examined in the literature review investigated teachers' appraisals and their relationship to the stress and coping process.

Ways of coping reported by teachers. In the teacher stress and coping literature, the most commonly investigated and commonly used way of coping was problemfocused coping, which was utilized in 19 of the studies. Similarly, problem-focused coping was the most commonly reported way of coping in the current study; reported to be used by $65 \%$ of the teachers. As stated earlier, problem-focused coping is typically associated with positive outcomes for teachers (e.g., Chan, 1998; Litt \& Turk, 1985), therefore, it seems to be good news that it is the most commonly used way of coping by teachers in the current study. Indeed, problem-focused coping is typically described as tackling the problem directly. Because the teachers in the current study were more likely to address the problems associated with the demands in this way, there may be greater potential of solving the problem and reducing or eliminating the stress associated with it.

Support Seeking. The next most frequently reported way of coping utilized by teachers in the current study was support seeking, mentioned by $35 \%$ of the teachers. In the teacher stress and coping literature, support seeking is often cited as a frequently used method of coping and is typically associated with positive outcomes for teachers (Freeman, 1987; Shen, 2009). Therefore, the fact that the top two ways of coping by teachers in the current study (i.e., problem-focused and support-seeking) are typically associated with positive outcomes seems to indicate that teachers are, in general, good at coping with the stress associated with their occupation. Indeed, of all the ways of coping mentioned by teachers in the current study, only problem-focused coping and supportseeking were mentioned significantly more often than could be expected by chance. 
Interestingly, of the five least reported ways of coping by teachers in the current study, all but one (information seeking) are typically associated with bad news. Moreover, escape and social isolation, typically referred to as "avoidant coping" and associated with negative outcomes for teachers (Chan, 1998; Green \& Ross, 1996), were not mentioned by a single teacher in the current study, adding further support to the contention that teachers are generally good at coping with stress. However, it is also possible that these two methods of coping are not really an option for teachers. Typically, teachers are responsible for supervising their students at all times. Therefore, they are offered no respite because they cannot simply leave the classroom or isolate themselves whenever they feel stressed.

It is interesting to note that of all the ways of coping reported by teachers in the current study, only delegation was reported significantly less often than could be expected by chance. This finding seems to indicate that teachers typically take responsibility for the problems associated with teaching as they are not likely to place the blame elsewhere. Once again, because the most frequently reported stressors tend to be students, teachers may feel they have more control over much of the stress they face and are less likely to delegate the responsibility to others.

Coping in relation to demands. None of the studies investigated in the literature review on teacher stress and coping examined the relationship between teacher coping and the demands they face. Therefore, a comparison of the findings is not possible. However, it is interesting to note that of the four ways of coping that were found to have a relation to the demands construct, the two that typically are associated with good news (i.e., self regulation and support seeking) were in relation to interactions with people (i.e., 
parents and administration), whereas the two that are typically associated with bad news (i.e., opposition and helplessness) were in relation to non-living entities (i.e., environment and workload). It may be that teachers feel they have no control over stressful aspects such as where they work and how much work is imposed on them and, therefore, tend to face the demand with opposition or simply give up all together. In contrast, when the stress stems from another person, the teacher may feel that something can be done to remedy the situation and, therefore, take positive action, such as attempt to regulate their emotions and/or seek help from others.

Specifically, with regards to coping through self-regulation, findings indicated a positive relation to the demand from parents. It could be that teachers feel there is no way to cope with the situation at hand other than to regulate their emotions while talking to the parent (e.g., in a parent-teacher conference). In addition, the results indicated that support seeking was more likely when the demand placed on them was from the administration. It could be that teachers find it difficult to deal with their supervisors directly, and are therefore more likely to seek support from others. Further, opposition was found to be more likely when the demand placed on the teacher was from the environment. Teachers are typically not given any choice as to how big their room will be, how many students they will have, how many supplies they will have at their disposal, etc. It may be that this lack of control causes teachers to feel resistance toward the obstacle and choose opposition as a way of dealing with it. Finally, the findings indicated that helplessness was more likely when the demand stemmed workload. Intuitively, this makes sense given that when the amount of work exceeds an individual's 
capacity to complete it, and he or she has no power to reduce the workload, then he or she may be left with few options other than to just give up.

Surprisingly, although students were found to be the most frequently reported demand by teachers, there was no association found between this demand variable and the ways teachers reported coping with it. It may be that because there is such a wide range of student related stressors, the association between the student demand and the way teachers chose to cope with it was not captured. For example, a teacher might report that a student is stressful because of learning difficulties, or the teacher may report the student to be stressful because of disruptive behavior. It may be that the teacher would choose a different method of coping with these differing demands. However, because all problems with students were placed in the same category of demands, this difference would not be captured. Therefore, further research is warranted.

Resolutions of the stressful episodes reported by teachers. None of the studies reviewed in the teacher stress and coping literature investigated the outcomes of coping by teachers. Therefore, it is not possible to compare the results with those from other studies. In the current study, one of the objectives was to determine whether or not the teachers were successful in dealing with the demands they faced. To meet this objective, the teachers' responses to the question "How did it turn out?" were analyzed. The findings indicated that $51 \%$ of teachers reported the outcome to be successful, $40 \%$ reported the outcome to be unsuccessful, whereas, only $9 \%$ of the teachers reported that the episode was still in the process of being resolved.

It is not surprising that only half of the coping episodes were reported to be successful given that teachers were asked to discuss a stressful episode. If the teachers 
were successful, the episode would most likely not be considered to be very stressful. In spite of this, teachers reported to be successful significantly more often than could be expected by chance ( $1 / 3$ or .33$)$. This finding seems to add support to the suggestion that teachers are generally effective at coping with the stress they face. However, because $9 \%$ of the episodes were reported to be unresolved, there is no way to tell which direction the outcome of those episodes ended up going (i.e., successful or unsuccessful).

Resolutions in relation to coping. Another objective of the current study was to examine whether the ways teachers cope result in different resolutions of the stressful events. Results indicated that teachers who reported using self-regulation as a way of coping with stress were more likely to report the outcome to be successful. Teachers must often employ self-regulation given that they work with young students who are typically less mature than they are. Because of this lack of maturity, students can act in ways that can be very frustrating for those who are responsible for supervising them. In addition, teachers often have challenging interactions with the administration, colleagues, and parents. All of these interactions carry the potential to arouse powerful negative emotions that must then be regulated to avoid increasing the tension between the teacher and his or her interaction partner. It may be that the use of self-regulation is associated with successful outcomes because it allows the teacher to continue to engage with others without exacerbating the situation.

Helplessness related to unsuccessful resolutions. Another way of coping that was related to the outcome was helplessness. Not surprisingly, teachers who reported using helplessness as a way of coping were more likely to report having an unsuccessful resolution. Certainly this makes intuitive sense given that individuals who feel helpless to 
do anything about their situation are not likely to take the necessary action that might resolve it, simply because they generally have no idea what to do. Indeed, this is why they feel helpless in the first place.

Maladaptive coping related to unsuccessful resolution. As an additional analysis, the 12 ways of coping were combined to form two groups, namely, adaptive (i.e., problem solving, support seeking, self-regulation, cognitive accommodation, negotiation, and information seeking) and maladaptive (i.e., opposition, helplessness, rigid cognition, delegation, escape, and social isolation). Interestingly, teachers who reported the use of more maladaptive ways of coping were more likely to report having an unsuccessful resolution. Given that coping is viewed as one of the most important aspects of reducing stress caused by the demands placed on teachers (Cooper, Dewe, \& Driscoll, 2001), it seems imperative for teachers to use adaptive ways to cope with stress to increase the likelihood of having successful resolutions to the coping episodes. For example, problemfocused coping has been shown to alleviate psychological distress (Chan, 1998), and teachers report it to be the most effective coping strategy (Litt \& Turk). Because of this, problem-focused coping is typically viewed as an adaptive way of coping with stress. Teachers who learn to cope adaptively with the stress they encounter may be more likely to reduce the negative feelings associated with it and have an increased likelihood of having a successful resolution in the coping episode.

Post-coping assessment of the coping episodes. Post-coping assessment was not investigated by any of the studies reviewed in the teacher stress and coping literature, therefore, the findings of this study cannot be compared to findings in other studies. However, how teachers assess their coping episodes and incorporate their experience into 
learning can be an important aspect of understanding the coping process. In the current study, the most commonly reported teacher assessment was "yes effective" (54\%), indicating that most of the teachers would try an effective strategy in future coping episodes. This finding is not all that surprising given that the teachers are asked to talk about events that are stressful to them and they most likely had difficulty resolving these issues. Therefore, it makes intuitive sense that teachers would be motivated to try something more effective in the future. Having motivation to learn from stressful events is an important factor that might increase the likelihood of success of future interventions designed to improve teachers' coping strategies.

The next most frequently reported teacher assessment was "no unfavorable" (19\%). This finding is somewhat surprising given that, even though the outcome was unfavorable, these teachers reported that they would not do anything differently. It may be that these teachers feel that they have tried everything there is to try and have given up trying new strategies. Alternatively, it may be that these teachers feel they are not to blame for the circumstances and therefore, they feel no need to do anything different. It appears that these teachers may benefit from interventions aimed at increasing awareness of effective coping strategies and building a reservoir of coping resources. Indeed, according to Betoret (2006), teachers who have more access to coping resources reported less burnout than those who have less access to such resources.

The next most frequently mentioned teacher assessment was "no favorable" (15\%), indicating that these teachers would not do anything differently because the outcome was favorable. This finding is not surprising given that there would be no reason to think of other strategies if the chosen method proves successful. Indeed, teachers who 
reported having a successful resolution were significantly more likely to report that they would not do anything differently because the outcome was favorable.

The final teacher assessment "yes ineffective" was only reported by $12 \%$ of the teachers, indicating that a small percentage of teachers said they would try something different but their strategy was viewed as ineffective (i.e., wishful thinking). It may be that these teachers felt overly frustrated about the coping episode and its outcome and therefore, came up with unrealistic ways of handling it differently (e.g. "If I had a magic wand I would...”). Like the teachers who reported that they would not do anything differently even though the outcome was unfavorable, these teachers might benefit from learning new coping strategies for future stressful encounters.

Ways of coping not related to teacher assessment. Interestingly, the only way of coping that was related to teacher assessment was delegation, which was related to "no unfavorable." Although it does make intuitive sense that teachers who are more likely to choose to delegate the responsibility elsewhere are also more likely to say they would not do anything differently even though the outcome was unfavorable, only two teachers reported the use of delegation, so the meaning of this finding is in question. It may be that teachers who reported that they would not do anything different did so because they felt as though they were not at fault. However, it may also be that the significance of the result is due largely because of the small sample of teachers in this group. Overall, it appears that the ways teachers cope with stress has little to do with how they assess the coping episode. 


\section{Levels of Teaching Experience and Its Relation to the Process of Coping}

A major aspect of this thesis was to investigate whether teachers with different levels of experience in teaching (i.e., early, middle, and late career teachers) differ in the process of coping (i.e., demands, appraisal, coping, resolution, and assessment). Previous research indicating that up to $46 \%$ of teachers leave the profession within the first 5 years of teaching (Jalongo \& Heider, 2006) suggests that learning how to cope with the demands of the profession may be particularly important for those who are just beginning their careers. To determine whether teachers differ in the coping process according to their level of experience, all of the constructs mentioned above were examined as a function of years of experience. A summary and discussion of the meanings of these findings are provided below.

It must be noted that few studies on teacher stress and coping looked at differences as a function of levels of experience. Therefore, no comparison with previous literature can be made. In addition, as noted in the section on the study's purpose, the findings below could be due to developmental changes that occur throughout the course of the teachers' careers, or they could be due to selection effects because those who are less effective at coping with the demands placed on teachers might be more likely to leave the profession early.

Differences in demands according to teachers' levels of experience. In the teacher stress and coping literature, as well as in the current study, students are often mentioned as a source of stress for teachers. For example, students were named the number one or number two source of stress in several studies (see Chan, 1998; Green \& Ross, 1996; Innes \& Kitto, 1989; and Griffith, et. al., 1999). Interestingly, in the current study, when 
it comes to group differences, late career teachers mentioned students significantly more often than the other groups (i.e., early and middle career teachers). It may be that late career teachers find students more stressful because they find the changing demographics of students harder to deal with, or older teachers may simply be more tired. However, given that teachers were asked to mention the first stressful experience that comes to mind, it could be that late career teachers mentioned students more often simply because they no longer find other demands as stressful. Indeed, late career teachers mentioned no negative emotion in association with the demands significantly more often than the other groups. In addition, late career teachers mentioned parents significantly less often than the other groups. However, it must be mentioned that this finding could stem from parents acting more respectful toward teachers with more experience. Still, these findings suggest that teachers may become more tolerant of the demands placed on them and become less emotionally reactive as a result. Alternatively, those teachers who are less tolerant may have already dropped out of the profession.

Although late career teachers seemed to be less emotionally reactive in the current study, other findings have indicated that younger teachers feel less emotionally exhausted than the older age group (Verhoeven, Kraaij, Joekes, \& Maes, 2003). It may be that older teachers are less emotionally reactive simply because they feel emotionally exhausted. Because the meaning of these findings is difficult to interpret, further investigation is warranted.

The only other group difference in demands found in the current study was that early career teachers mentioned the environment (e.g., lack of supplies, overcrowded classrooms, etc.) significantly less often than the other groups. This finding was different 
than expected given the assumption that early career teachers have less experience and therefore, would be more likely to experience difficulties from the environment in which they work. Ironically, it may be this lack of experience that prevents the younger teachers from feeling stress in relation to the environment simply because they do not realize how factors in the environment may be one cause of the problems they experience with students. Indeed, teachers with more years of experience are likely to have experienced many changes in their work environment over time and have much more to compare their current situation with than those with less experience.

In support of this idea, Beach and Pearson (1998) reported that teacher' references to conflicts and tensions from contextual and institutional demands increased throughout the pre-service year and into the first year of teaching. It could be that because inexperienced teachers are unaware of issues related to the classroom environment, they attribute the stress to other factors such as student behavior, when in reality, the disruptive behavior occurred as a result of something involving the classroom environment (e.g., seating arrangement, a delay in operating classroom equipment, etc.). Appraisals according to levels of experience. As mentioned earlier, because the studies in the teacher stress and coping literature viewed appraisals differently than that of the current study, making comparisons is difficult. In the current study, not only did early career teachers mention no negative emotion significantly less often and extreme negative emotion significantly more often than the other groups, late career teachers mentioned no negative emotion more often than the other groups. There appears to be a difference in the emotional reactivity of teachers with differing levels of experience. It 
could be that more experienced teachers become less emotionally reactive, or it could be that those who are more emotionally reactive leave the teaching profession early.

This finding is not surprising given that early career teachers typically have much less experience dealing with the demands faced in the profession. Therefore, younger teachers may be more likely to experience negative emotions in relation to those demands due to unfamiliarity. Interestingly, in one study that did investigate teacher stress and coping in relation to years of experience, Stoeber \& Rennert (2008) reported that they found no relation between years of experience and stress appraisal. However, because they measured appraisal in terms of challenge, threat, and loss, comparing the findings with the current study is not possible.

Teacher coping based on levels of experience. Very few studies in the teacher stress and coping literature investigated teacher coping as a function of years of experience. However, one study that did reported that older teachers use more meditation and deep breathing exercises than younger teachers (Seidman \& Zager, 1991). Interestingly, findings from the current study indicated that late career teachers used selfregulation less than the other groups. It may be that more experienced teachers do not feel the need to self-regulate during a coping episode, not only because they become less emotionally reactive as they gain experience in the teaching profession, but also because they choose methods of relaxation such as meditation and deep breathing exercises, which may mitigate the necessity to self-regulate during stressful encounters.

In addition to self-regulation, late career teachers were also found to use more cognitive accommodation. Interestingly, cognitive accommodation can be used as a method of self-regulation, adding further support to the suggestion that more experienced 
teachers are less emotionally reactive because they learn to utilize techniques that help them to reduce the negative emotions associated with stressful situations. For example, when having a stressful interaction with a student, the student may come across as being rude or disrespectful. As the teacher gains experience working with students, he or she is likely to encounter situations in which it becomes apparent that the student is actually having problems at home, triggering the inappropriate behavior originally assessed as “disrespectful." In turn, the teacher could then incorporate this knowledge into future interactions and use cognitive accommodation to reappraise the student's behavior as a cry for help rather than simply judge the student as being rude.

The only other way of coping that related to levels of experience was delegation (which included resolving self of responsibility, maladaptive help-seeking, self-pity, etc.), which was used significantly more often by middle career teachers than the other groups. This finding makes little intuitive sense as there seems to be no logical reason why teachers would not use this particular method of coping early in their career, begin to use it during the middle years, and then stop using it again later on. It must be noted, however, that only 2 teachers reported the use of delegation and both of these teachers were in the middle of their respective careers. Hence, this may not really reflect a robust finding. Therefore, further investigation may be warranted.

Resolutions based on levels of experience. As mentioned previously, none of the studies reviewed in the teacher stress and coping literature investigated the outcome of the stressful episodes experienced by teachers. In the current study, no differences were found between levels of experience and the teachers' reported resolutions to the stressful events. This finding seems to be counterintuitive as one would think that gaining 
experience in dealing with stressful events would provide the knowledge necessary to become more effective in resolving them. It may be that there is indeed no difference in how successful teachers are in dealing with stressful situations as they gain experience in the profession. However, it may also be that this particular notion was simply not captured by the methods incorporated in the current study. For example, teachers were asked to describe the first thing that comes to mind when thinking of a stressful event. It may be that all teachers, regardless of their level of experience, recalled events that were largely unsuccessful because otherwise, the event would not have been assessed as stressful in the first place. Indeed, only half of the reported resolutions were reported to be successful, whereas the other half were either reported as unsuccessful or had yet to be resolved. In addition, all of the teachers in the current study had at least three years of teaching experience, and the early career teacher group had a range of 3 to 8 years of experience. It may be that this group of teachers already had too much experience to capture group differences. Therefore, further investigation may be warranted.

Post-coping assessment based on levels of experience. Again, as mentioned previously, none of the studies reviewed in the teacher stress and coping literature investigated teacher assessment of stressful events. Therefore, no comparisons can be made between previous studies and the current one. In the current study, early career teachers reported that, when resolutions were unsuccessful, they would try an effective strategy in dealing with future stressful events significantly more often than did the other groups. This finding may suggest that younger teachers are more willing to search for solutions to the problems they face because they are more open and eager to learn and they have yet to try as many strategies. In contrast, late career teachers reported that, even 
when situations are not successfully resolved, they would try an effective strategy in the future significantly less often than did the other groups. It may be that older teachers are already doing everything that is possible. Alternatively, more experienced teachers may become more rigid as they grow older and gain experience because they feel as though they have tried everything so there is no need to try anything new.

Summary of how the coping process differs based on teachers' levels of experience. A key assumption in the current study was that more experienced teachers would be more effective in the coping process at each of the following steps: (1) They could perceive fewer demands, (2) experience fewer negative emotions, (3) use more adaptive coping, (4) have more successful resolutions, and (5) have more effective strategies for dealing with future coping episodes. Some of these assumptions were met while others were not. The findings relating to these assumptions will be summarized below.

Collectively, many of the assumptions were met with regards to levels of experience and its relation to the coping process. For example, early career teachers mentioned no negative emotion less and extreme negative emotion more than the other groups, while late career teachers mentioned no negative emotion more than the other groups. This finding suggests that teachers may become less emotionally reactive as they progress through their teaching careers. In addition, late career teachers mentioned students more and parents less than the other groups, suggesting that the perceived demands placed on teachers might change as they gain experience. Further, late career teachers used self-regulation less and cognitive accommodation more than the other groups, suggesting that teachers may become less emotionally reactive by learning 
effective strategies that help to maintain emotional balance. Alternatively, it could be that it is easier for more experienced teachers to deal with the emotions because they are not as strong.

In contrast to the above assumptions being met, there were a few surprises. For example, early career teachers mentioned the environment as a stressful demand significantly less often than the other groups, suggesting they may not have enough experience in teaching to be aware of the subtle effects of the classroom environment. In addition, there were no differences in teacher reported resolutions of the stressful episode based on levels of experience. It was suggested that this interaction might not have been captured by the method incorporated in this study and further investigation may be warranted.

\section{Limitations}

Although the design of the study does allow for many insights into teacher stress and coping, there were some limitations to the present investigation. This section summarizes limitations due to the sample, design, interview procedure, method, and coding system. Each of these limitations should be considered as to how they may have influenced the findings and how they should shape interpretations of the results.

Sample. Due to the size of the sample (i.e., $n=57$ ), the generalizability of the results may be limited. However, this is a rather large sample size for studies involving interviews as none of the studies reviewed in the teacher stress and coping literature that utilized interviews had more than 30 participants. In addition, the sample included over $90 \%$ female teachers, which is not representative of the entire population of teachers, and therefore the generalizability may be in question. However, teachers are comprised of a 
large percentage of females in general so the gender balance is not unreasonably skewed. Indeed, according to the National Center for Educational Statistics, 76 percent of all public school teachers were female during the 2007-2008 school year (NCES, 2011). Further, the sample consists of $65 \%$ elementary school teachers whose population is much closer to the gender distribution of the current study. Future studies on teacher stress and coping may want to actively recruit men to help increase the generalizability of the results.

The generalizability of the results is further complicated by a selection effect as the participants showed up for a stress reduction program voluntarily. Therefore, the participants are likely to be stressed but also well functioning, as those individuals who are not well functioning would most likely not show up for a treatment program. In addition, those who are the most stressed may not show up for intervention because they are not functioning well enough to seek help. Further, there may be a differential selection effect as the early career teachers who showed up for the intervention might all experience similar amounts of stress due to their lack of familiarity with the demands of the profession. In contrast, the late career teachers who showed up for the intervention may be less typical for their level of experience. They are more likely to be those who experience greater levels of stress because experienced teachers could be more aware of the demands placed on them, therefore, those who do not feel stressed would see no need for stress intervention.

Meaning of "years of experience." A major limitation in the study is the use of "years of teaching" as a proxy for experience. Differences in years of teaching are utilized as a means of explaining differences in patterns of coping behavior as a function 
of teaching experience. Unfortunately, however, the measure of years of experience is confounded with other factors that may be alternative explanations for differences in coping. First, it is confounded with age. Therefore, differences between groups may be based on differences in maturity or general wisdom accumulated with age, instead of teaching experience per se. Years of teaching was also confounded with cohort. For example, teachers' training may reflect the historical period in which they were in college, and these differences may be responsible for group differences in coping. Or, teachers may have started their careers before or after a major educational reform and the teachers' coping process might be influenced by this confound. A very important difference between groups are likely due to attrition, with more stressed out teachers leaving sooner, while the more stress resistant teachers remain. This would result in the group of more experienced teachers including more stress resistant teachers than does the group of less experienced teachers.

Design. Another limitation of the present study applied to the nature of the study itself. Because the current study was cross-sectional and correlational, the conclusions that were drawn might be limited. For example, there is no way to determine causality. It may be that differing demands lead to different methods of coping, or it may be that the way one chooses to cope leads to different demands. Therefore, it may be helpful to utilize a longitudinal design to better capture changes with experience over time. This suggestion will be expanded upon in the section on future studies.

Interview questions. Another limit of the study was the interview questions were designed for the purpose of the SMART-in-education program and were later integrated into the current study. Because of this design aspect, information pertinent to the current 
study was not always optimized. For example, the question, "How did it make you feel?" appeared after the question "What did you do?" (see Table 2 in appendix). Therefore, the teachers may have been describing how they felt about the stress or how they felt about their coping with the stress. However, as mentioned previously, appraisals are typically measured by asking individuals how they felt before coping with the stressful event. It may be more informative to use the label "emotional reactivity" rather than "appraisal" when attempting to capture how teachers felt during the stressful episode.

Another limit imposed by the nature of the interview questions was the restriction placed on a single coping episode. A key assumption of the current study was that the ways of coping would differ according to levels of experience. However, only one episode was investigated, and although teachers were allowed to mention several ways in which they coped with that episode, few differences were found in ways of coping as a function of levels of experience. It may be that more variance would be observed if teachers were asked to mention several of the most demanding issues they face and all the ways they use to cope with them. In this way, more of the strategies utilized to deal with stressful episodes might be captured.

Similarly, there was no difference found in the resolution of the coping episode as a function of levels of experience. However, because teachers were only asked to discuss the most stressful situations, it is possible that many of the teachers only mentioned the events that they deemed as unsuccessful. It may be that if teachers were asked to discuss both successful and unsuccessful coping episodes, more differences between levels of experience and outcomes of the stressful events could be captured. Because of the limits imposed by attempting to integrate interview questions designed for a different purpose, 
it is recommended that any future study pertaining to teacher stress and coping design the interview questions for the specific purpose of the study itself.

Method. Although there are numerous beneficial aspects of open-ended interviews, the downside is a lack of consistency and comparability. In the current study, several different graduate students conducted the interviews and the questioning was, at times, inconsistent. For example, there were times when some of the questions were worded differently or not asked at all. Further, some of the interviewers asked several follow-up questions in an attempt to tease out more detailed information from the participants, while other interviewers basically stuck to the script. This makes it more difficult to compare results across teachers. It might be more informative to ask every participant every question by simply reading from the script. In this way, consistency could be gained making the teachers answers more comparable.

Coding system. Another potential limitation to the study regards the coding systems used while analyzing the results. The coding systems were created for the purpose of this study and have not been tested in other research investigations. It may be useful to incorporate the coding system into future studies on stress and coping to determine its validity.

\section{Implications of the Findings}

Although the aspects described above did impose some limits on the interpretations of the results, much insight has been gained into the process of coping and its relation to levels of teaching experience. This new understanding will be summarized in the paragraphs below. 
Why teaching is so stressful. As mentioned earlier, findings in the current study of what teachers find stressful corresponded to those in the larger body of research on teacher stress and coping. For example, similar to previous research, teachers in the current study mentioned students, workload, parents, colleagues, administration, and environment as the most frequent sources of stress. However, none of the studies reviewed here investigated demands in relation to the entire coping process. Therefore, little is known about why teaching is perceived as being so stressful.

In the current study, findings indicated that $86 \%$ of the teachers attached either negative or extreme negative emotions to the demands faced. In particular, teachers were more likely to attach these negative emotions to stress brought on by parents, administration, and workload. In addition, the teachers perceived nearly fifty percent of the resolutions as being unsuccessful or unresolved, and almost twenty percent of the teachers reported that they would not do anything differently, even though the outcome of the coping episode was unfavorable. Finally, teachers who reported workload as a major source of stress were also more likely to report helplessness as a coping strategy, and helplessness was found to be associated with an unsuccessful resolution. Together, these results suggest that teaching may be perceived as highly stressful because the demands elicit strong negative reactions and teachers are not quite sure what to do about them, leading to a high percentage of unsuccessful coping episodes. Therefore, teachers may benefit from being made aware of the potential sources of stress and the role that negative emotions play in their ability to cope with it.

How teacher coping may contribute to stress. Previously it was suggested that teachers are typically good at coping with stress. This was due, in part, to the finding that 
the three most frequently reported ways of coping were all adaptive (i.e., problem solving $=65 \%$, support seeking $=35 \%$, and self-regulation $=22 \%$ ). However, due to the nature of the stress and the strong emotional reactions associated with it, coping with stress in the teaching profession is a challenging endeavor for many. In the current study, results indicated that the adaptive coping strategy of self-regulation was related to the stress elicited by parents. It could be that this demand is perceived by teachers to be uncontrollable, and the only way to deal with it is to regulate their emotions. For example, teachers typically meet with parents only when there is a problem associated with the parent's child, and both the parent and the teacher may be experiencing powerful emotions while interacting with one another. In turn, the teacher is forced to regulate his or her emotions throughout the stressful episode.

Self-regulation is typically viewed as an adaptive coping strategy and in the current study it was found to be associated with having a successful resolution. However, continually keeping one's emotions in check can be taxing to the individual, leading to an elevation in the level of stress and increasing the negative feelings associated with the stressful episode. Indeed, human service professions such as teaching are said to require much emotion regulation due to the social interactions involved (Schutz \& Zembylas, 2009). Therefore, although self-regulation may be an effective way of dealing with a stressful encounter and lead to a successful resolution, if the individual does not deal with the pent-up emotions, it may actually contribute to the stress experienced by the teacher.

Similarly, support seeking is typically viewed as an adaptive way of coping with stress and thirty-five percent of the teachers in the current study reported using support seeking to deal with the demands placed on them in teaching. In addition, support seeking 
was found to be associated with the demands brought on by the administration. However, unlike self-regulation, the use of support seeking by teachers was not found to be associated with a successful resolution. It is possible that, like the demands brought on by parents, teachers view the demands placed on them by the administration to be uncontrollable. Indeed, typically teachers have little say in expectations mandated by the administration (e.g., testing requirements, class size, room assignment, etc.). In order to deal with the stress brought on by the administration, teachers may turn to others for support. In so doing, they may rant about their frustrations with the administration. It is possible that many of these teachers find colleagues who support their view, thereby reinforcing their negative feelings about the administration. Indeed, in the current study, demands brought on by the administration were found to be associated with negative emotions. If teachers turn to colleagues as a means of validating their negative feelings rather than finding a solution to the problem, then support seeking may lose much of its adaptive quality.

In contrast to the stress brought on by parents and the administration, demands from the environment and the workload were typically dealt with by the maladaptive coping strategies of opposition and helplessness, and the use of more maladaptive ways of coping was found to be associated with having an unsuccessful resolution to the coping episode. It may be that the teachers perceive these demands as being uncontrollable, much like the demands from parents and administration. Indeed, teachers may have very little control over the classroom in which they teach, what supplies are provided, and how much work is handed down to them. If the teachers feel that these demands are beyond their control, they may believe that the only way to deal with them 
is to place the blame elsewhere or simply give up. By gaining a better understanding of how to select and employ more effective methods of coping with the demands faced in their profession, teachers might acquire the necessary coping resources that allow them to increase the success they have in dealing with those demands.

Why teachers may not learn from the coping episodes. In the current study, results indicated that $32 \%$ of the teachers reported that they would either do nothing differently in future coping episodes even though the outcome was unfavorable, or they suggested a strategy assessed by coders as ineffective (e.g., wishful thinking). It may be that, due to the perceived uncontrollability of many of the demands placed on them (such as those described above), many teachers feel incapable of doing anything about it, and therefore, fail to learn from the coping episode. Because many teachers are not learning from their experience in coping with stress, they may benefit from intervention programs designed with the intention of getting them to re-consider their appraisals of the demands faced and help them cope more effectively in future stressful situations.

How levels of experience relate to the coping process. In the current study, results indicated that late career teachers mentioned students more often and parents less often than the other groups, whereas early career teachers mentioned environment less often than the other groups. It may be that late career teachers are more familiar with the subtle influence the environment has on student behavior and take the necessary steps to prevent problems from arising. For example, an experienced teacher might recognize the importance of checking media equipment before class to insure it is working properly to prevent a disruption in the daily lesson, thereby reducing the likelihood of student misbehavior. In turn, the negative feelings associated with the demands placed on them 
might be reduced. Indeed, early career teachers reported that they experienced extreme negative emotions more and no negative emotions less than the other groups, whereas late career teachers mentioned no negative emotions more often than the other groups.

It is possible that by gaining a better understanding of how the perceptions and appraisals of demands change through the course of the teaching career, those interested in creating intervention programs for teachers to help them deal with stress brought on by their job will be better able to tailor the program accordingly. In turn, early career teachers might benefit from learning how to process negative emotions associated with the demands placed on them, affording them the opportunity to remain in the profession long enough to determine whether it is a good fit for both them and the schools where they are employed. In addition, all teachers might be able to gain clarity about which demands are the most challenging for them individually. In turn, they might be more prepared to deal with these challenges when they do arise.

It is important to mention that, despite the finding that late career teachers mentioned no negative emotion more than other teachers, they may actually be referring to more serious demands than their younger colleagues because, as mentioned above, they may be preventing many (and possibly more serious) problems from developing by taking proactive steps. Indeed, it is possible that late career teachers use self-regulation less often than other teachers because preventing serious problems from occurring in the first place reduces the need to self-regulate. In addition, results indicated that late career teachers used cognitive accommodation more than the other groups; perhaps further reducing their need to self-regulate during stressful encounters. These findings suggest that younger teachers might benefit from not only learning how to prevent problems from 
occurring, but also by discovering techniques of employing cognitive accommodation as a way of coping with stress when problems do occur.

How learning from stressful episodes relates to levels of experience. In the current study, findings indicate that there may be an important difference in how teachers incorporate learning from stressful episodes. For example, it was found that early career teachers reported that they would try an effective strategy when dealing with a future stressful episode more often than the other groups. In contrast, late career teachers reported that they would try an effective strategy less often than the other groups.

These findings suggest that both groups of teachers might benefit from interventions designed to increase awareness of alternative strategies to deal with stressful situations, although for different reasons. For example, early career teachers may be more open to suggestions and be willing to try new strategies because they are new to the profession and feel they still have much to learn. In addition, early career teachers may be more open to try different strategies because they are full of enthusiasm and eager to begin their educational career. Further, younger teachers may be more hopeful that they can make a difference in the lives of their students and be willing to try new strategies in order to do so. In contrast, late career teachers might be less willing to try new strategies because they feel that they have tried everything already and have experienced many impediments along the way. While early career teachers might benefit from learning strategies to reduce their emotional reactivity from their more experienced colleagues, late career teachers might regain some lost enthusiasm by working with early career teachers and observing their optimism. 


\section{Future Studies on the Development of Teachers' Coping}

Although much understanding has been attained from information provided by the current study, there is still more to gain through future research. By focusing on the process of coping in the short term, and looking at changes in coping based on levels of experience in the long term, more insight can be gained into the developmental process of coping as a whole. Suggestions for addressing these issues are provided in the paragraphs below.

Coping as a process. An important direction for future research is to elaborate the processes of coping studied here: including both personal and social factors (see Figure 3.1). Research has indicated that differences in personality traits might explain variances in coping behavior (Admiraal et al, 2000). For example, teacher appraisals may be influenced by personality traits. In order to capture appraisals, it might be informative to ask the teachers how they felt about the specific demand itself (primary appraisal), and how they feel about their ability to cope with it (secondary appraisal) so that more of the process of coping can be captured. Similarly, social support received by the teacher may play a part in his or her ability to cope with the demands in teaching. Such information may help explain some of the differences in the teachers' chosen method of coping, as well as the different outcomes (e.g., teacher engagement, teacher burnout) associated with the use of that particular strategy. Future researchers should consider these and other factors when designing studies on teacher stress and coping.

Focus on teacher learning. Future studies could focus more explicitly on how teachers learn by dealing with stressful events. Moreover, in order to better capture teacher learning, teachers could be asked to discuss a stressful episode that occurred over 
the course of days or weeks rather than something that occurred in a single day. For example, teachers could be asked to discuss an event in which they learned something that they could then be incorporated into future stressful experiences. They could be asked to discuss how they felt about the stressor, what they did about it, how they felt about their coping strategy, what was the outcome of coping, what they learned, and how they used what was learned later in another stressful situation. Teachers could also be asked how this coping episode might have influenced them the next time they were in the classroom. In turn, clarity could be gained into the entire coping process, including teacher assessment of the stressful episode.

Time series studies. In order to better capture the entire coping process, future research could utilize a time series study in which the teachers are asked to keep a daily journal of a particularly difficult demand (e.g., a single disruptive student) over a course of an extended period of time (e.g., a month or semester). In so doing, a better understanding of the developmental process of coping by teachers might be gained. For example, teachers could be asked whether this demand seemed to cause problems in other areas, which could provide clarity as to whether teachers go from reactive to proactive coping over a period of time.

Observational studies and objective demands. In addition to interview studies, future research could utilize observational data. This would allow teachers to be observed in their natural settings, affording the researcher the opportunity to compare what the teacher reports about his or her experience with what is actually observed in the classroom. In turn, the researchers might be better able to capture the most accurate 
information of what is taking place in the classroom. This could help to add clarity to the process of developing coping strategies by teachers.

Observational studies would also be useful in adding information about the objective demands that teachers actually face. In the teacher stress and coping literature, little is said about the objective demands (e.g., class size, classroom arrangement, media equipment, etc.) and how they might influence other demands in teaching. One example of an observational study could be to observe the objective demands faced by teachers and compare this with the objective demands reported by the teachers. As mentioned earlier, it could be that teachers are having difficulty with student disruptions because of the design of the classroom or the number of students placed in groups. It is possible that many teachers are not aware of how these types of demands influence student behavior because they just accept them as part of the reality of teaching. However, if these types of demands were brought to the surface of teacher awareness, educators may be able to reduce the effect they have on other challenging aspects of teaching such as student misbehavior.

Changes in the coping process based on levels of experience. Because the current study was cross-sectional and correlational, deciphering the meaning of differences based on levels of experience is tenuous. To better capture this difference, future studies could be conducted longitudinally. In this way, it might be possible to examine the development of coping strategies by individual teachers. For example, the same group of teachers could be interviewed at different stages of their careers. Results from these interviews could then be analyzed to determine changes in coping strategies as the individual teachers progress through their respective careers. In addition, a cohort 
sequential design might be utilized in order to more fully capture the coping process while, at the same time, reduce the cost and number of years required for typical longitudinal studies.

Retrospective study. Another way to capture changes in the coping process based on levels of experience might be to ask teachers about the different steps in the coping process and whether their coping now differs from that early in their careers. For example, clarity might be gained as to how teachers' emotional reactions change as a result of years of teaching experience. Similarly, teachers could be asked to reflect on whether other aspects of the coping process has changed over the years, such as what they find stressful, how they cope, and whether they feel more or less successful in dealing with stressful situations. In turn, insight might be gained in how the process of coping has changed by looking at each step.

How master teachers cope with stress. One assumption guiding the present study is that teachers who had more experience teaching were "better" in some ways than less experienced teachers. However, future studies could look directly at how "better" teachers cope by focusing explicitly on master teachers. Master teachers could be selected and studied to gain insight into how the most skilled teachers cope with stress. For example, Howard and Johnson (2004) interviewed ten teachers who were identified as "resilient" by their administrators. The teachers were asked questions such as, what are some day-to-day stressors, how do you handle them, and what are your main sources of support? Future studies could be conducted in which master teachers (selected by their peers or administrators) are interviewed to determine how their coping has changed over the course of their careers. In turn, clarity might be gained as to how effective teachers 
change how they cope with stress over time and provide a more complete picture of the developmental process of coping through the different stages of the teaching career.

\section{Applications to Improving Teacher Coping}

As can be seen by the information provided above, much has been learned about teacher stress and coping. In order to make use of this increased understanding, intervention programs designed with the purpose of helping teachers become more effective at coping with the demands faced in the profession need to be developed. In addition, steps can be taken to help reduce some of the demands faced by teachers. Suggestions for such intervention plans will be described in the paragraphs below.

Teaching proactive coping. It was suggested above that teachers might benefit by being made more aware of the sources of stress so they can take the necessary action to cope with it. One intervention program that might help teachers to become more effective at coping with stress could be to teach proactive coping. Proactive coping is the act of taking preemptive steps in a potentially stressful situation to reduce its effect or prevent it from taking form (Aspinwall \& Taylor, 1997). For example, teachers who are made aware of the influence the environment plays on disruptive student behavior could take steps to prevent it, such as arranging the seats to separate students who might distract one another. In turn, the stress caused by the classroom environment (and possibly attributed to other factors) might be reduced or eliminated altogether. In addition, teachers could be taught how to utilize post-coping assessment as a means of reflecting on and improving their ability to cope with future stressful episodes. In turn, teachers might become better at proactive coping by learning from past experiences. 
Mindfulness training for teachers. Results of the current study indicate that teachers typically attach negative emotions to the stress faced in their profession. In particular, early career teachers were more likely to report experiencing extreme negative emotions than the other groups. One intervention program that might help teachers recognize and process these emotions comes through mindfulness training. Mindfulness has been described as a process of bringing a given quality of attention to present moment experience (Kabat-Zinn, 1990). According to Bishop and colleagues (2004), contemporary psychology has incorporated mindfulness to use as a technique to increase awareness and effectively respond to the mental processes that lead to emotional unrest and maladaptive coping behavior. With this in mind, mindfulness training has the potential to help teachers at each step of the coping process. For example, teachers might become more aware of the emotions that arise from stressful episodes and act independently of them. In turn, teachers might be able to select effective ways of dealing with the event rather than allowing their emotions to cloud their judgment and exacerbate an already volatile situation (Skinner \& Beers, in press).

School-based interventions to reduce stress. One way for school leadership to help reduce the stress experienced by teachers is to attempt to reduce the demands experienced by teachers in the first place. For example, often times early career teachers are placed in schools that have difficulty attracting the more experienced (and perhaps more skilled) teachers, such as those in low socio-economic areas. By so doing, school districts are putting these young teachers at risk to experience high amounts of stress that they are ill equipped to handle. Instead, school district leadership could ensure there is a balance of experienced teachers in all schools so that teachers are more prepared to 
handle the pressures faced, and students are served by the teachers who are the most prepared to teach them.

Another way for school leaders to help reduce the stress experienced by teachers is to change the lay out of the building. As described earlier, one adaptive coping method that has been utilized by a high percentage of teachers is the use of social support. In order to fully capitalize on this beneficial approach, schools can be arranged in ways that are conducive to teachers coming in contact with one another more often. For example, common prep rooms can be incorporated so that teachers find themselves in the company of their colleagues on a daily basis. In turn, teachers could have a place to turn when dealing with stressful situations.

Mentoring pre-service and early career teachers. It was suggested previously that early career teachers might benefit from learning how to use effective strategies for coping with stress such as cognitive accommodation. Further, results of the current study indicate that late career teachers use this strategy more often. In addition, late career teachers experience extreme negative emotions less often than their younger colleagues. Therefore, pre-service and early career teachers might benefit from being assigned a mentor teacher who could then be available to give advice on effective ways of dealing with stress. Having a more experienced teacher available as a resource for young teachers might provide the necessary support that helps to reduce the beginning teacher's stress and help them to become more effective teachers earlier in their career. In addition, late career teachers might benefit from their younger colleagues by witnessing some of their more optimistic views of teaching. 
Teaching adaptive ways of coping with stress in education. It was suggested earlier that many teachers might benefit by learning more adaptive ways of coping with the stress they face in the teaching profession. It is possible that courses could be designed with the purpose of informing teachers at all levels about the types of stressors they may face and how they can successfully deal with them. By learning more adaptive ways of coping (e.g., cognitive accommodation, problem solving, information seeking, etc.) teachers might gain the necessary resources that allow them to be more successful in resolving stressful episodes when they arise. In addition, courses such as these could be incorporated into teacher preparation programs so that beginning teachers are better prepared to deal with the demands they may encounter.

In sum, there is much to be gained by investigating the process in which teachers acquire coping strategies necessary to effectively deal with the many demands placed upon them in the teaching profession. Gaining a better understanding of the development of the coping process by teachers might help to create intervention programs designed to train teachers to manage stress early in their career. In addition, the information gained from this study might help add clarity to the selection process when determining which candidates are likely to have success in the teaching profession and which candidates might be better suited for another line of work. In turn, the teachers who are selected and trained might be more enthusiastic about and engaged in teaching, increasing their ability to help students reach their full potential. 


\section{References}

Admiraal, W. F., Korthagen, F. A., \& Wubbels, T. (2000). Effects of student teachers' coping behaviour. British Journal of Educational Psychology, 70, 33-52.

Admiraal, W. F., Wubbels, T., \& Korthagen, F. A. (1996). Student teacher behaviour in response to daily hassles in the classroom. Social Psychology of Education, 1, 25-46.

Aspinwall, L. G., \& Taylor, S. E. (1997). A stitch in time: Self-regulation and proactive coping. Psychological Bulletin, 121, 417 -436.

Beach, R., \& Pearson, D. (1998). Changes in preservice teachers' perceptions of conflicts and tensions. Teaching and Teacher Education, 14, 337-351.

Bergers, G., Marcelissen, F. \& de Wolff, C. (1986). Questionnaire of organizational stress, QOS-D Manual. 86 AO. 3rd Edn, University of Nijmegen, Nijmegen, the Netherlands.

Betoret, F.D. (2006). Stressors, self-efficacy, coping resources, and burnout among secondary school teachers in Spain. Educational Psychology, 26, 519-539.

Bishop, S.R., Lau, M., Shapiro, S., Carlson, L., Anderson, N., Carmody, J., Segal, Z., Abbey, S., Speca, M., Velting, D., \& Devins, G. (2004). Mindfulness: A proposed operational definition. Clinical Psychology: Science and Practice, 11, 230-241.

Blasé, J. J. (1986). A qualitative analysis of sources of teacher stress: Consequences for performance. American Educational Research Journal, 23, 13-40.

Borg, M. G. (1990). Occupational stress in British educational settings: A review. Educational Psychology, 10, 103-126.

Burke, R. J., \& Greenglass, E. R. (1995). Job stressors, type A behavior, coping 
responses, and psychological burnout among teachers. International Journal of Stress Management, 2, 45-57.

Carmona, C., Buunk, A. P., Peiró, J. M., Rodríguez, I., \& Bravo, M. J. (2006). Do social comparison and coping styles play a role in the development of burnout? Crosssectional and longitudinal findings. Journal of Occupational and Organizational Psychology, 79, 85-99.

Carver, C.S., Sheier, M.F., \& Weintraub, J.K. (1989). Assessing coping strategies: a theoretically based approach. Journal of Personality and Social Psychology, 56, $267-$ 283.

Chan, D.W. (1998). Stress coping strategies, and psychological distress among secondary school teachers in Hong Kong. American Educational Research Journal, 35, $145-$ 163.

Chan, D. W. (1994). The Chinese ways of coping questionnaire: Assessing coping in secondary school teachers and students in Hong Kong. Psychological Assessment, 6, 108-116.

Cox, T., Mackay, C.J., Cox, S., Watts, C., \& Brockley, T. (1978). Stress and well-being in schoolteachers. Paper presented to the Ergonomics Society Conference on Psychophysiological Response to Occupational Stress, Nottingham University, Nottingham, England.

Cooper, C.L., Dewe, P., \& Driscoll, M.P. (2001). Organizational Stress: A Review and Critique of Theory, Research, and Applications. Foundations for Organizational Science, Sage Pulications, Thousand Oaks, CA.

Dick, R., \& Wagner, U. (2001). Stress and strain in teaching: A structural equation 
approach. British Journal of Educational Psychology, 71, 243-259.

Endler, N.S. and Parker, J.D.A. (1990). Coping Inventory for Stressful Situations (CISS): Manual. Multi-Health System, Toronto.

Farell, D. (1983). Exit, voice, loyalty, and neglect as responses to job satisfaction: A multidimensional scaling study. Academy of Management Journal, 26, 596-607.

Fimian, M.G., \& Fastenau, P.S. (1990). The validity and reliability of the teacher stress inventory: A re-analysis of aggregate data. Journal of Organizational Behavior, 11, $151-157$.

Folkman, S., \& Lazarus, R. S. (1988). Manual for the Ways of Coping Questionnaire. Palo Alto: Consulting Psychologists Press.

Green, S. B., \& Ross, M.E. (1996). A theory-based measure of coping strategies used by teachers: The problems in teaching scale. Teaching \& Teacher Education, 12, 315325.

Greenglass, E.R., Burke, R.J., \& Konarski, R. (1998). Components of burnout, resources, and gender-related differences. Journal of Applied Social Psychology, 28, 1088-1106.

Griffith, J., Steptoe, A., \& Cropley, M. (1999). An investigation of coping strategies associated with job stress in teachers. British Journal of Educational Psychology, 69, $517-531$.

Griva, K., \& Joekes, K. (2003). UK teachers under stress: Can we predict wellness on the basis of characteristics of the teaching job? Psychology and Health, 18, 457-471.

Innes, J.M., \& Kitto, S. (1989). Neuroticism, self-consciousness and coping strategies, and occupational stress in high school teachers. Personal and Individual Differences, 10, 303-312. 
Howard, S., \& Johnson, B. (2004). Resilient teachers: Resisting stress and burnout. Social Psychology of Education, 7, 399-420.

Huberman, M.A. (1993) The Lives of Teachers. New York: Teachers College Press.

Hui, E. K. P., \& Chan, D. W. (1996). Teacher stress and guidance work in Hong Kong secondary school teachers. British Journal of Guidance and Counseling, 24, 199-211.

Jalongo, M. R., \& Heider, K. (2006). Editorial teacher attrition: an issue of national concern. Early Childhood Education Journal, 33, 379-380.

Johnson, S., Cooper, C., Cartwright, S., Donald, I., Taylor, P., \& Millet, C. (2005). The experience of work-related stress across occupations. Journal of Managerial Psychology, 20, 178-187.

Kabat-Zinn, J. (1990). Full catastrophe living: Using the wisdom of your mind to face stress, pain and illness. New York: Dell.

Karasek, R.A. (1985). Job Content Instrument: Questionnaire and User's guide. University of Southern California, Los Angeles.

Kyriacou, C. (2001). Teacher stress: Directions for future research. Educational Review, $53,27-35$.

Lazarus, R. (1993). Coping theory and research: Past, present, and future. Psychosomatic Medicine, 55, p 234-247.

Lazarus, R.S., \& Folkman, S. (1987). Transactional theory and research on emotions and coping. European Journal of Personality, 1, 141-169.

Lazarus, R. S., \& Folkman, S. (1984). Stress, appraisal, and coping. New York: Springer. Litt, M. D., \& Turk, D. C. (1985). Sources of stress and dissatisfaction in experienced 
high school teachers. The Journal of Educational Research, 78, 178-185.

Maes, S., Kittel, F., Scholten, H. \& Verhoeven, C. (1989). Structured Interview of Content Organization of Work. Section of Clinical and Health Psychology, Leiden University, Leiden.

Maes, S. \& van der Doef, M. (1997). Leidse Arbeids Kwaliteit Schaal voor Docenten (LAKS-DOC) [Leiden quality of work scale for teachers]. Section of Clinical and Health Psychology, Leiden University, Leiden, The Netherlands.

Maslach, C., Shaufeli, W. B., \& Leiter, M. P. (2000?). Job burnout. Annual Review of Psychology, 52, 397-422.

Mearns, J. \& Cain, J.E. (2003). Relationships between teachers' occupational stress and their burnout and distress: Roles of coping and negative mood regulation expectancies. Anxiety, Stress and Coping, 16, 71-82.

National Center for Educational Statistics. (2011). Elementary and secondary education. http://nces.ed.gov/programs/digest/d10/ch_2.asp.

Olff, M., Brosschot, J.F., \& Godaert, G. (1993). Coping styles and health. Personal and Individual Differences, 15, 81-90.

Parker, P.D., \& Martin, A.J. (2009). Coping and buoyancy in the workplace: Understanding their effects on teachers' work-related well-being and engagement. Teaching and Teacher Education, 25, 68-75.

Pascual, E., Perez-Jover, V., Mirambell, E., Ivanez, G., \& Terol, M.C. (2003). Job conditions, coping and wellness/health outcomes in Spanish secondary school teachers. Psychology and Health, 18, 511-521.

Peklaj, C., \& Puklek, M. (2001). Coping with stress and cognitive interference in student 
teachers performance as important factors influencing their achievement. Horizons of Psychology, 10, 7-19.

Pomaki, G., \& Anagnostopoulou, T. (2003). A test and expansion of the demand/control/social support model: prediction of wellness/health outcomes in Greek teachers. Psychology and Health, 18, 537-550.

Rasku, A., \& Kinnunen, U. (2003). Job conditions and wellness among Finnish upper secondary school teachers. Psychology and Health, 18, 441-456.

Rubino, C., Luksyte, A., Perry, S., \& Volpone, S.D. (2009). How do stressors lead to burnout? The mediating role of motivation. Journal of Occupational Health Psychology, 14, 289-304.

Salo, K. (1995). Teacher-stress processes: How can they be explained? Scandinavian Journal of Education Research, 39, 205-222.

Schutz, P.A. \& Zembylas, M. (Eds.) (2009). Advances in teacher emotion research: The impact on teachers' lives. New York: Springer.

Schweizer, K., \& Dobrich, P. (2003). Self-reported health, appraisal, coping, and stress in teachers. Psychology Science, 45, 92-105.

Seidman, S. A., \& Zager, J. (1991). A study of coping behaviours and teacher burnout. Work \& Stress, 5, 205-216.

Shen, Y. E. (2009). Relationships between self-efficacy, social support and stress coping strategies in Chinese primary and secondary school teachers. Stress and Health, 25, 129-138. 
Skaalvik, E.M., \& Skaalvik, S. (2007). Dimensions of teacher self-efficacy and relations with strain factors, perceived collective teacher efficacy, and teacher burnout. Journal of Educational Psychology, 99, 611-625.

Skinner, E.A., \& Beers, J.C. (in press). Mindfulness and teachers' coping in the classroom: A developmental model of teacher stress, coping, and everyday resilience. Handbook on Mindfulness in Education: Emerging Theory, Research, and Programs. Springer-Verlag.

Skinner, E.A., Edge, K., Altman, J., \& Sherwood, H. (2003). Searching for the structure of coping: A review and critique of category systems for classifying ways of coping. Psychological Bulletin, 129, 216-269.

Stoeber, J., \& Rennert, D. (2008). Perfectionism in school teachers: Relations with stress appraisals, coping styles, and burnout. Anxiety, Stress, \& Coping, 21, 37-53.

Verhoeven, C., Kraaij, V., Joekes, K., \& Maes, S. (2003). Job conditions and wellness/health outcomes in Dutch secondary school teachers. Psychology and Health, 18, 473-487.

Wentzel, K.R. (2009). Students' relationships with teachers as motivational contexts. Handbook of Motivation at School. (Chapter 15) 301-322. (Routledge Publishing, New York).

Zurlo, M. C., Pes, D., \& Cooper, C. L. (2007). Stress in teaching: A study of occupational stress and its determinants among Italian schoolteachers. Stress and Health, 23, 231241. 


\section{Appendix A}

Studies Reviewed Investigating Teacher Stress and Coping

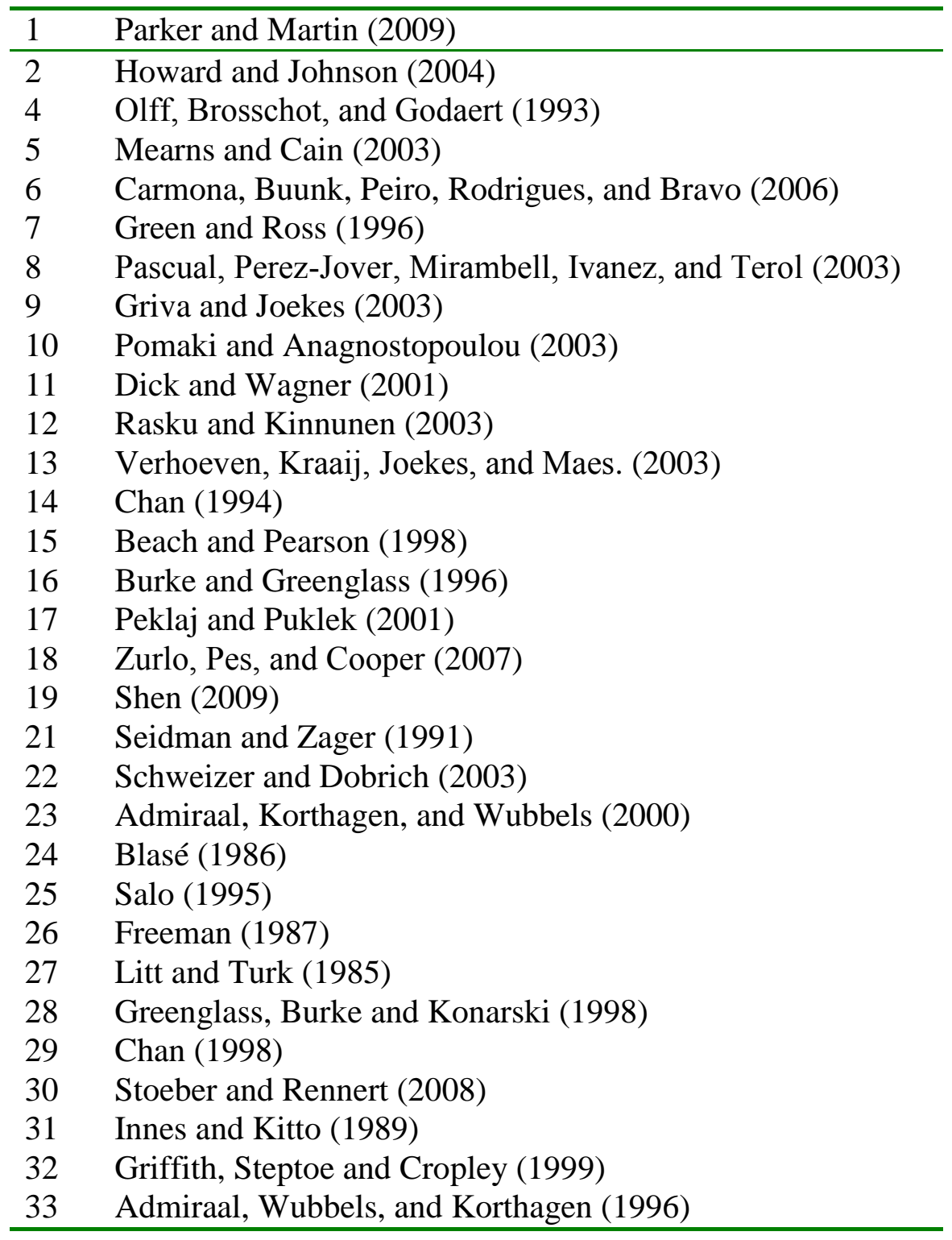

Note. Studies number 3 and 20 were removed because, after further examination, they did not meet the parameters established when choosing studies for review. 


\section{Appendix B}

\section{Coding Menu}

A. Demands in Teaching

1. Problems with students (e.g., student misbehavior, low pupil achievement, unmotivated students, dealing with students' personal problems)

2. Problems with the classroom environment (e.g., environmental risks, overcrowded classrooms, interruptions, equipment malfunction, insufficient funds for equipment, lack of support in classroom)

3. Administration/School policy (e.g., work relationship with supervisor, poor leadership, supervisor evaluation, school mismanagement, unproductive or inefficient staff meetings, school/educational policy, standardized/state testing requirements)

4. Problems with colleagues (e.g., work relationships with teachers, counselors, classified staff)

5. Workload (e.g., time pressures, amount of work, paperwork, extra committees, student assessment, report cards, planning curriculum, preparing for class, too many meetings/conferences)

6. Problems with parents/guardians (unsupportive parents, unproductive or inefficient parent conferences/meetings, parents complaining)

Note. If the problem with assessment is perceived to come from too much work or too little time, it is coded as 5 . If the problem is perceived to come from requirements from the school/educational system to which the teacher disagrees, it is coded as 3 .

\section{B. Appraisals of Teaching Demands}

0 . No negative emotion mentioned

1. Negative emotion (e.g., frustrated, upset, anxious, sad)

2. Extreme negative emotion (e.g., furious, overwhelmed, angry)

Note. Code the appraisal as a 0 if no negative emotion was mentioned along with the event, as a 1 if one or more negative feeling(s) are described, and a 2 if any of the feelings mentioned by the teacher are considered extreme. It may be necessary to look to a difficult day to extract the feelings described by the teacher but be careful to try and look to the terms that seem to apply to the specific example provided. Any example of a physical response (headache, rash, stomachache) to a stressor is considered an extreme negative emotion. Negative emotion words would be considered extreme if they are preceded by words like "very" or "really" (for example, "really discouraging").

\section{Teacher Coping}

First code all the ways of coping utilized by the teacher during the single coping episode (this does not include strategies that the teacher says they 'typically' use. They must indicate that it has been used in this case). Use the coping checklist provided below. 
Then record the total number of adaptive and maladaptive ways of coping utilized in the single coded episode sheet.

Note. Numbers 1, 2, 5, 6, 9, and 10 are considered "effective" (i.e., adaptive) while numbers 3, 4, 7, 8, 11, and 12 are all considered "ineffective" (i.e., maladaptive) coping behaviors (See 12 Families of Coping below).

D. Resolution of Stressful Episodes

1. In process of being resolved (teacher indicates that they are still working on resolving the issue)

2. Unsuccessful

3. Successful (even if partially successful, but there is no indication that they are continuing to resolve the issue)

Note: This category refers to resolution of the episode not the stress itself.

\section{E. Post-Coping Assessment and Teacher Learning}

1. No (subject indicates that he/she would not do anything different because the outcome with the strategy/strategies used was favorable. Note: If they simply say no, this might need to be determined based on the "How did it turn out?" question)

2. No (shows rigidity to change, either in a stubborn or a confused way. This includes responses like, "I don't know what I could have done differently" because of the rigid component).

3. Yes (indicates that they would try an effective strategy, or stop using an ineffective one: i.e., "Next time I'll try to look at the other teacher's point of view" or "I'll stop losing my temper with the student when he does X")

4. Yes (indicates that they would try an ineffective strategy. This includes wishful thinking (I would make it so that I had less grading to do), unrealistic changes, as well as changes they would make to their own actions that would be ineffective (more rigid control of students, trying to escape from the problem)

Directions: Choose the coping episode example that is most complete (i.e., all five of the constructs can be most easily identified). If it is too difficult to decide between two, choose the first one mentioned, as it is typically more spontaneous. Be sure that each step described by the teacher applies directly to the coping episode being examined.

\section{Single Coded Episode}

\begin{tabular}{|c|l|l|l|l|l|l|}
\hline \multirow{2}{*}{ ID \# } & \multirow{2}{*}{ Demand } & Appraisal & \multicolumn{2}{|c|}{ Coping } & Resolution & \multirow{2}{*}{ Assessment } \\
\cline { 4 - 6 } & & & EFFECTIVE & INEFFECTIVE & & \\
\hline 1 & & & & & & \\
\hline 2 & & & & & & \\
\hline 3 & & & & & & \\
\hline 4 & & & & & & \\
\hline 5 & & & & & & \\
\hline
\end{tabular}




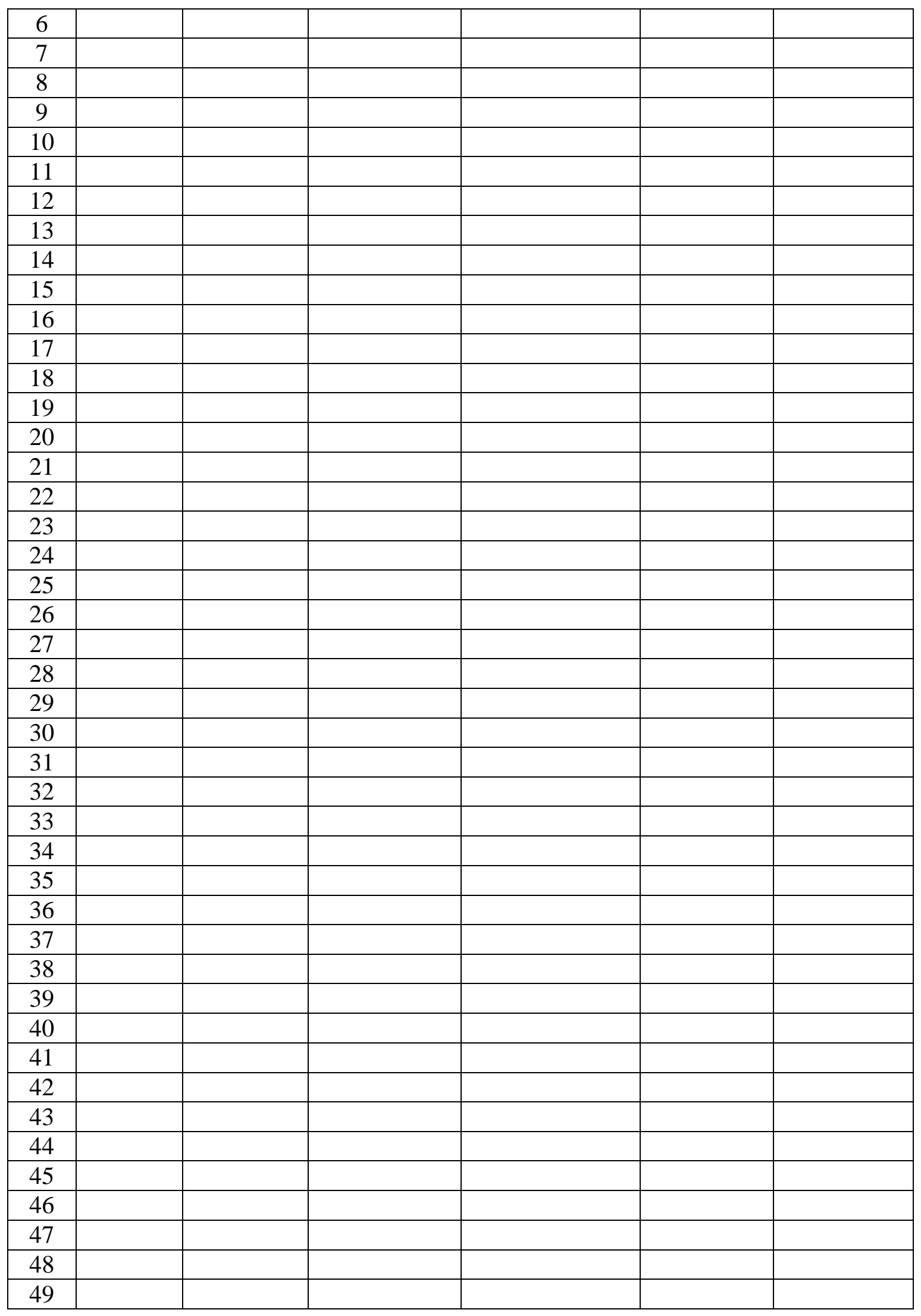




\begin{tabular}{|l|l|l|l|l|l|l|}
\hline 50 & & & & & \\
\hline 51 & & & & & & \\
\hline 52 & & & & & & \\
\hline 53 & & & & & & \\
\hline 54 & & & & & & \\
\hline 55 & & & & & & \\
\hline 56 & & & & & & \\
\hline 57 & & & & & & \\
\hline 58 & & & & & & \\
\hline 59 & & & & & & \\
\hline 60 & & & & & & \\
\hline
\end{tabular}

Coping Response During Single Coping Episode (How did you handle it?)

\section{Categories of Coping Strategies}

1. Problem-Solving (e.g., strategizing, instrumental action, planning, positive/productive distraction) When problem solving involves perpective taking, also code 9. Including other people to solve a problem is problem solving (look at verbs used)

2. Information Seeking (e.g., reading, observation, asking others)

3. Submission/Helplessness (e.g., Confusion, cognitive interference, cognitive exhaustion, giving up, resignation, self-doubt, self-blame)

4. Escape (e.g., behavioral avoidance, mental withdrawal, denial, wishful thinking, minimization, distraction)

5. Self-regulation (e.g., emotion regulation, behavior regulation, emotional expression, resilience, perseverance)

6. Support seeking (e.g., contact seeking, comfort seeking, instrumental aid, social referencing)

7. Delegation/Absolving self of responsibility(use verb related to themselves; ie "I don't have the resources...”) (e.g., maladaptive help-seeking, self-pity)

8. Social Isolation (e.g., Social withdrawal, Concealment, Avoiding others) Includes concealing what's going on (ie, troubles, worries) in one's life 
9. Cognitive or Physical Accommodation (e.g., Cognitive restructuring, Acceptance, Perspective Taking)Includes problem solving code when problem solving includes understanding of another's feelings about the situation. Includes the use of diplomacy.

10. Negotiation (e.g., Bargaining, Persuasion, Priority-setting) To code for persuasion, there must be some kind of rational or reason for why

11. Rigid Cognition (e.g., Rumination, Rigid perseveration, Intrusive thoughts)

12. Opposition (e.g., Other blame (uses verb related to the other, ie "They were pointing at me"), Projection, Aggression)

Instructions:

- Code one specific episode

- For each participant statement, indicate whether or not it fits into each of the above coping categories

- Code as follows: yes $=\mathrm{X}$, no = leave blank

- On the data sheet, underline the relevant passage and indicate both the number of the strategy and which example was used. For example if a passage was coded " 7 " for "Delegation/Absolving self of responsibility" because the language used communicated whining, underline the words that were whiney, then place a ' 7 ' and 'whining' in the margin next to the passage.

\section{Coping Strategy Examples}

1. Problem Solving

(e.g., strategizing, instrumental action, planning, positive/productive distraction) Strategizing:

- "I...that I found that...kind of one on one interaction is...or any, yeah, yeah, any student so that once you kind of separate them from the pack, it's a little bit...it's, it's easier to, to deal with any sort of student..."

- "I tried to speak to each individual...teacher involved. I was very unhappy with the results, so I thought about the process of how I could bring about change. I spoke to the administrator."

- Note: also instrumental action

- "You don't want to jump in because that of course doesn't allow him to try to fix it himself."

Planning:

- "I try to keep my classes fairly structured."

\section{Instrumental action:}

- "You need to have a time-out, when you're ready, come back and show me..."

- "I gave them a worksheet of fraction games to keep them out of my hair..." 
- Giving guidance (to student)

- "Sitting with him" (one on one work)

- "I know I need an hour nap before I can tackle my evening"

- "I had to get him out of the classroom because he was too upset."

- "I asked him to move over to the study carols, I continued my instructions to the rest of the class, I went over to talk to him"

Positive/productive distraction:

- "I'm completely in the classroom working intensely with the students, then it takes my mind off it."

2. Information Seeking

(e.g., reading, observation, asking others)

Reading

"I read up on the files I guess I tried to gather information"

Asking others:

- "I did try to get advice from colleagues..."

3. Submission/Helplessness

(e.g., confusion, cognitive interference, cognitive exhaustion, giving up, resignation).

Giving up

- “...it's something that I've dealt with almost daily for the last 10 months and I'm done. If I can't change him, and I know I can't..."

○ Note: possible cognitive exhaustion

- “...there's just no point..."

- "I gave up on him on occasion..."

Cognitive interference:

- "I'm not very productive because I can't pick a task."

Cognitive exhaustion

- I feel like, mentally overwhelmed at times

Resignation:

- "You just kind of get used to it."

- "I'm not the one who can really solve that for them, you know"

4. Escape

(e.g., behavioral avoidance, mental withdrawal, denial, wishful thinking, minimization, distraction)

Behavioral avoidance:

- "Just turn off the alarm clock and phone in sick.." 
5. Self-regulation

(e.g., emotion regulation, behavior regulation, emotional expression, resilience, perserverance)

\section{Emotion Regulation:}

- "...it took a lot of self-control on my part not to meet her anger..."

- "...I tried to be more aware of my own reactions..."

- "I had to explain my methods with confidence"

\section{Behavior Regulation:}

- "...I try to stay neutral and really calm..."

- "I had to keep going with the oral exams, and put on the face that said, okay, yup, let's go."

- "I had to um, keep a smile on"

Perserverance:

- "One foot in front of the other..."

- “...This too shall pass...I'll get through it, just persevere.”

- "Just persist, the nature of teaching is that you never give up."

6. Support Seeking

(e.g., contact seeking, comfort seeking, instrumental aid, social referencing)

Contact seeking ${ }^{1,}$ support seeking ${ }^{2}$ :

- "I did try to get advice from colleagues** so that I wasn't alone ${ }^{1}$ facing a tough situation...we would support each other ${ }^{2}$..."

**note: see info seeking

Instrumental aid:

- "...consultation with classroom teacher and from other teachers..."

- "Had to ask somebody to come and get him and take him out of the room and he was sent to the office."

- "I called the counselor"

- "I ended up approaching the administration for help"

Social Referencing:

- "I'm happy on the fact that I have co-workers seeing what I see."

7. Absolving Self of Responsibility

- 'It's frustrating when you're not seeing the fruits of your labor...that sometimes is beyond what we can do here at school."

- "I've never had a problem with a colleague before..."

- "...(students) not willing to take any direction.."

8. Social Isolation

(e.g., social withdrawal, concealment, avoiding others) 


\section{Concealment:}

- "I didn't voice my stress... and kept it in, not that I, wanted to keep it inside I just thought, by not voicing it out to the rest of the department, I mean it was my personal stress, my medical stress, I didn't need other people to know about it"

- "I was going through a tough time but I didn't tell anybody"

9. Cognitive Accommodation

(e.g., Cognitive restructuring, Acceptance, Perspective taking)

Acceptance:

- "I have to remember that the person has problems, so when the meeting's over try to let go and move on."

- "It's neither good nor bad, it just is."

Perspective taking:

- "...I tried to see the situation from the mom's point of view..."

- "...tried to acknowledge what she was saying..."

10. Negotiation

(e.g., bargaining, persuasion, priority-setting, mediation)

Bargaining:

- ...'I would dish out warnings, like first warning, second warning..."

- "What I did was to try and find a win-win alternative."

Persuasion, Mediation:

- "So a lot of it's conflict resolution and and, just...you know...trying to get the parties to sit down and say "okay look, this is how they feel, do you understand that? Do you understand how they feel? Okay." And then everybody kind of, hopefully it reach-, reaches a resolution and, and it was stressful trying to set it all up and kind of get it all in, making sure that everybody's massaged in right, the right way to try and make them feel good so that at the end it was... and now they're the best of friends."

11. Rigid Behavior/Rumination

(e.g., rumination, rigid perseveration, intrusive thoughts)

\section{Rumination:}

- "I take it home"

- "I was really upset. It took me awhile to get over it."

- I wake up at 2am thinking of this particular kid

Intrusive thoughts:

- "I dream about it."

12. Opposition 
(e.g., other blame, projection, aggression)

\section{Other blame:}

- "I feel like sometimes they bring their emotional baggage to work and then they look for confrontations around here or make things just more difficult" (emphasis added)

- "When he sees red he just doesn't see reason."

- "No wonder this kid hates me, because if the parent is badmouthing the teacher..."

- "The other person's not really hearing what I'm saying"

- “...it's fine for her to have questions, but maybe it would've been more appropriate to ask me afterwards for clarification..."

- $\quad$ some people are just so headstrong and not willing to compromise on times

Note: Watch out for recounting of events that others did - if it's something that someone actually did and teacher is just presenting the facts, it's not blaming others. Example:

"..the computer lab had been torn apart by kids in the morning..."

\section{Aggression:}

- "I got mad."

Enter data from the single coping episode into the table below:

\begin{tabular}{|l|c|c|c|c|c|c|c|c|c|c|c|c|}
\hline ID\# & $\begin{array}{c}1 \\
\text { Prob } \\
\text { Solv }\end{array}$ & $\begin{array}{c}2 \\
\text { Info } \\
\text { Seek }\end{array}$ & $\begin{array}{c}\text { Help- } \\
\text { less }\end{array}$ & $\begin{array}{c}4 \\
\text { Esc }\end{array}$ & $\begin{array}{c}5 \\
\text { Self } \\
\text { Rel }\end{array}$ & $\begin{array}{c}6 \\
\text { Supp } \\
\text { Seek }\end{array}$ & $\begin{array}{c}7 \\
\text { Del }\end{array}$ & $\begin{array}{c}8 \\
\text { Soc } \\
\text { Iso }\end{array}$ & $\begin{array}{c}9 \\
\text { Acc }\end{array}$ & $\begin{array}{c}10 \\
\text { Neg }\end{array}$ & $\begin{array}{c}11 \\
\text { Sub }\end{array}$ & \begin{tabular}{c} 
Opp \\
\hline 1
\end{tabular} \\
\hline 2 & & & & & & & & & & & & \\
\hline 3 & & & & & & & & & & & & \\
\hline 4 & & & & & & & & & & & & \\
\hline 5 & & & & & & & & & & & & \\
\hline 6 & & & & & & & & & & & & \\
\hline 7 & & & & & & & & & & & & \\
\hline 8 & & & & & & & & & & & & \\
\hline 9 & & & & & & & & & & & & \\
\hline 10 & & & & & & & & & & & & \\
\hline 11 & & & & & & & & & & & & \\
\hline 12 & & & & & & & & & & & & \\
\hline
\end{tabular}




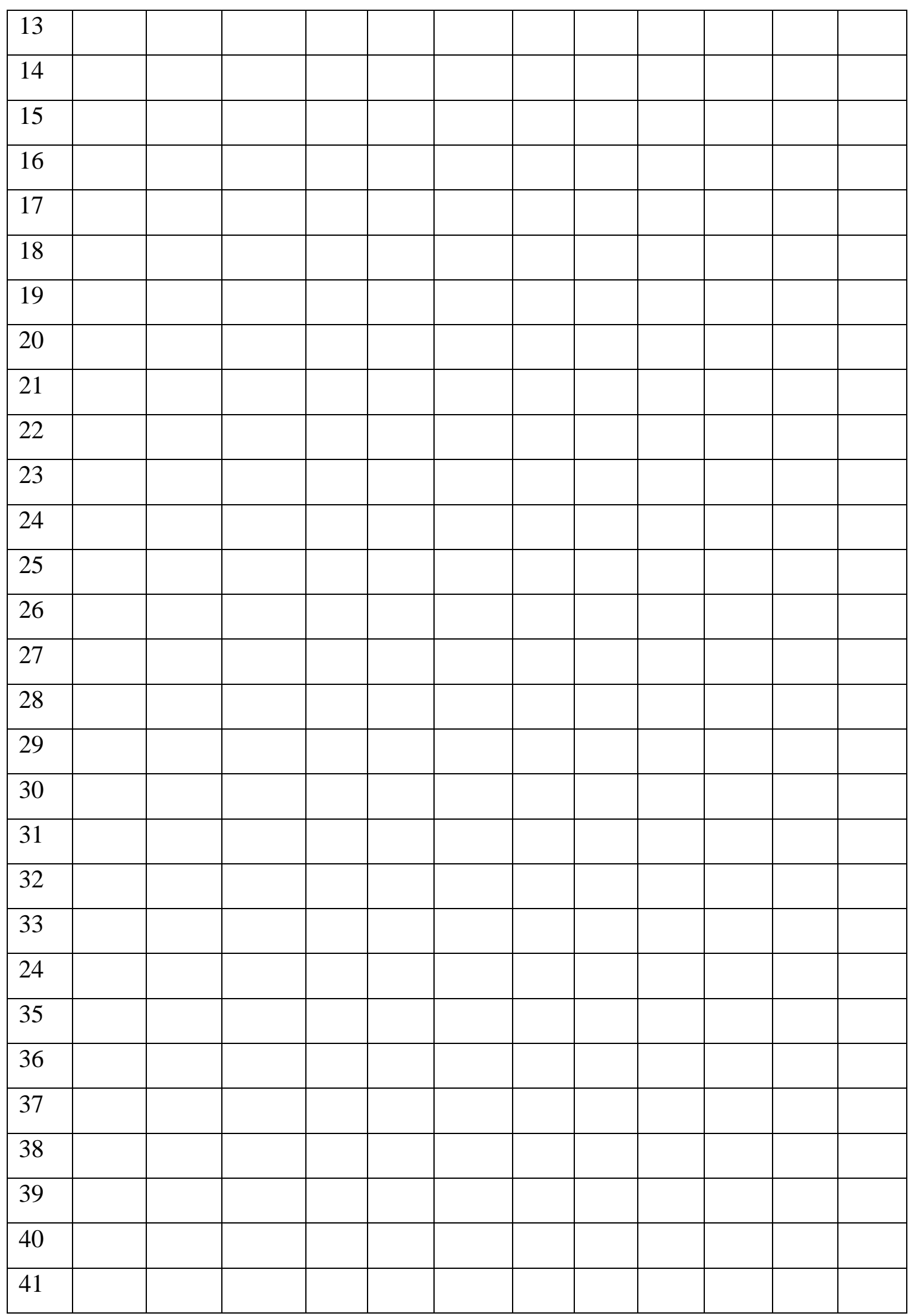




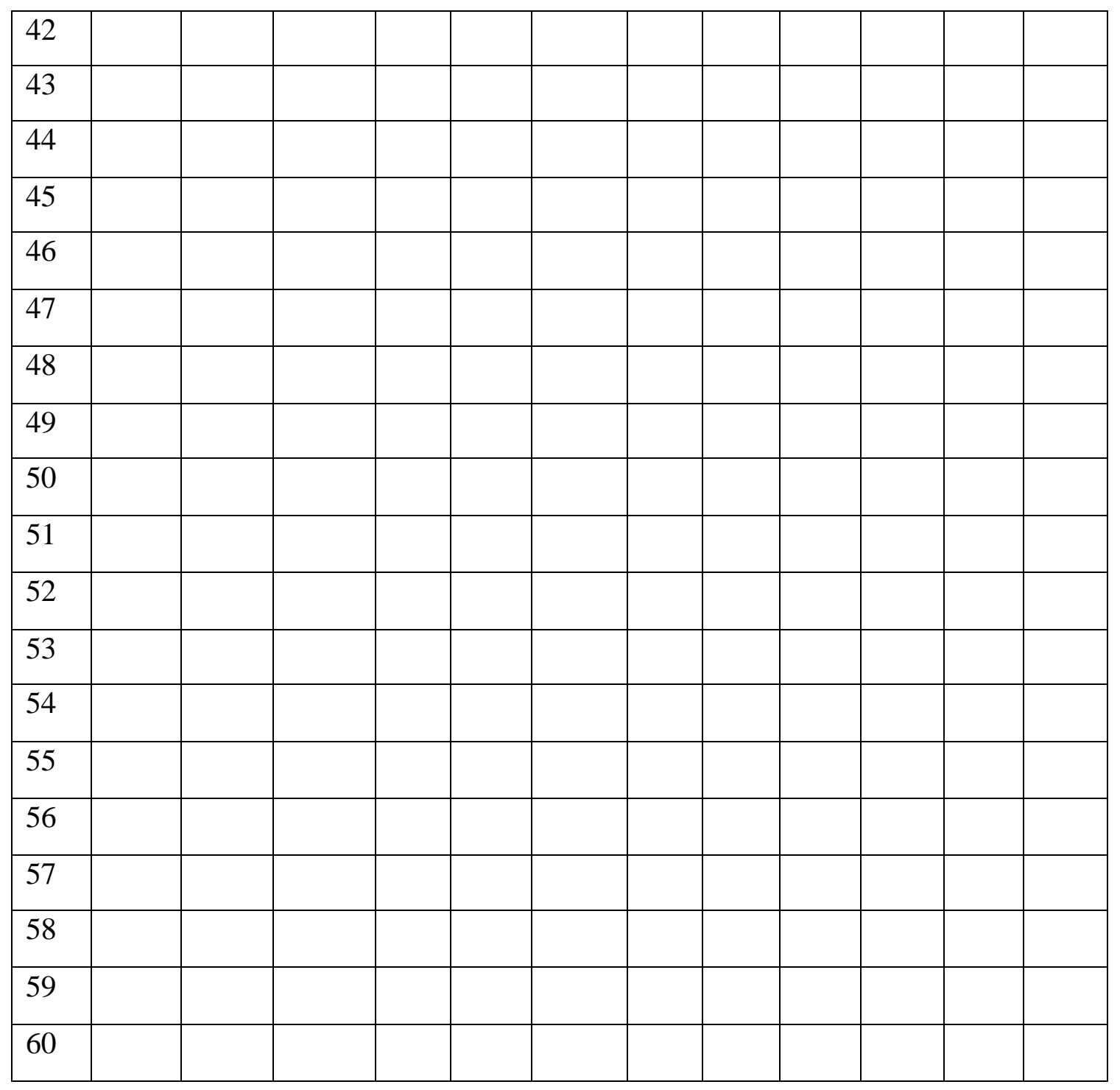

Notes: 


\section{Appendix C}

Coping Utterances

\begin{tabular}{|c|c|c|c|c|}
\hline ID & $\begin{array}{l}\text { Coping } \\
\text { Utterance1 }\end{array}$ & $\begin{array}{l}\text { Coping } \\
\text { Utterance2 }\end{array}$ & $\begin{array}{l}\text { Coping } \\
\text { Utterance3 }\end{array}$ & $\begin{array}{l}\text { Coping } \\
\text { Utterance4 }\end{array}$ \\
\hline 1 & $\begin{array}{l}\text { I like to have } \\
\text { my little } \\
\text { checklists and } \\
\text { check off } \\
\text { things when } \\
\text { they're done }\end{array}$ & $\begin{array}{l}\text { I feel like I just } \\
\text { can't quite get } \\
\text { everything } \\
\text { done that } \\
\text { needs to be } \\
\text { done }\end{array}$ & $\begin{array}{l}\text { I'm quite, quite } \\
\text { hard on myself }\end{array}$ & \\
\hline 2 & $\begin{array}{l}\text { I ended up } \\
\text { approaching } \\
\text { the } \\
\text { administration } \\
\text { for help }\end{array}$ & $\begin{array}{l}\text { I took it home } \\
\text { with me and I } \\
\text { was thinking all } \\
\text { evening about } \\
\text { what to do and } \\
\text { I couldn't sleep } \\
\text { and it made me } \\
\text { feel like } \\
\text { anxious, it } \\
\text { affected just } \\
\text { my own time at } \\
\text { home so I } \\
\text { couldn't just } \\
\text { relax and let it } \\
\text { go, I was still } \\
\text { worrying about } \\
\text { it at night }\end{array}$ & $\begin{array}{l}\text { I was trying to } \\
\text { problem solve }\end{array}$ & \\
\hline 3 & $\begin{array}{l}\text { Some people } \\
\text { are just so } \\
\text { headstrong } \\
\text { and not willing } \\
\text { to compromise } \\
\text { on times and it } \\
\text { just created an } \\
\text { extreme level } \\
\text { of stress to this } \\
\text { point where } \\
\text { I'm still feeling } \\
\text { residual } \\
\text { feelings of } \\
\text { (pause) anger, }\end{array}$ & $\begin{array}{l}\text { I stood my } \\
\text { ground and the } \\
\text { other person } \\
\text { yelled at me in } \\
\text { front of the } \\
\text { entire staff. } \\
\text { And this } \\
\text { person is also } \\
\text { an outside } \\
\text { friend and it } \\
\text { turned } \\
\text { out...and I said, } \\
\text { "Well, that's } \\
\text { when mine is }\end{array}$ & & \\
\hline
\end{tabular}




\begin{tabular}{|c|c|c|c|c|}
\hline & $\begin{array}{l}\text { frustration } \\
\text { towards } \\
\text { certain staff } \\
\text { members }\end{array}$ & $\begin{array}{l}\text { and I'm leaving } \\
\text { it that." And } \\
\text { she said, "Well, } \\
\text { fine well I'm } \\
\text { going to leave } \\
\text { mine as is too." } \\
\text { And I said, } \\
\text { "Fine." }\end{array}$ & & \\
\hline 4 & $\begin{array}{l}\text { What I did, } \\
\text { was I asked } \\
\text { him to move } \\
\text { over to the } \\
\text { study carols }\end{array}$ & $\begin{array}{l}\text { I went over to } \\
\text { talk to him }\end{array}$ & $\begin{array}{l}\text { I had him go } \\
\text { down to the } \\
\text { principal's and } \\
\text { the principal } \\
\text { called his } \\
\text { mother; his } \\
\text { mother came } \\
\text { and picked him } \\
\text { up. }\end{array}$ & \\
\hline 5 & $\begin{array}{l}\text { The first and } \\
\text { most effective } \\
\text { is proxemics } \\
\text { where I just } \\
\text { stop what I'm } \\
\text { doing and look } \\
\text { at them and if } \\
\text { they don't stop } \\
\text { interrupting or } \\
\text { they don't } \\
\text { return to task } \\
\text { then I'll move } \\
\text { towards them } \\
\text { by half a step } \\
\text { or a step and } \\
\text { that typically } \\
\text { works. Or if it } \\
\text { doesn't, I will } \\
\text { continue } \\
\text { moving in } \\
\text { their, in a } \\
\text { proxemic } \\
\text { towards them } \\
\text { and gesture to } \\
\text { them to turn } \\
\text { or to refocus. }\end{array}$ & $\begin{array}{l}\text { I'll ask them } \\
\text { that question, } \\
\text { "Is that kind?" } \\
\text { So it's not a } \\
\text { behavioral } \\
\text { response on } \\
\text { my part, it's a } \\
\text { cognitive } \\
\text { response and } \\
\text { then I turn it } \\
\text { around and ask } \\
\text { them the } \\
\text { question, "Is } \\
\text { that kind? Is } \\
\text { that } \\
\text { necessary?" So } \\
\text { then they are } \\
\text { responding at a } \\
\text { cognitive level } \\
\text { so I'm ignoring } \\
\text { the behavior } \\
\text { and I'm not } \\
\text { responding } \\
\text { with a } \\
\text { behavioral } \\
\text { consequence. }\end{array}$ & & \\
\hline
\end{tabular}




\begin{tabular}{|c|c|c|c|c|}
\hline & & $\begin{array}{l}\text { I'm not saying, } \\
\text { "If you don't } \\
\text { cut that out, } \\
\text { I'm going to } \\
\text { time you out." }\end{array}$ & & \\
\hline 6 & $\begin{array}{l}\text { I sent it back } \\
\text { and I was } \\
\text { trying to be as } \\
\text { firm as } \\
\text { possible }\end{array}$ & $\begin{array}{l}\text { That I just had } \\
\text { to go to the } \\
\text { principal }\end{array}$ & & \\
\hline 7 & $\begin{array}{l}\text { I would try } \\
\text { deal with the } \\
\text { child }\end{array}$ & $\begin{array}{l}\text { Then I would } \\
\text { try and deal } \\
\text { with the parent }\end{array}$ & $\begin{array}{l}\text { Deal with the } \\
\text { administrator }\end{array}$ & $\begin{array}{l}\text { I would try and } \\
\text { get some help } \\
\text { maybe from } \\
\text { the union }\end{array}$ \\
\hline 8 & $\begin{array}{l}\text { I'm giving him } \\
\text { the benefit of } \\
\text { the doubt }\end{array}$ & $\begin{array}{l}\text { It worries me } \\
\text { that what I feel } \\
\text { and my } \\
\text { judgment of } \\
\text { the child may } \\
\text { different than } \\
\text { what's exactly } \\
\text { tested and put } \\
\text { on paper }\end{array}$ & & \\
\hline 9 & $\begin{array}{l}\text { I get resentful } \\
\text { that I'm not } \\
\text { being given } \\
\text { any time to do } \\
\text { it and then I } \\
\text { have to do it } \\
\text { on my own } \\
\text { time }\end{array}$ & $\begin{array}{l}\text { I don't have a } \\
\text { working } \\
\text { computer at } \\
\text { home so I have } \\
\text { to do it here }\end{array}$ & & \\
\hline 10 & $\begin{array}{l}\text { I did go and } \\
\text { get help }\end{array}$ & $\begin{array}{l}\text { I wrote down } \\
\text { all, everything } \\
\text { that had } \\
\text { happened }\end{array}$ & $\begin{array}{l}\text { I stood in front } \\
\text { of him and said } \\
\text { what I needed } \\
\text { to say without, } \\
\text { you know, } \\
\text { quivering }\end{array}$ & \\
\hline 11 & $\begin{array}{l}\text { I worry, I take } \\
\text { the worries } \\
\text { home with me. } \\
\text { I wake up at } \\
\text { 2am thinking }\end{array}$ & & & \\
\hline
\end{tabular}




\begin{tabular}{|c|c|c|c|c|}
\hline & $\begin{array}{l}\text { of this } \\
\text { particular kid } \\
\text { and } \\
\text { wondering, } \\
\text { thinking of } \\
\text { strategies at } \\
\text { 2am, 4am and } \\
\text { at some point I } \\
\text { wake up and } \\
\text { one of my first } \\
\text { thoughts is } \\
\text { what I plan to } \\
\text { do for the } \\
\text { particular kid } \\
\text { that (both talk) } \\
\text { it stays with } \\
\text { me Saturday } \\
\text { and Sunday as } \\
\text { well. }\end{array}$ & & & \\
\hline 12 & $\begin{array}{l}\text { I don't want to } \\
\text { do this } \\
\text { anymore }\end{array}$ & $\begin{array}{l}\text { I have tried to } \\
\text { make myself } \\
\text { easier by } \\
\text { reducing one } \\
\text { block }\end{array}$ & $\begin{array}{l}\text { What I try to } \\
\text { aim for is try to } \\
\text { do as much as } \\
\text { possible at } \\
\text { school, like on } \\
\text { Monday's or } \\
\text { Friday and I try } \\
\text { to have my } \\
\text { own time at } \\
\text { home just to } \\
\text { relax more }\end{array}$ & \\
\hline 13 & $\begin{array}{l}\text { Try and find a } \\
\text { win-win } \\
\text { alternative }\end{array}$ & $\begin{array}{l}\text { Proposed it to } \\
\text { my } \\
\text { administrator }\end{array}$ & & \\
\hline 14 & $\begin{array}{l}\text { I took that as, } \\
\text { hold on, I } \\
\text { worked very } \\
\text { hard, I'm doing } \\
\text { something, } \\
\text { you're not } \\
\text { recognizing the } \\
\text { effort and the } \\
\text { outcome of } \\
\text { the effort that }\end{array}$ & & & \\
\hline
\end{tabular}




\begin{tabular}{|c|c|c|c|c|}
\hline & $\begin{array}{l}\text { I'm making, } \\
\text { that it's in your } \\
\text { favor, that I'm } \\
\text { working for } \\
\text { you and you're } \\
\text { working } \\
\text { against me }\end{array}$ & & & \\
\hline 15 & $\begin{array}{l}\text { Remind her } \\
\text { that it is not } \\
\text { her time to } \\
\text { speak }\end{array}$ & $\begin{array}{l}\text { I let her go take } \\
\text { a break in the } \\
\text { book area, just } \\
\text { calm down and } \\
\text { she can come } \\
\text { back when } \\
\text { she's ready }\end{array}$ & & \\
\hline 16 & $\begin{array}{l}\text { Feeling } \\
\text { helpless in } \\
\text { trying to, in } \\
\text { being able to } \\
\text { make a change } \\
\text { there }\end{array}$ & & & \\
\hline 17 & $\begin{array}{l}\text { I feel like } \\
\text { there's this } \\
\text { bigger picture } \\
\text { going on }\end{array}$ & $\begin{array}{l}\text { I feel like } \\
\text { overwhelmed } \\
\text { at times that I } \\
\text { can't help } \\
\text { them solve } \\
\text { their bigger life } \\
\text { issues }\end{array}$ & & \\
\hline 18 & $\begin{array}{l}\text { I'll take my } \\
\text { kids outside }\end{array}$ & $\begin{array}{l}\text { So I try to step } \\
\text { down from } \\
\text { conflict }\end{array}$ & & \\
\hline 19 & $\begin{array}{l}\text { I had to um, } \\
\text { keep a smile } \\
\text { on }\end{array}$ & $\begin{array}{l}\text { Explain my } \\
\text { methods }\end{array}$ & $\begin{array}{l}\text { I went to go } \\
\text { find some } \\
\text { colleagues and } \\
\text { ranted }\end{array}$ & \\
\hline 21 & $\begin{array}{l}\text { We have } \\
\text { school } \\
\text { meetings }\end{array}$ & $\begin{array}{l}\text { Referred him } \\
\text { to an outside } \\
\text { agency }\end{array}$ & $\begin{array}{l}\text { We modified } \\
\text { his program }\end{array}$ & \\
\hline 22 & $\begin{array}{l}\text { But requiring } \\
\text { me to make } \\
\text { sure that they } \\
\text { have their } 30 \\
\text { minutes of }\end{array}$ & $\begin{array}{l}\text { I gotta give up } \\
\text { something and } \\
\text { often I am } \\
\text { sorry to say it's } \\
\text { the daily }\end{array}$ & $\begin{array}{l}\text { I can't provide } \\
\text { the } 30 \text { minutes } \\
\text { because I don't } \\
\text { have time in } \\
\text { the day, cause }\end{array}$ & \\
\hline
\end{tabular}




\begin{tabular}{|c|c|c|c|}
\hline & $\begin{array}{l}\text { activity when I } \\
\text { only have } \\
\text { them for five } \\
\text { hours, not my } \\
\text { job }\end{array}$ & $\begin{array}{l}\text { physical } \\
\text { activity } \\
\text { because I think } \\
\text { they are } \\
\text { getting it } \\
\text { anyway }\end{array}$ & $\begin{array}{l}\text { there are so } \\
\text { many other } \\
\text { things to do } \\
\text { that I think are } \\
\text { more } \\
\text { important for } \\
\text { something that } \\
\text { should be } \\
\text { done after } \\
\text { school }\end{array}$ \\
\hline 23 & $\begin{array}{l}\text { I just have to } \\
\text { think on my } \\
\text { feet to try and } \\
\text { address their } \\
\text { needs }\end{array}$ & & \\
\hline 24 & $\begin{array}{l}\text { You mentioned } \\
\text { that you will, } \\
\text { um get your } \\
\text { students to } \\
\text { help you }\end{array}$ & $\begin{array}{l}\text { I'm always here } \\
\text { at school late } \\
\text { or I come back } \\
\text { to the school }\end{array}$ & $\begin{array}{l}\text { I don't get how } \\
\text { they do it. I } \\
\text { really don't get } \\
\text { it }\end{array}$ \\
\hline 25 & $\begin{array}{l}\text { Also looking at } \\
\text { it from the } \\
\text { other person's } \\
\text { point of view }\end{array}$ & $\begin{array}{l}\text { I have to be } \\
\text { mindful of the } \\
\text { overall } \\
\text { relationship } \\
\text { and you know, } \\
\text { try to build } \\
\text { overall rapport. }\end{array}$ & \\
\hline 26 & $\begin{array}{l}\text { I had to get the } \\
\text { vice principal } \\
\text { involved }\end{array}$ & & \\
\hline 27 & $\begin{array}{l}\text { You think that } \\
\text { maybe the } \\
\text { other person } \\
\text { has } \\
\text { undermined } \\
\text { what you are } \\
\text { trying to do } \\
\text { with the } \\
\text { student }\end{array}$ & $\begin{array}{l}\text { It's hard to } \\
\text { maintain your } \\
\text { tone of voice }\end{array}$ & \\
\hline 28 & $\begin{array}{l}\text { I mean I'm } \\
\text { thinking what } \\
\text { else can I do }\end{array}$ & $\begin{array}{l}\text { I have had the } \\
\text { counselor } \\
\text { come in a few }\end{array}$ & $\begin{array}{l}\text { I have had } \\
\text { some different } \\
\text { about how to }\end{array}$ \\
\hline
\end{tabular}




\begin{tabular}{|c|c|c|c|c|}
\hline & & times & $\begin{array}{l}\text { get um, their } \\
\text { attention for } \\
\text { certain things } \\
\text { as well, but } \\
\text { we're getting } \\
\text { there }\end{array}$ & \\
\hline 29 & $\begin{array}{l}\text { It really had } \\
\text { nothing to do } \\
\text { with me but it } \\
\text { had to do with } \\
\text { her }\end{array}$ & $\begin{array}{l}\text { She just didn't } \\
\text { want to accept } \\
\text { it }\end{array}$ & & \\
\hline 30 & $\begin{array}{l}\text { I've just come } \\
\text { out of } \\
\text { mediation }\end{array}$ & $\begin{array}{l}\text { When you } \\
\text { don't have a } \\
\text { leader ah, it } \\
\text { causes stress, }\end{array}$ & $\begin{array}{l}\text { Certain things } \\
\text { that the drama } \\
\text { department } \\
\text { have asked for } \\
\text { um, you know, } \\
\text { haven't been } \\
\text { recognized or, } \\
\text { you know, } \\
\text { there are } \\
\text { issues that } \\
\text { haven't been } \\
\text { dealt with }\end{array}$ & $\begin{array}{l}\text { Other } \\
\text { departments' } \\
\text { needs being } \\
\text { recognized } \\
\text { over the } \\
\text { drama } \\
\text { departments } \\
\text { needs }\end{array}$ \\
\hline 31 & $\begin{array}{l}\text { Could not } \\
\text { figure out how } \\
\text { to deal with... } \\
\text { just failed } \\
\text { completely in } \\
\text { figuring out } \\
\text { how to deal } \\
\text { with her }\end{array}$ & & & \\
\hline 32 & $\begin{array}{l}\text { Just talking to } \\
\text { other } \\
\text { colleagues }\end{array}$ & $\begin{array}{l}\text { I also talk to } \\
\text { the parents } \\
\text { and let them } \\
\text { know what a } \\
\text { difficult time } \\
\text { I'm having }\end{array}$ & & \\
\hline 33 & $\begin{array}{l}\text { I wrote back an } \\
\text { email right } \\
\text { away }\end{array}$ & $\begin{array}{l}\text { So I just } \\
\text { decided to take } \\
\text { it really casual } \\
\text { and it is not the } \\
\text { big picture ...so } \\
\text { instead of }\end{array}$ & $\begin{array}{l}\text { Feel free to } \\
\text { come and see } \\
\text { me }\end{array}$ & $\begin{array}{l}\text { I called him } \\
\text { and told him } \\
\text { what } \\
\text { happened and } \\
\text { what I did }\end{array}$ \\
\hline
\end{tabular}




\begin{tabular}{|c|c|c|c|c|}
\hline & & $\begin{array}{l}\text { fighting back, } \\
\text { which boy that } \\
\text { was my first, } \\
\text { first uh, } \\
\text { reaction, but } \\
\text { you know, I } \\
\text { decided that } \\
\text { this is not } \\
\text { something that } \\
\text { I want to do. }\end{array}$ & & \\
\hline 34 & $\begin{array}{l}\text { I was doing my } \\
\text { best to explain } \\
\text { it a different } \\
\text { way }\end{array}$ & $\begin{array}{l}\text { I took a deep } \\
\text { breath }\end{array}$ & $\begin{array}{l}\text { Said maybe I } \\
\text { should try } \\
\text { another } \\
\text { method }\end{array}$ & $\begin{array}{l}\text { I ended up } \\
\text { speaking to my } \\
\text { co-workers }\end{array}$ \\
\hline 35 & $\begin{array}{l}\text { I just kind of } \\
\text { boiled in that } \\
\text { for months } \\
\text { really, and } \\
\text { again, } \\
\text { questioned } \\
\text { why am I her }\end{array}$ & $\begin{array}{l}\text { I had to just } \\
\text { keep } \\
\text { refocusing on } \\
\text { the kids }\end{array}$ & $\begin{array}{l}\text { I finally had to } \\
\text { investigate } \\
\text { myself and I } \\
\text { found out that } \\
\text { that was not } \\
\text { true }\end{array}$ & $\begin{array}{l}\text { Brought it to } \\
\text { my } \\
\text { administrators }\end{array}$ \\
\hline 36 & $\begin{array}{l}\text { I will remind } \\
\text { them nicely }\end{array}$ & $\begin{array}{l}\text { I find it hard to } \\
\text { think of what } \\
\text { would be a } \\
\text { really good } \\
\text { kind smart } \\
\text { comment to } \\
\text { make to focus } \\
\text { their attention } \\
\text { to me }\end{array}$ & & \\
\hline 37 & $\begin{array}{l}\text { It's just } \\
\text { learning how } \\
\text { exactly how to } \\
\text { do it to take on } \\
\text { just the right } \\
\text { amount, I }\end{array}$ & & & \\
\hline 38 & $\begin{array}{l}\text { I have to cut } \\
\text { back on work } \\
\text { with my } \\
\text { students }\end{array}$ & $\begin{array}{l}\text { Seeing the } \\
\text { whole picture. } \\
\text { Seeing the } \\
\text { immediate } \\
\text { need, but then } \\
\text { also seeing the } \\
\text { whole picture }\end{array}$ & & \\
\hline
\end{tabular}




\begin{tabular}{|c|c|c|c|c|}
\hline & & $\begin{array}{l}\text { and seeing } \\
\text { where you } \\
\text { almost have to } \\
\text { shut one door } \\
\text { in order to } \\
\text { open a window }\end{array}$ & & \\
\hline 40 & $\begin{array}{l}\text { I'm pretty } \\
\text { flexible, I will } \\
\text { find something } \\
\text { else to do }\end{array}$ & $\begin{array}{l}\text { I don't try to } \\
\text { ruffle any } \\
\text { feathers, I kind } \\
\text { of think, well } \\
\text { the rules are } \\
\text { there for a } \\
\text { reason, so, I'm } \\
\text { not gonna } \\
\text { make a big } \\
\text { stink }\end{array}$ & & \\
\hline 41 & $\begin{array}{l}\text { You need to } \\
\text { use a to be a, } \\
\text { diplomatic } \\
\text { about it }\end{array}$ & $\begin{array}{l}\text { I've invited the } \\
\text { teachers more } \\
\text { than once, like } \\
\text { to, you know, } \\
\text { come and you } \\
\text { know well, } \\
\text { environment is } \\
\text { such a good } \\
\text { thing. You } \\
\text { could create a } \\
\text { whatever, a } \\
\text { power point } \\
\text { presentation or } \\
\text { something, you } \\
\text { know, we could } \\
\text { work on it } \\
\text { together }\end{array}$ & $\begin{array}{l}\text { I do } \\
\text { accommodate } \\
\text { them if they } \\
\text { have a request }\end{array}$ & \\
\hline 42 & $\begin{array}{l}\text { That's pretty } \\
\text { impossible. } \\
\text { Um, } \\
\text { everybody's } \\
\text { tired. Uh, } \\
\text { that's really } \\
\text { tough }\end{array}$ & & & \\
\hline 44 & $\begin{array}{l}\text { You still have } \\
\text { to do all your } \\
\text { job but you }\end{array}$ & $\begin{array}{l}\text { To be sure that } \\
\text { you are saying } \\
\text { the right things }\end{array}$ & & \\
\hline
\end{tabular}




\begin{tabular}{|c|c|c|c|c|}
\hline & $\begin{array}{l}\text { have to take } \\
\text { time to do } \\
\text { those reports } \\
\text { and to be sure }\end{array}$ & to parents & & \\
\hline 46 & $\begin{array}{l}\text { Allowed the } \\
\text { student to stay } \\
\text { in the } \\
\text { classroom }\end{array}$ & $\begin{array}{l}\text { And I said, } \\
\text { "When you } \\
\text { bring the work } \\
\text { tomorrow, I'll } \\
\text { gladly give you } \\
\text { the laptop." }\end{array}$ & $\begin{array}{l}\text { I try to really } \\
\text { keep my own } \\
\text { emotions in } \\
\text { check }\end{array}$ & $\begin{array}{l}\text { I said: "I think } \\
\text { you need to go } \\
\text { to the library } \\
\text { to cool down" }\end{array}$ \\
\hline 47 & $\begin{array}{l}\text { I've gotta pick } \\
\text { up that slack } \\
\text { and end up } \\
\text { doing the work } \\
\text { myself. }\end{array}$ & $\begin{array}{l}\text { I have to save } \\
\text { day }\end{array}$ & & \\
\hline 48 & $\begin{array}{l}\text { So it frustrates } \\
\text { me that part of } \\
\text { my time is } \\
\text { being } \\
\text { compromised } \\
\text { by students } \\
\text { that don't } \\
\text { want to be } \\
\text { there and um, } \\
\text { and it } \\
\text { frustrates me } \\
\text { just that all } \\
\text { kids aren't } \\
\text { excited about } \\
\text { learning. }\end{array}$ & & & \\
\hline 49 & $\begin{array}{l}\text { I said, "Do you } \\
\text { want to stay in } \\
\text { the circle or } \\
\text { you're gonna } \\
\text { have to leave } \\
\text { the circle }\end{array}$ & $\begin{array}{l}\text { I just say, "I'm } \\
\text { sorry, you have } \\
\text { to leave the } \\
\text { circle and go } \\
\text { and sit." }\end{array}$ & $\begin{array}{l}\text { Focus on the } \\
\text { positive }\end{array}$ & \\
\hline 50 & $\begin{array}{l}\text { Do everything I } \\
\text { can }\end{array}$ & $\begin{array}{l}\text { Say it's maybe } \\
\text { just } \\
\text { developmental. }\end{array}$ & Worry & \\
\hline 51 & $\begin{array}{l}\text { Now I think } \\
\text { the best thing } \\
\text { we can do is }\end{array}$ & & & \\
\hline
\end{tabular}




\begin{tabular}{|c|c|c|c|c|}
\hline & $\begin{array}{l}\text { try and give } \\
\text { each student } \\
\text { some idea of } \\
\text { some } \\
\text { success...I } \\
\text { want the } \\
\text { students to } \\
\text { know that } \\
\text { every bit of } \\
\text { education they } \\
\text { get is a step } \\
\text { forward and } \\
\text { that's what we } \\
\text { try to promote }\end{array}$ & & & \\
\hline 52 & $\begin{array}{l}\text { To make light } \\
\text { of something } \\
\text { in a positive } \\
\text { way }\end{array}$ & $\begin{array}{l}\text { To do } \\
\text { something } \\
\text { that's not } \\
\text { going to } \\
\text { embarrass the } \\
\text { child }\end{array}$ & & \\
\hline 53 & $\begin{array}{l}\text { I might ask a } \\
\text { student to } \\
\text { leave the } \\
\text { room, you } \\
\text { know, take a } \\
\text { timeout }\end{array}$ & $\begin{array}{l}\text { Sometimes it's } \\
\text { a matter of just } \\
\text { moving around } \\
\text { the room so } \\
\text { wherever the } \\
\text { chatty pockets } \\
\text { are I go and } \\
\text { stand right } \\
\text { there and that } \\
\text { tends to kind } \\
\text { of shut some of } \\
\text { that down }\end{array}$ & $\begin{array}{l}\text { I do frequent } \\
\text { seating plan } \\
\text { shifts. }\end{array}$ & \\
\hline 54 & $\begin{array}{l}\text { Doubting } \\
\text { myself, my } \\
\text { ability, there's } \\
\text { partial self } \\
\text { blame, self } \\
\text { doubt }\end{array}$ & & & \\
\hline 55 & $\begin{array}{l}\text { You don't have } \\
\text { the time. You } \\
\text { just don't have } \\
\text { the resources } \\
\text { to help them }\end{array}$ & & & \\
\hline
\end{tabular}




\begin{tabular}{|c|c|c|c|c|}
\hline 56 & $\begin{array}{l}\text { I met with the } \\
\text { teacher and } \\
\text { Vice Principal } \\
\text { together and } \\
\text { said we need } \\
\text { to be on the } \\
\text { same page, }\end{array}$ & $\begin{array}{l}\text { I felt that I was } \\
\text { being pointed } \\
\text { at }\end{array}$ & $\begin{array}{l}\text { I was almost } \\
\text { giving up at } \\
\text { then end }\end{array}$ & \\
\hline 57 & $\begin{array}{l}\text { I've brought } \\
\text { him to school } \\
\text { based team } \\
\text { and I've asked } \\
\text { for extra } \\
\text { support }\end{array}$ & $\begin{array}{l}\text { I compensate } \\
\text { as much as I } \\
\text { can, and help } \\
\text { him as much as } \\
\text { I can }\end{array}$ & $\begin{array}{l}\text { I can give her } \\
\text { some ideas }\end{array}$ & \\
\hline 58 & $\begin{array}{l}\text { And I tried to } \\
\text { explain, } \\
\text { because she's } \\
\text { comparing her } \\
\text { to her older } \\
\text { son. I said you } \\
\text { know, that's } \\
\text { not him and } \\
\text { that he has a } \\
\text { learning } \\
\text { disorder }\end{array}$ & $\begin{array}{l}\text { (I feel) she } \\
\text { doesn't seem } \\
\text { to accept or } \\
\text { understand } \\
\text { that }\end{array}$ & $\begin{array}{l}\text { I tried to turn } \\
\text { it back to what } \\
\text { the evening } \\
\text { was supposed } \\
\text { to be, a } \\
\text { celebration of } \\
\text { the kids' work }\end{array}$ & \\
\hline 60 & $\begin{array}{l}\text { I say, "Ok, I } \\
\text { think now you } \\
\text { will have to go } \\
\text { in the hall." }\end{array}$ & $\begin{array}{l}\text { I cut his work } \\
\text { (to make it } \\
\text { shorter) }\end{array}$ & $\begin{array}{l}\text { Sometimes I } \\
\text { find strategies } \\
\text { and say ok, } \\
\text { now just you } \\
\text { know like, } \\
\text { which one do } \\
\text { you like }\end{array}$ & $\begin{array}{l}\text { I have to } \\
\text { accept. I find it } \\
\text { difficult to } \\
\text { accept that's } \\
\text { the way he is } \\
\text { and then I'm } \\
\text { not going to } \\
\text { change this } \\
\text { personality. } \\
\text { All I can do is } \\
\text { try to deal with } \\
\text { it the best I } \\
\text { can. }\end{array}$ \\
\hline
\end{tabular}




\section{Appendix D}

Summary of Results Table

\begin{tabular}{|c|c|c|}
\hline Research Question & Results & $\mathrm{P}$ value \\
\hline \multicolumn{3}{|l|}{ 1. Demands in Teaching } \\
\hline a. What do teachers perceive as stressful? & $\begin{array}{l}\text { Students }=40 \% \\
\text { Workload }=18 \% \\
\text { Parents }=15 \% \\
\text { Colleagues }=13 \% \\
\text { Admin. }=9 \% \\
\text { Environ. }=6 \%\end{array}$ & $\begin{array}{c}p<.05 \\
n s \\
n s \\
n s \\
n s \\
p<.05\end{array}$ \\
\hline $\begin{array}{l}\text { b. Do perceptions of demands differ according to } \\
\text { years of teaching experience? }\end{array}$ & $\begin{array}{l}\text { LCT mentioned } \\
\text { students more } \\
\text { ECT mentioned } \\
\text { environment less } \\
\text { LCT mentioned } \\
\text { parents less }\end{array}$ & $\begin{array}{l}p<.05 \\
p<.05 \\
p<.05\end{array}$ \\
\hline \multicolumn{3}{|l|}{ 2. Appraisals of Teaching Demands } \\
\hline $\begin{array}{l}\text { a. How do teachers react emotionally to the } \\
\text { demands of teaching? }\end{array}$ & $\begin{array}{l}\text { Extreme Neg. }=44 \% \\
\text { Neg. Emotion }=42 \% \\
\text { No Negative }=15 \%\end{array}$ & $\begin{array}{c}n s \\
n s \\
p<.05\end{array}$ \\
\hline $\begin{array}{l}\text { b. Does emotional reactivity differ according to } \\
\text { years of teaching experience? }\end{array}$ & $\begin{array}{l}\text { ECT mentioned no } \\
\text { neg. emotion less } \\
\text { and extreme neg. } \\
\text { more } \\
\text { LCT mentioned no } \\
\text { neg. emotion more }\end{array}$ & $\begin{array}{l}p<.05 \\
p<.05\end{array}$ \\
\hline $\begin{array}{l}\text { c. Do different demands lead to different kinds of } \\
\text { emotional reactions? }\end{array}$ & $\begin{array}{l}\text { Parent related to } \\
\text { extreme negative } \\
\text { Admin. and } \\
\text { workload related to } \\
\text { negative emotion }\end{array}$ & $\begin{array}{l}p<.05 \\
p<.05\end{array}$ \\
\hline \multicolumn{3}{|l|}{ 3. Teacher Coping } \\
\hline $\begin{array}{l}\text { a. What are the ways teachers cope with stressful } \\
\text { events? }\end{array}$ & $\begin{array}{l}\text { Prob Solve }=65 \% \\
\text { Support Seek }=35 \% \\
\text { Self Reg. }=22 \% \\
\text { Opposition }=20 \% \\
\text { Delegation }=4 \%\end{array}$ & $\begin{array}{c}p<.05 \\
p<.05 \\
\quad n s \\
\quad n s \\
p<.05 \\
\end{array}$ \\
\hline $\begin{array}{l}\text { b. Do the ways teachers cope with stressful } \\
\text { events differ according to years of teaching }\end{array}$ & $\begin{array}{l}\text { MCT more likely to } \\
\text { use delegation }\end{array}$ & $p<.05$ \\
\hline
\end{tabular}




\begin{tabular}{|c|c|c|}
\hline experience? & $\begin{array}{l}\text { LCT less likely to } \\
\text { use self-regulation } \\
\text { and more likely to } \\
\text { use cog. } \\
\text { accommodation }\end{array}$ & $p<.05$ \\
\hline $\begin{array}{l}\text { c. Do the different appraisals lead to different } \\
\text { ways of coping? }\end{array}$ & No difference found & $n s$ \\
\hline $\begin{array}{l}\text { d. Does the nature of the demand of the stressful } \\
\text { event lead to different coping strategies for } \\
\text { teachers? }\end{array}$ & $\begin{array}{l}\text { Self Regulation } \\
\text { related to Parents } \\
\text { Support Seeking } \\
\text { related to Admin. } \\
\text { Opposition related to } \\
\text { Environment } \\
\text { Helplessness related } \\
\text { to Workload }\end{array}$ & $\begin{array}{l}p<.05 \\
p<.05 \\
p<.05 \\
p<.05\end{array}$ \\
\hline \multicolumn{3}{|l|}{ 4. Resolution of Stressful Episodes } \\
\hline a. How are stressful events typically resolved? & $\begin{array}{l}\text { Successful }=51 \% \\
\text { Unsuccessful }=40 \% \\
\text { In Process }=9 \%\end{array}$ & $\begin{array}{c}p<.05 \\
n s \\
p<.05\end{array}$ \\
\hline $\begin{array}{l}\text { b. Do the resolutions differ according to years of } \\
\text { experience? }\end{array}$ & No differences found & $n s$ \\
\hline $\begin{array}{l}\text { c. Do the ways teachers cope result in different } \\
\text { resolutions of stressful events? }\end{array}$ & $\begin{array}{l}\text { Self Reg. related to } \\
\text { successful } \\
\text { Helplessness related } \\
\text { to unsuccessful }\end{array}$ & $\begin{array}{l}p<.05 \\
p<.05\end{array}$ \\
\hline \multicolumn{3}{|l|}{ 5. Post-Coping Reflection and Teacher Learning } \\
\hline $\begin{array}{l}\text { a. Do teachers incorporate their experiences with } \\
\text { stressful events into learning effective } \\
\text { strategies for dealing with difficult situations } \\
\text { in the future? }\end{array}$ & $\begin{array}{l}\text { Yes effective }=54 \% \\
\text { No unfavor. }=19 \% \\
\text { No favorable }=15 \% \\
\text { Yes Ineffect. }=12 \% \\
\end{array}$ & $\begin{array}{c}p<.05 \\
n s \\
n s \\
n s\end{array}$ \\
\hline $\begin{array}{l}\text { b. Do teachers' reflections and learning differ } \\
\text { according to years of experience? }\end{array}$ & $\begin{array}{l}\text { ECT say yes } \\
\text { effective more than } \\
\text { others } \\
\text { LCT say yes } \\
\text { effective less than } \\
\text { others }\end{array}$ & $\begin{array}{l}p<.05 \\
p<.05\end{array}$ \\
\hline $\begin{array}{l}\text { c. Does the way that stressful episodes are } \\
\text { resolved result in different kinds of learning } \\
\text { and reflection? }\end{array}$ & $\begin{array}{l}\text { Successful related to } \\
\text { no favorable }\end{array}$ & $p<.05$ \\
\hline
\end{tabular}




\begin{tabular}{|l|l|l|}
\hline $\begin{array}{l}\text { d. Do the ways that teachers cope with stressful } \\
\text { episodes result in different kinds of learning and } \\
\text { reflection? }\end{array}$ & $\begin{array}{l}\text { Delegation related to } \\
\text { no unfavorable }\end{array}$ & $p<.05$ \\
\hline
\end{tabular}

